\title{
Faux bruits, rumeurs et fake news
}

Philippe Bourdin (dir.)

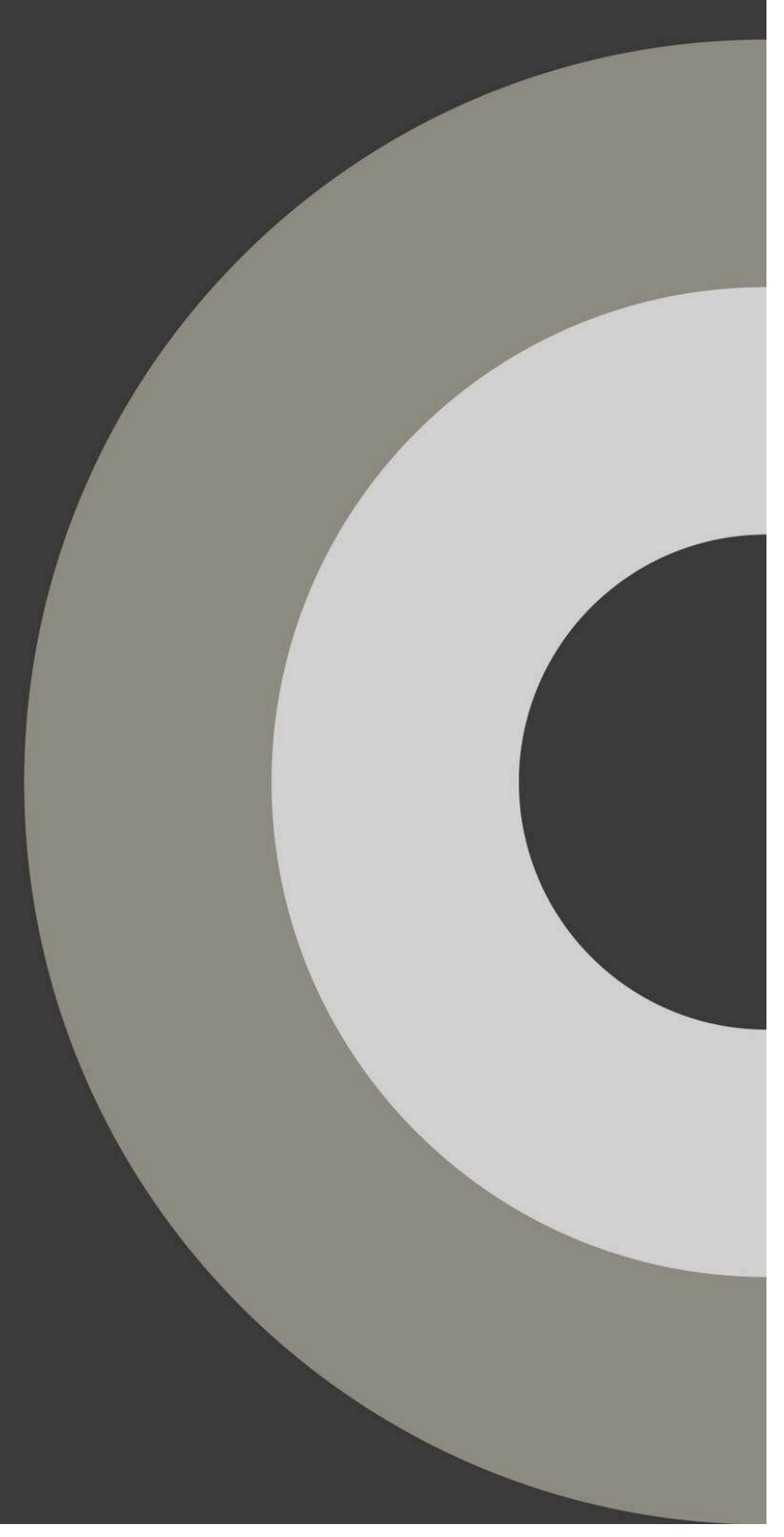




\section{Faux bruits, rumeurs et fake news}

\section{Philippe Bourdin (dir.)}

DOI : 10.4000/books.cths. 15395

Éditeur : Éditions du Comité des travaux historiques et scientifiques Lieu d'édition : Paris

Année d'édition : 2021

Date de mise en ligne : 29 juin 2021

Collection: Actes des congrès nationaux des sociétés historiques et scientifiques

EAN électronique : 9782735509287

\section{OpenEdition}

Books

https://books.openedition.org

Référence électronique

BOURDIN, Philippe (dir.). Faux bruits, rumeurs et fake news. Nouvelle édition [en ligne]. Paris : Éditions du Comité des travaux historiques et scientifiques, 2021 (généré le 08 décembre 2022). Disponible sur Internet : <http://books.openedition.org/cths/15395>. ISBN : 9782735509287 . DOI : https://doi.org/ 10.4000/books.cths. 15395 .

Ce document a été généré automatiquement le 8 décembre 2022.

(c) Éditions du Comité des travaux historiques et scientifiques, 2021 Licence OpenEdition Books 
Si volatils soient-ils, impossibles à rassembler derrière un terme générique, faux bruits, rumeurs et fake news méritent d'être étudiés pour ce qu'ils disent de l'état de nos sociétés et de leurs inégalités. Autant que la diachronie nous incite à parier sur des continuités dans l'humanité, plutôt que sur des ruptures construites de toutes pièces par des entreprises médiatiques abondant le courant alternatif des actualités et trouvant ennuyeuses les bonnes nouvelles, l'analyse rétrospective, comme en témoignent les contributions réunies dans ce recueil, se veut simplement un encouragement à la réflexion critique.

Le Congrès national des sociétés historiques et scientifiques rassemble chaque année universitaires, membres de sociétés savantes et jeunes chercheurs. Ce recueil est issu de travaux présentés lors du $144^{\mathrm{e}}$ Congrès sur le thème « Le réel et le virtuel ».

\section{PHILIPPE BOURDIN}

Professeur d'Histoire moderne, Université Clermont-Auvergne, Institut universitaire de France, Centre d'Histoire « Espaces et Cultures » 
SOMMAIRE

Introduction

Philippe Bourdin

La Grande Peur de 1789 : réflexions autour de l'identification de la panique à la révolution paysanne

Henri Vignolles

Georges Lefebvre : le complot aristocratique et la phase violente de la Grande Peur

La critique du « complot aristocratique »

La Grande Peur et la rumeur : des problèmes populaires?

Les fausses nouvelles et leurs conséquences en Révolution : le cas des massacres de septembre 1792 en province

Côme Simien

Un enchevêtrement rumoral

Des rumeurs descriptives et prescriptives

Des rumeurs cloisonnées et toujours en lien avec le réel

Le fédéralisme girondin : une fausse nouvelle à la vie dure

Anne de Mathan

Aux sources d'une fausse nouvelle

Des mots qui tuent

Le psittacisme des discours politiques

"La peste est parmi eux» : contagions et guerre civile dans l'Ouest de la France (1793-1796) Anne Rolland-Boulestreau

À la source de la rumeur

Le succès d'une métaphore

Contrer la rumeur

La théâtralité révolutionnaire des fausses nouvelles

Philippe Bourdin

Jeux de salon, recours aux antiques

Le souvenir de Calas

Les affres de la suspicion

Les rumeurs dans l'espace public au commencement de la Restauration (1814-1816)

François Ploux

En régime d'incertitude

Peurs et rancœurs

Rumeur et charisme napoléonien

"Le vin est la plus saine et la plus hygiénique des boissons » : anatomie d'une légende (XIXe$\mathrm{xX}$ siècles)

Stéphane Le Bras

Le « vin hygiénique » : naissance et diffusion primitive d'un concept (années 1820-années 1860)

Le « vin hygiénique » et Pasteur : ressorts d'une instrumentalisation (années 1870-années 1930) 


\section{NOTE DE L'ÉDITEUR}

Les articles de cet ouvrage ont été validés par le comité de lecture des Éditions du Comité des travaux historiques et scientifiques dans le cadre de la publication des actes du $144^{\mathrm{e}}$ Congrès national des sociétés historiques et scientifiques tenu à Marseille en 2019. 


\title{
Introduction
}

\author{
Philippe Bourdin
}

1 Les années 2020 seraient-elles définitivement placées sous la menace des fake news, ces nouvelles falsifiées dans l'intention de nuire qui nourrissent désormais les analyses des historiens et des sociologues ${ }^{1}$ ? Il n'a guère été de jour sans que ces deux mots n'aient été éructés depuis le très officiel bully pulpit, le pupitre solennel de la Maison Blanche, ou dans les tweets rageurs du $45^{\mathrm{ème}}$ président des États-Unis, cherchant à décrédibiliser un organisme d'information ou un acteur institutionnel qui lui paraissait menaçant. Ainsi furent voués aux gémonies CNN, le Washington Post ou le New York Times, le procureur Robert Mueller enquêtant sur l'influence russe lors des présidentielles de 2016. Mal élu, mais ayant fait campagne sur le rejet et la violation systématique des codes politiques, associant à sa cause victimaire les supposés laissés pour compte des élites de la côte est, Donald Trump ne manqua pourtant pas de rendre lui-même insalubre son espace communicationnel. Héros adolescent de ses propres dime novels, il réécrivit sa geste depuis son élection marquée par l'ombre de Vladimir Poutine (elle n'était absente ni de la dernière campagne présidentielle française ni de la campagne anglaise en faveur du Brexit), et sa décevante cérémonie d'investiture. Il fut celui qui punit ou qui soigna, rédempteur et consolateur à l'égal du Créateur qu'il ne manqua pas d'invoquer. La COVID-19 lui permit de susurrer de précieux conseils prophylactiques à ceux, heureusement peu nombreux, auxquels une rasade d'eau de Javel et une exposition aux rayons du soleil apparaissaient comme autant de promesses de guérison. L'attente des miracles, il est vrai, a toujours été favorisée par ces maux brutaux auxquels est confrontée toute société, qui ne sait compter avec le temps nécessaire et incertain de la science - «dure » ou pas, celle-ci reste toujours humaine, fragile et éventuellement détournée par les lobbies, les marchands du temple ${ }^{2}$. Dans la concurrence des États, des laboratoires, des carrières, de l'exposition médiatique, peuvent ainsi apparaître de faux druides bardés de la reconnaissance universitaire, et faisant mine, à l'orée d'une carrière couronnée et dotée de tous les moyens publics, de jouer les francs-tireurs au nom du gouvernement des meilleurs. La France ne manque pas d'orner régulièrement ses écrans de ces messies d'un jour, soucieux de leur incarnation physique, sans que la parole contradictoire issue de leurs rangs serrés ne rassure quiconque et n'élève la perception du savoir. 
2 Le bouton de fièvre défigurant l'oncle Sam n'est donc qu'un des signes cliniques, le plus visible, des prurits démangeant de tout temps les régimes autoritaires - et ils ne manquent pas sur tous les continents -, mais aussi des tentations communicantes ou censoriales qui affectent un peu partout dans le monde les démocraties. Faute de projet mobilisateur à long terme, malmenés par des élections intermédiaires peu mobilisatrices, tétanisés par les accidents économiques ou pandémiques, leurs dirigeants s'enferrent dans l'immédiat, courent après les réseaux sociaux qui occupent l'empire du vide. Le communautarisme, le complotisme, le négationnisme que ces derniers encouragent, l'individualisme qu'ils portent au pinacle, chacun soignant son ego et ses égaux pour confirmer et affirmer sa vérité et surtout ses préjugés, malmènent un universalisme fondé sur la raison, sur des valeurs et des droits majoritairement admis, à défaut d'être toujours et partout partagés. Ce gigantesque café du commerce, qui dispute de tout et tranche sur tout, donnant le ton de telle ou telle manifestation publique prétendument spontanée, s'abreuve d'avis d'experts parfois autoproclamés, gratifiés de titres ronflants qu'aucune institution n'a jamais validée, de direction ou de présidence de sociétés de conseil créées dans le feu de l'événement et bien pauvres en agents. Avancerions-nous inexorablement vers la société totalitaire imaginée avec effroi par Aldous Huxley dans Le meilleur des mondes: l'être humain n'y serait plus qu'un parfait consommateur de masse, incapable de penser par lui-même et donc de vivre librement ; traumatisés par des sirènes hurlantes à chaque fois qu'ils s'approchent des livres, les enfants seraient détournés de recourir aux outils capables de remettre en question des certitudes trop établies?

Des contre-feux sont allumés. L'école contribue à l'éducation aux médias, à leurs modes d'écriture et de construction de l'information; elle peut compter en France sur l'appui de la Bibliothèque nationale, qui, en 2019, a coorganisé avec l'Institut national de l'Audiovisuel un colloque et une exposition sur le thème des "fausses nouvelles ". Certaines messageries en ligne se préoccupent de la circulation des fake news. WhatsApp, messagerie instantanée filiale de Facebook, a annoncé en janvier 2019 qu'elle allait limiter le partage de messages « à cinq personnes ou groupes de personnes à la fois »auparavant, un utilisateur pouvait partager un message jusqu'à vingt fois. C'est là l'extension d'une mesure déjà mise en place en Inde depuis juillet 2018, pays où se connectent 200 millions d'utilisateurs actifs mensuels et où le gouvernement avait sévèrement critiqué les conséquences des bruits sur la toile ( 25 meurtres au moins en un an).

4 Presse et télévision doivent affronter la méfiance montante de leur lectorat et de leurs auditeurs, et la déshérence qui s'ensuit, que prouvent l'une après l'autre les enquêtes de Viavoice. Ils répondent par la force de certains reportages, des révélations qui égratignent les pouvoirs, parfois fruits d'associations internationales de journalistes (ainsi des Panama papers, portés à la connaissance du public par un consortium de 378 journalistes, issus de 77 pays: l'International Consortium of Investigative Journalists). Mais Cash Investigation, Envoyé spécial, sur France Télévisions, les enquêtes de Mediapart, du Canard enchaîné, du Monde, etc., ne sont pas eux-mêmes à l'abri d'erreurs, d'approximations. Certaines publications proposent de contrôler les sources, ou de remonter aux origines d'une information ou d'une déclaration pour repérer les fake news; d'autres ressources accessibles sur Internet valident les sites sérieux et informent les lecteurs sur les plus suspects: les décodeurs du Monde ou de Libération, Newschecker, Décodex, etc. Ces outils sont très présents aux États-Unis, où les propos 
présidentiels sont régulièrement vérifiés par les pages Internet du Washington Post, de Politifact ou de Snopes.com. L'absence de moyens humains et techniques suffisants empêche cependant souvent les journalistes d'accomplir cette mission; par définition, ils sont de toute façon toujours en retard sur le mensonge qu'ils cherchent à repousser comme Sisyphe son rocher. Or les algorithmes relaient n'importe quelle information, des élucubrations sur les attentats du 11 septembre 2001 contre les Twin Towers de New York à celles sur l'assassinat des talents de Charlie Hebdo le 7 janvier 2015. L'Asie a créé ses fermes à clics qui fabriquent des fake news à la chaîne et de faux comptes twitter. Les sites extrémistes, qui en ont bien compris l'usage politique, surfent sur cette situation, parlant de "réinformation» pour proposer des informations «alternatives » aux médias traditionnels: Breitbart, Infowars aux États-Unis, Soral, Wikistrike ou Média-presse-info en France, sites parfois adoubés par des leaders populistes, comme Bolsonaro au Brésil.

Reste un espace étroit pour la loi, avec le risque qu'elle soit confisquée par un pouvoir ou mise au service d'une vérité unique. Les faux bruits, avec ce qu'ils recèlent de mise en cause, de fragilisation, et autant que l'anonymat de bien de leurs auteurs le permettent, ont depuis longtemps valu sanction, excommunication ou censure : le concile de Latran IV, en 1215, les dénonce comme un " péché de langue »; les cours de justice anglaises du XIV e siècle les considèrent comme une subversion troublant l'ordre public. Les mots ne sont pas encore fixés dans leur acception actuelle, plus englobante : celui de «bruit » apparaît en ancien français au XII siècle, pour désigner une émission de son confuse et inorganisée; au début $d u$ xiII ${ }^{e}$ siècle, celui de "rumeur » évoque d'abord un bruit retentissant, une annonce informelle dont la source est indéterminée, avant d'exprimer ce qui ressort du jugement public, de l'opinion collective, de la renommée; quant à la "nouvelle ", elle est assimilée à une information précise, réfléchie, ordonnée, mais dont l'origine et la véracité demeurent incertaines ${ }^{3}$. Le recours au législatif continue de tenter les politiques, quoiqu'ils ne soient pas dupes de la possibilité de son application : la question de la responsabilité des sites hébergeurs, les GAFA (Google, Apple, Facebook, Amazon), demeure par exemple entière, et ce bien au-delà de leurs devoirs fiscaux. Aux États-Unis, le Premier amendement installe la presse comme quatrième pouvoir - ce que, par exemple, l'affaire du Watergate a démontré -, et protège toutes les formes de discours, même les plus extrêmes, à la seule condition qu'il n'y ait pas d'incitation directe à la violence. La jurisprudence de la Cour suprême, notamment dans l'arrêt New York Times v. Sullivan de 1964, précise que pour établir la diffamation, il faut pouvoir prouver qu'un organe de presse a, au moment de la diffusion de l'information, connaissance de son caractère fallacieux ou erroné et que la publication est faite "dans l'intention de nuire ». Certains discours minoritaires et éminemment contestables (créationnistes, climatosceptiques, suprémacistes, platistes, etc.) sont de fait mis sur un pied d'égalité avec d'autres, plus classiques et corroborés par la science. En France, la loi sur la liberté et les délits de la presse de 1881, toujours en vigueur, punit d'une lourde amende les fausses nouvelles. Mais en juillet 2018, suite aux dérives constatées lors de l'élection présidentielle, l'Assemblée nationale éprouve le besoin de la préciser ; elle adopte donc deux textes législatifs contre la manipulation de l'information en périodes électorales, et instaure une plus grande surveillance des réseaux sociaux et des médias sous l'influence d'un État étranger. Depuis, les fake news sont partout entrées plus que jamais dans l'arsenal politique des pouvoirs en place et de leurs adversaires, ou au service d'intérêts idéologiques, religieux, économiques. Mais leur part dans l'histoire est bien plus ancienne que l'actualité ne le laisse croire, et leurs 
vecteurs parfois moins technicisés que la toile efflorescente : des rumeurs que colporte la rue, on fait "Radio coiffeur ", "Radio couloir ", "Radio Treichville " à Abidjan, « Radio briqueterie » à Yaoundé...

6 Car cette mémoire immatérielle de l'humanité s'est d'abord construite sur une vaste et longue culture orale, quand bien même les élites intellectuelles ont depuis longtemps théorisé sur l'art de la manipulation. Dès le $\mathrm{VI}^{\mathrm{e}}$ siècle avant notre ère, le général et stratège chinois Sun Tzu n'explique-t-il pas dans l'Art de la guerre toute l'importance de la tromperie et de la duperie dans la conduite d'un conflit, insistant notamment sur la nécessité de trouver un compromis entre vérité et mensonge afin de rendre les fausses nouvelles les plus crédibles et efficaces possible? Pour ce faire, il faut bien calibrer son objectif, et notamment les personnes-cibles, en jouant sur le couple affect-intellect. Ce sont ces ressorts qui sont exploités au $\mathrm{I}^{\mathrm{er}}$ siècle pour justifier les persécutions romaines envers les Chrétiens. Ces derniers, qui se marient entre «frères et sœurs » et qui mangent «le corps du Christ» lors de l'eucharistie, sont accusés d'inceste et de cannibalisme. Cette monstruosité est aussi ce que retiennent les récits puritains des Amérindiens au XVII siècle, peuples ignorés de la Bible et aussitôt comparés à des animaux, à des anthropophages, aux serviteurs de Satan. Depuis que l'humanité fait société, la circulation des bruits est consubstantielle à un monde où l'ouïe l'emporte sur la vue, où les sons sont beaucoup plus signifiants que de nos jours, rythmant le quotidien laborieux, religieux, politique et militaire, des cris aux chants des métiers, du tocsin au glas, des modulations du sifflet des ruraux à la simple cloche attachée aux animaux d'élevage. Les marchés, les files d'attente devant les boutiques, les tavernes, le lavoir, sont les premiers espaces de circulation des «on dit». Dans le dernier espace, exclusivement féminin, commencent dans le Sud-Ouest français les mauvaises réputations, les colères, les bagarres, qui très vite peuvent mettre en branle les parentèles, les clientèles, les clans, des villages entiers contre d'autres, à peine apaisés par le jeu de la soule 4 . Les échos du monde extérieur parviennent par la chanson, genre privilégié de la diffusion d'une information, que vend le colporteur. Se font et se défont par son biais la légende des héros populaires, de la poule au pot qu'Henri IV prétendrait offrir à son peuple aux bandits d'honneur - Cartouche en France sous la Régence, Jonathan Wild dans le Londres de la même époque, les frères James dans l'Amérique des années 1880, avant Bonnie Parker et Clyde Barrow dans celle des années 1930. Nul n'est épargné par le bruit, jusqu'aux monarques absolus: fausses morts de Louis XIV ${ }^{5}$; enlèvements d'enfants et de jeunes blondes nubiles imputés à "l'ogre " Louis $\mathrm{XV}^{6}$; réincarnation en Russie de Pierre III, assassiné sur ordre de Catherine II, en dix prétendants différents, dont Pougatchev, qui, à ce titre, prend la tête de la grande révolte paysanne de 1773-1774; etc. La période plus contemporaine n'est pas exempte de ces croyances en la résurrection: parce que d'aucuns prétendent qu'Hitler ne se serait pas suicidé dans son bunker, mais qu'il aurait rejoint les communautés nazies accueillies en Amérique latine, le FBI mène l'enquête jusqu'en 1956...

7 L'invention de la presse, la diffusion exponentielle de l'imprimé, la naissance d'une opinion publique dans l'Europe de la période moderne accélèrent la diffusion de l'information en général, et de la fausse en particulier. Elle s'arrange d'une contestation parlementaire qui fragilise la monarchie française par ses pamphlets, ses libelles, ses affiches, en un moment où les académies, les salons, les loges, les correspondances facilitent les échanges. Les libellistes sont autant des maîtres chanteurs, des agitateurs de tout poil, mercenaires de plume ou têtes brûlées grandissant ou disparaissant dans 
la provocation et le voyeurisme. Ils prétendent donner à leurs suiveurs la clef des secrets liés au pouvoir personnel, et, révélant les prétendus vices cachés des puissants, diffament à volo. Le lieutenant général de police de Paris, Lenoir (1774-1775, puis 1776-1785), prend très au sérieux cette prose, qu'il considère comme désormais inhérente au système politique de l'Ancien Régime. Elle est par exemple l'une des traductions du conflit politique et personnel qui oppose des principaux ministres comme Necker et Calonne, et amuse fort l'intrigant Maurepas, jusqu'au moment où les thèmes de l'impuissance de Louis XVI ou des infidélités de Marie-Antoinette (Les Amours de Charlot et Toinette) le décident à sévir. Mais les efforts se concentrent essentiellement sur les échelons les plus bas de la chaîne de production et de diffusion sous le manteau, n'atteignant pas les inspirateurs des bruits, souvent hautement protégés?

8 Une jeune génération d'avocats nourrit un genre à succès: les nouvelles à la main. Prenant à témoin un public attiré par quelques retentissants procès, leur rhétorique tend naturellement à être manichéenne. Dans la mesure où son objet est de faire ressortir l'innocence d'une partie, par opposition à la culpabilité de l'autre, les personnages de leur récit reconstitué sont présentés sans nuances, comme autant de stéréotypes sociaux : l'aristocrate ou l'ecclésiastique débauché, l'héroïne virginale ou la femme publique, l'homme sensible harcelé par ses ennemis, s'inscrivent plus fortement que jamais dans "l'imaginaire social» des Français et des Françaises de la fin de l'Ancien Régime ${ }^{8}$. Les avocats, que la Révolution portera nombreux dans les Assemblées et les nouvelles administrations, en appellent de plus en plus ouvertement à leurs lecteurs pour qu'ils se prononcent, en juges et en témoins, en «tribunal de la nation " (juge suprême en lieu et place du roi) sur la vérité et le bien-fondé d'une affaire donnée, abordant souvent dans les dernières pages de leurs factums la grande question du contrat social, de la régénération politique, de l'égalité devant la loi, d'un idéal démocratique en lieu et place de la tyrannie ${ }^{9}$. Des affaires marquant durablement la mémoire collective les ont mobilisés, qui rappellent combien la justice elle-même peut condamner sur des preuves falsifiées : pour Calas, Sirven ou le chevalier de la Barre dans les années 1760, souvenons-nous des combats de Voltaire, appuyé sur un groupe de juristes mené par Élie de Beaumont, avocat au Parlement de Paris, et prenant à témoin le grand public.

9 La démultiplication des feuilles, qu'autorise la liberté de presse proclamée par la Révolution française, sert encore de porte-voix à nombre d'hommes de loi qui se font journalistes. Pour la seule année 1789, 140 journaux nouveaux paraissent à Paris, 44 en province, souvent éphémères, écrits, imprimés et diffusés à la criée, par placardage, par abonnement, par un seul et même homme. Ils comptent dans la naissance et l'amplification des peurs, dans l'été 1789 comme en septembre $1792^{10}$, car leurs promoteurs se montrent peu soucieux de vérifier leurs sources, ou impuissants à le faire : ils colportent le vocabulaire dépréciatif né des événements et de la suspicion, destiné à confondre l'adversaire politique et social ("l'aristocrate », le "fédéraliste ${ }^{11}$ ", le «brigand ", etc.). La guerre des mots use de tous les supports, et le théâtre, alors si couru et depuis toujours habitué aux apparences et au travestissement, joue un important rôle ancillaire ${ }^{12}$. La vérité défendue est d'abord celle du pamphlétaire, du libelliste, d'un bord à l'autre de l'échiquier politique. À gauche, le Père Duchesne de Jacques-René Hébert fait primer une langue orale et argotique, qui se veut emblématique de la culture populaire et d'un combat politique sans concession, dénonciateur et manichéen. Sa prose recourt volontiers au monde animal, à la tératologie, à la scatologie, à l'anticléricalisme, à la calomnie - fondée sur une supposée 
corruption par le pouvoir, les réseaux de sociabilité, l'argent, la nourriture ou le sexe. À droite, un ton semblablement accusateur, polémique, agressif, prévaut chez Du Rozoi ou Rivarol, acharnés contre Lafayette, Robespierre, Théroigne de Méricourt, etc. Entre les deux, la même obsession dénonciatrice existe chez Camille Desmoulins, auteur des Révolutions de France et de Brabant et du Vieux Cordelier, ou chez le girondin Carra, à la tête des Annales patriotiques et littéraires. Ce dernier distingue parmi les journalistes entre le bon grain et l'ivraie (les " aristocratico-royalistes »), abuse du complotisme, de la suspicion portée contre les personnes publiques, fondée tantôt sur ses propres convictions intimes, tantôt sur la recherche de preuves, souvent sur les peurs collectives, les rumeurs, entretenues par les dangers pressentis. Le risque assumé est de devoir reconnaitre et corriger ses erreurs, non sous la pression de la justice, mais à la demande des intéressés, et d'être frappé à son tour par de semblables outrances - elles le conduisent à la guillotine à l'automne $1793^{13}$.

Il n'est guère étonnant de constater la part écrasante de la Révolution et de la Restauration ${ }^{14}$ françaises dans les contributions qui suivent. L'idée d'une fin du monde, propice à toutes les élucubrations millénaristes, accompagne les bouleversements qui ébranlent les pouvoirs en place et les incertitudes qui s'ensuivent. Les révolutionnaires français de 1789, conscients d'écrire l'histoire ${ }^{15}$, aspirent certes, comme Robespierre, à voir «l'aurore de la félicité universelle». Cela n'épargne d'aucune projection eschatologique: Chaumette, procureur de la Commune de Paris en 1792-93, pousse la Convention à voter au plus vite la mort du roi, dans laquelle il voit le gage des victoires militaires et des récoltes abondantes. Les théoriciens royalistes, comme de Maistre, Bonald ou Barruel, encore ignorants de la parenthèse impériale dont se revendiquera toute une génération, pensent que Dieu envoie sur terre une punition aux hommes qui prétendent faire la loi à sa place, et que du feu satanique qui brûle, selon eux, la France, naîtront un trône et un autel restaurés et plus forts que jamais. Entre espoirs et réalité, il y a un présent qui résiste, des mémoires à l'œuvre, et l'espace pour tous les faux bruits, toutes les vaines attentes, une explosion d'autant plus diffuse quand l'information a longtemps été corsetée - comme s'y est employé le Premier Empire.

11 À la rupture institutionnelle peut s'ajouter une crise de subsistances, propice aux soupçons d'un " complot de famine » : déjà éprouvé lors de la " guerre des farines », qui soulève un large Bassin parisien en 1775 contre les " accapareurs » et les "affameurs ", le thème rebondit à l'heure de la Grande Peur de juillet-août 1789 et inscrit durablement ces accusations dans le vocabulaire de la suspicion. Mais la fausse nouvelle est tout autant un moteur de l'économie, servi par des affairistes sans scrupules, avides de profits rapides - des billets de confiance de John Law sous la Régence aux fluctuations malveillantes des actuels cours des Bourses internationales (dues, par exemple, à des rumeurs de rachat, de changement de direction des entreprises, de malfaçons, etc.), si l'on ose ce raccourci chronologique. Les grandes crises religieuses sont tout aussi propices aux élucubrations - et c'est évidemment un moteur essentiel de la décennie 1789-1799. Le xviII ${ }^{\mathrm{e}}$ siècle a donné le ton avec le jansénisme populaire qui se développe autour de la personne du diacre François de Pâris, mort en 1727, et de sa vie édifiante : combien de miracles de guérisons, fût-ce au prix de convulsions, autour de sa tombe du cimetière Saint-Médard, scrupuleusement rapportés par les Nouvelles ecclésiastiques à l'heure où le pouvoir royal est affaibli par la longueur du règne de Louis $\mathrm{XV}$, les scandales de la Cour, la fronde des parlements, la division de plus en plus sensible entre haut et bas clergé ${ }^{16}$ ? 
La guerre est tout autant un facteur aggravant. La rumeur est une arme utilisée de tout temps contre l'adversaire. La Première Guerre mondiale, comme en témoignera l'historien Marc Bloch, est ainsi un moment aigu d'inflation des « bobards » diffusés par les puissances belligérantes, mais également par les soldats entre eux (en 1914, on répète à loisir que les balles allemandes, défectueuses, sont inoffensives; en 1917, on accuse les soldats américains récemment arrivés, et non encore combattants, de propager de faux bruits; sans compter les fausses pistes tracées par l'état-major français pour cacher ses défaites). À l'heure de la Révolution française, on ne peut comprendre l'un des moteurs des massacres de septembre sans prendre en compte le contexte militaire dégradé. La frontière orientale est bousculée, on pense à Paris le massif de l'Argonne franchi, la capitale à quelques jours de marche. Les sections se réunissent en continu, et à corps rompus esprits fatigués : la menace d'un complot des prisons, imaginé par la presse de tous bords et par le ministre de la Justice Danton, gagne en consistance, d'autant que le tribunal extraordinaire fondé après le 10 août ne s'est pas pressé de statuer sur le sort de ceux détenus dans d'anciens bâtiments religieux, qui gardent cour ouverte au sein des quartiers populaires. La psychose s'accentue encore si, au fil du déplacement des troupes, sourdent des menaces de maladies, d'épidémies - ainsi de la Virée de galerne ${ }^{17}$. Dans tous ces moments de tensions politiques, religieuses, économiques, militaires, médicales, la peur de l'autre (l'étranger, la femme, les " classes dangereuses »), systématiquement instrumentalisée, ses succédanés (racisme, xénophobie, antisémitisme, etc.) pourvoient alors plus que jamais aux nouvelles falsifiées, aux explications surnaturelles, apocalyptiques ou conspirationnistes, à la mise au ban de boucs émissaires. Avant 2020, les Français - déjà confinés, déjà interpellés par des médecins hésitants sur la dangerosité des lieux publics, déjà isolés de leurs familles en cas de maladie, et enterrés à la sauvette si mort s'ensuivait -, n'ont-ils pas régulièrement vu la main de l'étranger, des Juifs ou les effets de la sorcellerie derrière les grandes pandémies, telles les pestes (la «Peste noire » de 1347-1352, comme celle de Marseille en 1720), le choléra en 1832 et en 1854, et les grippes du Xxe siècle (« espagnole » en 1918, "asiatique » en 1956-1958, "de HongKong » en 1968-1969)?

Si volatils soient-ils, et avec la difficulté à les rassembler derrière un terme générique, tant la malignité ou la naïveté de l'homme sont derrière chacun, tant la démultiplication des moyens de la communication et des échanges les favorise, les rumeurs, les faux bruits, les fake news, méritent donc d'être étudiés avec sérieux pour ce qu'ils disent de l'état de nos sociétés et de leurs inégalités. Ils nous parlent incidemment de peurs ancestrales, des obstacles à l'altérité, des limites de la connaissance, de notre rapport au danger et à la mort, en bref de nos mentalités et de notre éducation comme de "l'extension du domaine de la crédulité ${ }^{18}$ ». Autant que la diachronie nous incite à parier sur des continuités dans l'humanité, plutôt que sur des ruptures construites de toutes pièces par des entreprises médiatiques abondant le courant alternatif des actualités et trouvant ennuyeuses les bonnes nouvelles, l'analyse rétrospective ne conduit cependant pas à mésestimer les réels dangers des faits falsifiés. Elle se veut simplement un encouragement à la réflexion critique au lieu de la sidération mutique. 


\section{BIBLIOGRAPHIE}

Seth ASHLEY, Jessica ROBERTS, Adam MASKL (dir.), American journalism and «fake news »: examining the facts, Santa Barbara (Californie), ABC-CLIO, 2018.

Philippe BOURDIN et Stéphane LE BRAS (dir.), Les fausses nouvelles : un millénaire de bruits et de rumeurs dans l'espace public français, Clermont-Ferrand, Presses universitaires Blaise Pascal, 2018.

Philippe BOURDIN (dir.), La Révolution (1789-1871). Écriture d'une histoire immédiate, Clermont-Ferrand - Vizille, Presses universitaires Blaise Pascal, 2008.

Gérald BRONNER, Cabinet de curiosités sociales, Paris, Presses universitaires de France, 2018.

Jean-Luc FRAY, « Bruits, rumeurs et fausses nouvelles à l'époque médiévale. Une esquisse méthodologique et historiographique (espace "français" et comparaisons européennes) ", dans Philippe Bourdin et Stéphane Le Bras, Les fausses nouvelles : un millénaire de bruits et de rumeurs dans l'espace public français, Clermont-Ferrand, Presses universitaires Blaise Pascal, 2018, p. 29-46.

Yves CASTAN, Honnêteté et relations sociales en Languedoc (1715-1780), Paris, Plon, 1974.

Nicole CASTAN, Justice et répression en Languedoc à l'époque des Lumières, Paris, Flammarion, 1980.

Monique COTTRET, Jansénismes et Lumières. Pour un autre XVIII ${ }^{e}$ siècle, Paris, Albin Michel, 1998.

Robert DARNTON, Le Diable dans un bénitier. L'art de la calomnie en France (1650-1800), Paris, Gallimard, 2010.

Arlette FARGE, Jacques REVEL, Logiques de la foule. L'affaire des enlèvements d'enfants. Paris, 1750, Paris, Hachette, 1988.

François-Bernard HUYGHE, Fake news. La manipulation en 2019, Versailles, VA éditions, 2019.

Alexandre JOUX, Maud PÉLISSIER, L'information d'actualité au prisme des fake news, Paris, L'Harmattan, 2018.

Stefan LEMNY, Jérémy MALOIR, «La pratique dénonciatrice dans la presse révolutionnaire : l'exemple de Jean-Louis Carra », dans Philippe Bourdin et Jean Claude Caron (dir.), L'homme politique et la presse, de Camille Desmoulins à Émile de Girardin, Clermont-Ferrand, Presses universitaires Blaise Pascal, 2018, p. 55-72.

Hervé LEUWERS, L'invention du barreau français (1660-1830). La construction nationale d'un groupe professionnel, Paris, Éditions de l'EHESS, 2006.

Alexis LÉVRIER, « Les fausses morts du Roi-Soleil, ou l'impossible contrôle de l'information », dans Le Temps des médias, revue d'histoire, $\mathrm{n}^{\circ}$ 30, 2018-1 : « La fausse information, de la Gazette à

Twitter », p. 32-46.

Catherine MAIRE, De la cause de Dieu à la cause de la Nation. Le jansénisme au XVIII siècle, Paris, Gallimard, 1998.

Sarah MAZA, Vies privées, affaires publiques. Les causes célèbres de la France prérévolutionnaire, Paris, Fayard, 1997.

Soria MYRIAM (dir.), La Rumeur au Moyen Âge. Du mépris à la manipulation, $V^{e}-X V^{e}$ siècles, Rennes, Presses universitaires de Rennes, 2011. 
Roy PINKER, Fake news \& viralité avant Internet. Les lapins du Père-Lachaise et autres légendes médiatiques, Paris, Éditions du CNRS, 2020.

\section{NOTES}

1. Par exemple : Ph. Bourdin, S. Le Bras (dir.), Les fausses nouvelles : un millénaire de bruits et de rumeurs dans l'espace public français ; F.B. Huyghe, Fake news. La manipulation en 2019 ; A. Joux et M. Pélissier (dir.), L'information d'actualité au prisme des fake news : "La fausse information, de la Gazette à Twitter "; R. Pinker, Fake news \& viralité avant Internet. Les lapins du Père-Lachaise et autres légendes médiatiques.

2. Cf. infra la contribution de S. Le Bras.

3. J.-L. Fray, « Bruits, rumeurs et fausses nouvelles à l'époque médiévale. Une esquisse méthodologique et historiographique (espace "français" et comparaisons européennes)»; M. Soria (dir.), La rumeur au Moyen Âge. Du mépris à la manipulation, $V^{e}-$ $\mathrm{XV}$ siècles.

4. Y. castan, Honnêteté et relations sociales en Languedoc (1715-1780) ; N. Castan, Justice et répression en Languedoc à l'époque des Lumières.

5. A. Lévrier, «Les fausses morts du Roi-Soleil, ou l'impossible contrôle de l'information ».

6. A. Farge, J. Revel, Logiques de la foule. L'affaire des enlèvements d'enfants.

7. R. Darnton, Le Diable dans un bénitier. L'art de la calomnie en France (1650-1800).

8. S. Maza, Vies privées, affaires publiques. Les causes célèbres de la France prérévolutionnaire.

9. H. Leuwers, L'invention du barreau français (1660-1830). La construction nationale d'un groupe professionnel.

10. Cf. infra les contributions d'H. Vignolles et de C. Simien.

11. Cf. infra les contributions d'A. de Mathan et d'A. Rolland-Boulestreau.

12. Cf. infra la contribution de Ph. Bourdin.

13. S. Lemny, J. Maloir, «La pratique dénonciatrice dans la presse révolutionnaire: l'exemple de Jean-Louis Carra ».

14. Cf. infra la contribution de F. Ploux.

15. Ph. Bourdin, La Révolution (1789-1871). Écriture d'une histoire immédiate.

16. C. Maire, De la cause de Dieu à la cause de la Nation. Le jansénisme au XVIII siècle;

M. Cottret, Jansénismes et Lumières. Pour un autre XVIII ${ }^{e}$ siècle.

17. Cf. infra la contribution d'A. Rolland-Boulestreau.

18. G. Bronner, Cabinet de curiosités sociales, p. 173. 


\section{AUTEUR}

\section{PHILIPPE BOURDIN}

Professeur d'Histoire moderne, Université Clermont-Auvergne, Institut universitaire de France, Centre d'Histoire « Espaces et Cultures » 


\title{
La Grande Peur de 1789 : réflexions autour de l'identification de la panique à la révolution paysanne
}

\author{
Henri Vignolles
}

1 Entre le 21 juillet et le 6 août 1789, quelques semaines après l'insurrection parisienne, de fausses nouvelles circulent dans une très grande partie des campagnes françaises. Elles annoncent l'attaque imminente de plusieurs milliers de «brigands "; ils ont déjà ravagé la province voisine, ils violent, massacrent et incendient sans distinction. Ces nouvelles suscitent des mouvements de panique, auxquels succèdent des armements défensifs et des demandes de secours. Ces deux derniers phénomènes assurent la diffusion des alertes et des paniques au loin. Des armées improvisées, dotées d'un armement sommaire, partent à la rencontre des brigands tandis que les femmes fuient le village pour cacher les enfants et quelques biens emportés à la hâte. Les recherches infructueuses de l'ennemi et les démentis en provenance des localités que l'on annonçait ravagées instruisent peu à peu les communautés de la fausseté de ces nouvelles.

2 Il s'agit là d'un récit classique, volontairement trivial de ce qu'a été la Grande Peur de l'été 1789. Il ne rend pas seulement compte de l'exceptionnalité de l'évènement, mais de l'image mémorielle que synthèses académiques et programmes scolaires ont véhiculée depuis près d'un siècle. Un tel résumé abolit ce que cet évènement d'une portée nationale indéniable a pu produire comme diversité selon les régions voire les localités dans lesquelles la «terreur panique » a été vécue. Le défaut de schématisation est plus ou moins inhérent à toute volonté de synthèse ; il ne serait que d'une incidence mineure s'il n'entretenait pas une certaine méconnaissance sur la Grande Peur. Les variations sur le nombre de brigands annoncés, l'importance numérique des armées défensives constituées, la nationalité conférée aux brigands, ou encore le type de refuge recherché par les habitants (champs, forêts, ville voisine), peuvent être considérées comme relativement accessoires. D’autres généralisations, plus déterminantes pour l'inflexion qu'elles confèrent à la vision globale de la Grande Peur, sont plus problématiques. 
3 De fait, le récit «classique » ajoute volontiers une phase durant laquelle les paysans armés par la Grande Peur auraient profité de l'occasion pour s'attaquer au régime féodal dans son ensemble. Dans un second temps, les paysans se seraient rendus dans les châteaux locaux pour exiger et détruire les "terriers ", c'est-à-dire les titres de propriété légitimant la perception des droits féodaux et reconnaissant la propriété féodale des seigneurs. Ces derniers auraient été fréquemment contraints de légitimer ces actions, de participer à des festivités improvisées et d'offrir vin et nourriture aux insurgés. Dans les cas les plus violents, la Grande Peur évoluerait même en incendie de châteaux. Les historiens qualifient cette phase "d'offensive » ou de "punitive »; elle est bien souvent considérée comme la phase la plus significative de la Grande Peur, car elle permet de l'identifier pleinement à l'intervention paysanne - révolutionnaire dans la Révolution française.

Dans cet article, nous montrerons qu'en plus de ne pas être systématique, l'idée d'une phase punitive repose sur un présupposé, quoique largement implicite, lui-même problématique : la rumeur - dont la Grande Peur serait une forme paroxystique - est un problème populaire. Nous chercherons à comprendre comment l'assimilation des paniques de l'été 1789 à la révolution paysanne s'est imposée dans l'historiographie de la Révolution française, avant d'esquisser un parallèle entre l'image de la Grande Peur et une certaine façon de considérer les rumeurs.

\section{Georges Lefebvre : le complot aristocratique et la phase violente de la Grande Peur}

5 Georges Lefebvre, maitre des études révolutionnaires après la mort d'Albert Mathiez, unanimement reconnu pour l'importance de sa contribution, l'originalité de ses recherches, sa profonde érudition et la puissance de ses synthèses, publie en $1932 \mathrm{La}$ Grande Peur de 1789, première et unique monographie à l'échelle nationale du phénomène ${ }^{1}$. Au fil des années, l'ouvrage devient la référence indépassable sur le phénomène ${ }^{2}$. Parallèlement, la Grande Peur devient un évènement incontournable de tout récit de l'année 1789 , et toutes les synthèses universitaires sur la Révolution française ne citent plus que Lefebvre pour l'aborder. C'est en se référant à l'autorité de Lefebvre que la thèse de la phase punitive de la Grande Peur est encore soutenue, répandue et légitimée.

6 Sur la complexité du rapport entre la Grande Peur et la violence paysanne, G. Lefebvre est resté bien plus prudent que ses héritiers. Il avait constaté que les régions touchées par d'importantes insurrections agraires ne connaissaient pas la Grande Peur, insistant sur l'incompatibilité entre les deux phénomènes ${ }^{3}$ :

«Bien qu'elle [la Grande Peur] ait assurément favorisé les progrès de l'armement et suscité de nouveaux troubles agraires, il n'est pas exact qu'elle leur fut indispensable. [...] Entre la révolte agraire et la grande peur, il y a si peu de dépendance que la seconde n'apparait pas dans la première, le Dauphiné excepté4. »

7 C'est par le truchement de la thèse explicative centrale de Lefebvre que cette incompatibilité a progressivement disparu. Dans son ouvrage, Lefebvre commence par longuement étudier comment le contexte socio-économique crée un climat de peur sociale : disette, crainte de la faim et des vagabonds, peur des brigands et insurrections agraires. Il avance ensuite un argument clé : une croyance a produit la « synthèse » de l'ensemble des peurs qu'il avait préalablement étudiées, c'est l'idée du «complot 
aristocratique ». Pour G. Lefebvre, la Révolution a été, dans sa première phase à partir de 1787-1788, un triomphe de l'aristocratie qui «crut tenir sa revanche et ressaisir l'autorité politique dont la dynastie capétienne l'avait dépouillée ${ }^{5}$ ». Dans son combat contre l'autorité monarchique, elle aurait libéré la force politique de la bourgeoisie en l'associant à ce bras de fer. Mais la volonté de l'aristocratie de conserver sa prééminence sociale ${ }^{6}$ aurait déterminé un véritable " conflit de classe ${ }^{7}$ ", qui provoque le blocage des États généraux entre mai et juillet 1789. Durant cette crise naît l'idée du complot aristocratique, avec la «conviction que les nobles défendraient obstinément leurs privilèges ${ }^{8} »$. Celle-ci, toujours selon Lefebvre, a la particularité d'être partagée par toutes les couches du tiers état, et de prendre la forme d'un agrégat d'accusations et de préventions sociales. C'est-à-dire que la conviction née de l'opposition politique se nourrit de thèmes qui lui sont extérieurs, comme la crainte de l'accaparement : alors qu'on l'attribuait traditionnellement à la rapacité de certains individus, il tend à être pensé comme l'arme politique des privilégiés.

Début juillet, l'idée du complot aristocratique est avivée par le renvoi de Necker, la concentration de troupes autour de Paris et la crainte d'un coup de force suggéré à Louis XVI par ses frères. Les mots célèbres de Camille Desmoulins évoquant une « SaintBarthélemy des patriotes » illustrent bien la puissance de cette conviction.

Lefebvre explique que la victoire de l'insurrection parisienne n'a pas éteint le potentiel mobilisateur du complot aristocratique ; au contraire, le mot d'ordre aurait gagné la campagne et les paysans. Cette transmission est attestée par certains récits de la Grande Peur, qui évoquent très explicitement comment les émigrés, très souvent Artois, conduisent une horde de brigands ou d'étrangers pour punir l'audace politique du tiers état. Dans Quatre-vingt-Neuf, Lefebvre inverse même l'ordre de la démonstration en faisant de l'insurrection parisienne non pas une cause, mais «le premier acte de la Grande Peur ${ }^{9}$ ». La thèse de Lefebvre a un double avantage, elle donne une explication crédible à la force de contagion des fausses nouvelles et elle confère un sens "révolutionnaire " à ces évènements de manière bien plus convaincante que toute tentative antérieure. Mais si Lefebvre a généralisé cette explication, par respect de ses sources, il n'a pas étendu cette généralisation à la phase violente de la Grande Peur, qu'il observe principalement dans le Dauphiné et exceptionnellement ailleurs. Au contraire, il soulignait en général la non-violence des évènements ailleurs, soucieux de contredire l'alarmisme d'un Hippolyte Taine.

Le fait que Lefebvre décrive longuement les épisodes d'insurrection agraire précédant la Grande Peur dans son ouvrage de référence, pour mieux les distinguer, a entretenu malgré lui la confusion entre les deux phénomènes. Infléchir le sens de la Grande Peur comme une insurrection agraire a permis, cartes à l'appui, de présenter une France rurale monolithique dans son offensive contre l'Ancien Régime. Ce, en utilisant un syllogisme simple: puisque la Grande Peur est quasi-générale, en faire une sorte d'insurrection agraire, c'est montrer que presque toute la France est en insurrection, quitte à passer outre les distinctions opérées par Lefebvre, tout en le citant.

11 Quatre-vingt-neuf, en faisant de l'insurrection parisienne le premier épisode de la Grande Peur, évacue un certain nombre des distinctions qui avait été établies dans la monographie de 1932. Timothy Tackett a par ailleurs montré qu'entre ces deux ouvrages, le complot aristocratique était passé du statut d'hypothèse à celui d'étape fondamentale dans l'explication de la « politisation de la France rurale ${ }^{10}$ ». 
Il est beaucoup plus difficile d'affirmer que Georges Lefebvre est l'instigateur de l'identification de la Grande Peur aux insurrections agraires. L'insistance sur la " phase offensive » lui est bien antérieure, et ne fait pas partie des acquis dont on lui attribue parfois à tort la paternité. Les historiens ont retenu tout d'abord la réfutation catégorique de toute une tradition historiographique qui faisait de la Grande Peur une machination provoquée à dessein pour influer sur le cours de la Révolution. G. Lefebvre a également établi la géographie et la chronologie des alarmes que l'on conserve aujourd'hui, de même que l'élément explicatif décisif du "complot aristocratique ". Cependant, le sens de la Grande Peur avait déjà été fixé.

En comparant les écrits des historiens antérieurs à Georges Lefebvre à ceux de ses héritiers, il est aisé de constater que $L a$ Grande Peur de 1789 n'a pas altéré le récit qui s'est élaboré aux tournants des $\mathrm{xIX}^{\mathrm{e}}$ et $\mathrm{xx}^{\mathrm{e}}$ siècles. Dans le huitième tome de l'Histoire générale du IV siècle à nos jours de Lavisse et Rambaud consacré à la Révolution française, Alphonse Aulard écrit à propos de la Grande Peur :

«C'est l'étrange, la mystérieuse panique connue sous le nom de la grande peur, l'un des rares évènements de la Révolution dont le souvenir ait subsisté dans les campagnes, le plus important de tous peut-être. Partout, ou presque partout, on croit, on annonce que des "brigands" viennent. Pendant qu'on s'arme et qu'on se fortifie dans les villes, les campagnards émigrent dans des retraites, cavernes ou forêts. La panique passée, quand on constate qu'il n'y a pas de brigands, on n'en reste pas moins debout et insurgé. Cet ennemi dont on a eu peur n'était pas, après tout, imaginaire: c'est l'ancien régime, c'est la féodalité. Les assemblées d'habitants, sur la place du village ou dans l'église, décident de ne plus payer de droits féodaux. Clément aux personnes, le paysan s'attaque aux droits, brûle les châteaux pour brûler les titres, et se persuade souvent qu'il obéit ainsi aux ordres du roi. En fait, la féodalité est par terre, le peuple victorieux, quand l'Assemblée se décide à ratifier cette victoire par les décrets rendus dans la nuit du 4 août ${ }^{11}$. »

Près de quatre-vingts ans plus tard, Albert Soboul, dans sa dernière synthèse sur la Révolution française, livre un récit donnant à la Grande Peur un sens tout à fait identique :

«Mais les paysans restèrent sous les armes. Délaissant la poursuite de brigands imaginaires, ils se portèrent sur le château du seigneur, se firent livrer sous la menace les vieux titres d'archives où étaient consignés les droits détestés, les chartes qui légitimaient dans un passé lointain la perception des redevances, et en allumèrent de grands feux sur la place du village ${ }^{12}$. "

15 L'exemple est ici tiré de l'œuvre de Soboul autant parce qu'il est un « héritier » de Lefebvre que par l'influence que ses écrits ont pu avoir dans le monde académique et auprès du grand public. Mais il ne s'agit pas d'un exemple isolé, pris au milieu d'affirmations contraires. On trouverait facilement d'autres auteurs ayant repris à leur compte l'une des distinctions de Lefebvre. François Furet rappelle, par exemple, que la Grande Peur n'évolue en guerre aux châteaux que dans le Dauphiné, mais par le truchement du complot aristocratique; il opère l'identification de la Grande Peur et de la révolution paysanne ${ }^{13}$.

\section{La critique du « complot aristocratique »}

Ce n'est que relativement récemment que l'explication par la conviction d'un complot aristocratique a été contestée. En 1992, l'historien américain Clay Ramsay publie une monographie sur la Grande Peur à l'échelle du Soissonnais ${ }^{14}$. Il confirme l'un des points 
clés de l'analyse de Lefebvre : l'incapacité de la Grande Peur de se déployer dans les zones de révolte ouverte. Il en conclut qu'un minimum de paix sociale est nécessaire à son développement. Il conteste, même dans une région proche de la capitale - tant géographiquement qu'économiquement -, la prégnance du complot aristocratique dans les représentations collectives durant l'été 1789 . Selon Ramsay, cette catégorie de pensée n'apparaît dans le Soissonnais que plus tardivement et n'explique pas la Grande Peur.

Dans un article paru en 2004, Timothy Tackett met en doute la démonstration de Lefebvre pour l'ensemble des provinces, considérant que les exemples à l'appui d'une conviction généralisée d'une conspiration aristocratique dans les campagnes sont bien minces ${ }^{15}$. L'historien américain montre que la plupart des exemples proposés par Lefebvre sont issus soit de Paris, soit d'autres centres urbains. Il voit au contraire dans la Grande Peur l'occasion de multiples solidarités verticales entre noblesse et peuple. Tackett dissocie ce que Lefebvre avait associé dans Quatre-vingt-neuf: l'insurrection parisienne et la Grande Peur comme étant le déploiement d'une même logique dans deux espaces différents. Il propose à la fin de son article, sous forme d'hypothèse, une alternative :

«Pour la grande majorité des gens, le déclencheur ne fut pas la brusque synthèse d'un complot aristocratique, mais la terreur d'une anarchie imminente, de l'effondrement de toutes les forces de l'ordre public - autant à Paris qu'en province - qui découla directement de la crise de la mi-juillet ${ }^{16}$.»

Par extension, Timothy Tackett estime que c'est davantage la recherche des causes de la fausse nouvelle qui a été facteur de violence. La question des origines de la Grande Peur et de la validité de l'explication par le complot aristocratique est épineuse, et l'on peut considérer que le débat est encore ouvert. En revanche - et c'est peut-être le plus surprenant - il est plus aisé d'infirmer que la violence, la phase "punitive ", est loin d'être une étape systématique de la Grande Peur. Clay Ramsay le démontre pour le Soissonnais, Francisque Mège récuse l'évolution en une guerre aux châteaux pour l'Auvergne, Hubert Delpont n'intègre pas la Grande Peur dans son étude sur les insurrections agraires au motif que dans le Sud-Ouest la Grande Peur est restée à un stade défensif ${ }^{17}$.

Si la Grande Peur n'est pas l'expression détournée de l'animosité paysanne envers le régime féodal et qu'elle n'annonce pas la nuit du 4 août qu'elle a pourtant contribué à causer, quelle est sa nature ? L'étude de la Grande Peur dans le sud-ouest de la France invite à dépasser une autre évidence pour commencer à répondre à cette importante question: l'évènement serait-il qu'exclusivement rural, voire paysan, et ses seuls enseignements porteraient-ils sur la «mentalité populaire" ou la révolution paysanne?

\section{La Grande Peur et la rumeur : des problèmes populaires?}

C'est en étudiant une région où l'on ne trouve pas de traces d'une phase «punitive » et où des villes telles que Montauban et Toulouse font l'expérience de la Grande Peur que cette problématique a émergé. Avant de considérer la Grande Peur comme n'étant pas a priori un évènement exclusivement paysan, nous étions contraints de faire rentrer l'étude des sources dans un double modèle. 
21 Premièrement, et en conformité avec l'historiographie de la Révolution française, la Grande Peur devrait être le paroxysme de la révolution paysanne et l'on ne devrait l'étudier qu'à travers elle. Mais Tackett a insisté sur les solidarités "verticales » au moment de la Grande Peur. C'est déjà affirmer que des éléments non-paysans y ont participé. Ils ne sont pourtant restés sous la plume des historiens qu'une variable dans la description de l'état d'esprit de la paysannerie.

Deuxièmement, il nous fallait, en suivant nombre d'implicites de la littérature scientifique sur le phénomène de la "rumeur ", considérer qu'elle ne concernait que les milieux populaires, parce qu'analphabètes, parce que liés à une culture orale, et parce que plus suspects d'être irrationnels. Ces implicites ont contribué à forger des stéréotypes sociaux très présents dans le monde social, médiatique et scientifique ${ }^{18}$.

Or l'étude des sources de la Grande Peur laisse apparaître une réalité bien plus ambiguë. L'écrasante majorité d'entre elles, qu'elles soient d'origine urbaine ou rurale, émanent d'une élite sociale (administration communale, subdélégation d'intendance, courriers de notables, curés de campagne, etc.). Leurs auteurs affichent parfois une distance claire avec le développement de la fausse nouvelle, exhibant leurs vaines tentatives d'en arrêter le cours; plus souvent, ils affectent une distance évasive et impersonnelle, sur le mode du " on disait », " on dit »; enfin, il n'est pas rare qu'ils ne remettent aucunement en cause l'authenticité de la nouvelle.

Il semble que plus la source a été rédigée sur le moment, plus il est rare d'y trouver des expressions manifestes de doute. Il est fréquent de voir des registres de délibérations communales raturés ou amendés lorsque des décisions liées à la Grande Peur ont été prises. À Albi, deux corrections ont été effectuées a posteriori, quelques jours après le passage de la Grande Peur, dans une tentative de masquer la participation à la rumeur. Dans une délibération de "l'assemblée des trois ordres" datée du 31 juillet, les mentions des brigands ont été raturées, l'une a même été remplacée par « tous ceux qui entreprendront de troubler l'ordre public ${ }^{19} »$. Une fois la peur passée, les élites sociales albigeoises ont trouvé très utile de conserver, voire d'instrumentaliser ce qu'elles avaient produit : la milice bourgeoise et un discours légitime sur le maintien de l'ordre. Un exemple remarquable de reconstruction mémorielle du récit se décèle dans l'affirmation paradoxale d'un «bourgeois de Toulouse» au moment de l'alarme toulousaine :

«On se prépara à bien les recevoir [les brigands]. Quoique je n'ajoutasse foi à tout ce que l'on disait, je ne fus pas cependant des derniers à me pourvoir de balles ${ }^{20}$. » Les historiens sont tributaires de ces témoignages inspirés par la moralisation de la crédulité et la crainte de se voir associé à une vaste tromperie. Au-delà des professions de foi rétrospectives, il existe des actes concrets de l'action des diverses formes d'autorités au moment de la Grande Peur.

L'exemple le plus emblématique de l'implication d'élites sociales dans la Grande Peur est sans doute celui du parlement de Toulouse. Le $1^{\text {er }}$ août, il rend et ordonne la publication d'un arrêt autorisant la levée de milices bourgeoises :

« Nous venons d'être informés des alarmes que cause dans différentes parties de votre Ressort, notamment aux environs de Montauban, une troupe de brigands qui porte le trouble \& la désolation dans les campagnes, menace de brûler les récoltes, de dévaster les villages, \& répand partout la terreur \& l'effroi. Les citoyens de tous les états \& de toutes les conditions sont également intéressés à se garantir de leur fureur, à défendre leurs propriétés ; c'est par un concert unanime, par une réunion de forces qu'on peut parvenir à repousser ces ennemis communs. 
Nous sommes, Messieurs, dans des conjonctures où l'intérêt général doit confondre tous les ordres de la société, où il ne doit régner parmi eux qu'un même esprit dirigé vers le bien, où tous doivent s'armer pour la cause publique, pour défendre principalement cette classe si intéressante du cultivateur, qui deviendroit la principale victime de ces brigandages, pour empêcher que la disette, qui en seroit la suite funeste, ne vienne nous assiéger dans nos murs ${ }^{21}$.»

Soit l'on attribue aux parlementaires les mêmes caractéristiques mentales que l'on accorde facilement aux paysans : crédulité, rapport imaginaire à la réalité, emprise des émotions et d'une mémoire collective traumatisée. Soit l'on prend au sérieux les énoncés, les mots d'ordre, les préférences, les ambiguïtés que contient un tel arrêt. L'insistance sur l'unité des différents "ordres de la société » ou "états » est par exemple très révélatrice des préoccupations sociopolitiques des rédacteurs de l'arrêt, animés par la crainte du délitement de l'ordre social. D'où l'utilité et la pertinence de «ces ennemis communs » dont l'existence permet de faire circuler des injonctions à l'unité. La crainte de la disette, en fin de texte, est un euphémisme pour exprimer les conséquences sociales de la disette : l'émeute, voire l'insurrection populaire. La ville de Toulouse a été le théâtre d'une importante émeute frumentaire quelques jours plus tôt, le 27 juillet, contexte qui éclaire la réactivité des parlementaires ${ }^{22}$. En la croisant avec d'autres sources émanant des autorités et d'autres types de discours, il est possible de restituer toute l'ambiguïté, le double langage et les euphémismes que contiennent la dénonciation et la crainte des brigands.

Il ne s'agit pas d'une source méconnue, Georges Lefebvre la cite et les différentes histoires de la ville de Toulouse ne manquent pas de la mentionner. Elle n'a pourtant jamais été commentée autrement que pour constater le passage de la Grande Peur à Toulouse : comme s'il y avait une obstination à ne pas prendre en compte les logiques de la participation des parlementaires à la rumeur. Pascal Froissart a publié un ouvrage salutaire en 2002 sur l'histoire de la rumeur, non comme phénomène social mais comme objet de science ${ }^{23}$. Il permet de comprendre l'angle mort que l'association entre "rumeur» et "élites» a longtemps constitué. Sa critique de la posture des « rumorologues ${ }^{24}$ ", qui entendent caractériser, prédire, voire contrôler la rumeur, porte sur une littérature qui est régulièrement utilisée par des historiens dès lors que leurs recherches abordent la question des rumeurs et des fausses nouvelles ${ }^{25}$. Pour Froissart, plus que l'existence d'un phénomène intemporel nommé " rumeur ", dont on pourrait cerner des caractéristiques invariables, il existe une volonté de croire en la rumeur, née au début du $\mathrm{xx}^{\mathrm{e}}$ siècle dans le sillage du positivisme. Cette volonté serait la projection d'un fantasme social née de la crainte de l'émergence des "masses", renvoyées à leurs supposées passivité, crédulité, voire primitivité.

P. Froissart montre, entre autres, que les grands classiques de l'étude des rumeurs n'ont fait que reprendre un protocole issu de la psychologie du témoignage élaboré par le psychologue allemand William Stern (1871-1938). Une expérience de bouche-à-oreille en laboratoire est censée représenter le mode de diffusion des rumeurs : on demande à un sujet $\mathrm{A}$ de mémoriser un énoncé élaboré par le scientifique, de le répéter à un sujet $B$, qui le répétera à un sujet $C$ et ainsi de suite. Le "rumorologue " récolte ensuite l'énoncé final, et c'est ainsi que les grands concepts du «rumorisme» se sont mis en place : focalisation sur un détail, perte des autres détails, accentuation des intensités, etc. Autant de règles qui, selon Froissart, ne font que décrire «l'entropie informationnelle ", phénomène peu signifiant au demeurant. Le principal problème est que cette expérience, qui met les individus hors contexte et hors de tout investissement 
personnel avec le contenu du message qu'ils font circuler, s'est imposée comme une modélisation de la rumeur. Cette modélisation ignore toute culture écrite, savante, littéraire ou médiatique, les excluant d'un quelconque rôle dans la rumeur. Une telle extrapolation identifie la rumeur à un manque, à une information qui circule dans un public malsain et/ou mal informé, c'est-à-dire à une certaine forme de pathologie sociale.

L'analogie avec l'historiographie de la Révolution française ne va pas de soi. Lefebvre et la plupart des historiens qui ont étudié la paysannerie française et le mouvement populaire pendant la Révolution française n'étaient guère adeptes de modélisations hors contexte, et ne songeaient en aucun cas à jeter un voile de dédain sur leurs actions collectives. Lefebvre avait construit sa réflexion, notamment dans Les foules révolutionnaires, en opposition aux caractères que Gustave Le Bon avait conféré aux foules ${ }^{26}$. En bref, ils ne partageaient pas la crainte et la dépréciation des masses de certains de leurs contemporains. Mais, dans l'obstination à traiter la Grande Peur comme un phénomène exclusivement paysan ou populaire, même pour en souligner le rôle "positif ", il y a un biais commun avec l'ensemble des opérations intellectuelles qui ont postulé la rumeur comme une pathologie des masses ${ }^{27}$. L'histoire de la Grande Peur peut être réinvestie en prenant en compte la culture et l'action des «élites »terme utilisé ici pour son caractère inclusif -, pour en comprendre le déclenchement et la dynamique.

\section{BIBLIOGRAPHIE}

ALLPORT Gordon et POSTMAN Leo, « Les bases psychologiques des rumeurs », dans Lévy André (dir.), Psychologie sociale, textes fondamentaux, Paris, Dunod, 1965, p. 170-185.

DELPONT Hubert, La victoire des croquants : les révoltes paysannes du Grand Sud-Ouest pendant la Révolution 1789-1799, Nérac, Amis du vieux Nérac, 2002.

FOURNIER Georges, Journées révolutionnaires à Toulouse, Nîmes, J. Chambon, 1989.

FROISSART Pascal, La rumeur : histoire et fantasmes, $2^{\mathrm{e}}$ éd., Paris, Belin, 2010.

FURET François et RICHET Denis, La Révolution française, 3e éd., Paris, France, Fayard, 1989.

LAVISSE Ernest et RAMBAUD Alfred (dir.), Histoire générale du IV siècle à nos jours. tome VIII, La Révolution française, 1789-1799, Paris, France, Armand Colin \& Cie, 1896.

LE BON Gustave, Psychologie des foules, $9^{\mathrm{e}}$ éd., Paris, Presses universitaires de France (coll.

«Quadrige »), 2013.

LEFEBVRE Georges, La grande peur de 1789 ; suivi de Les foules révolutionnaires, $3^{\mathrm{e}}$ éd., Paris, Armand Colin, 2014. 
LEFEBVRE Georges, Quatre-vingt-neuf, $2^{\mathrm{e}}$ éd., Paris, Éditions sociales, 1970.

MÈGE Francisque, La dernière année de la province d'Auvergne. La Grande Peur, Clermont-Ferrand, Bouy, 1901.

PASQUIER Félix, Notes et réflexions d'un bourgeois de Toulouse au début de la Révolution, d'après des lettres intimes, Toulouse, M. Bonnet, 1917.

RAMSAY Clay, The ideology of the Great Fear: the Soissonnais in 1789, Baltimore, Johns Hopkins university press, 1992.

RAMSAY Clay, "L'idéologie de la Grande Peur : le cas du Soissonnais », Annales historiques de la Révolution française, 1995, vol. 299, no 1, p. 13-31.

SовоUL Albert, La Révolution française, Nouvelle Édition revue et augmentée du Précis d'histoire de la Révolution française, Paris, Gallimard (coll. « Tel »), 1992.

TACKETT Timothy, « La Grande Peur et le complot aristocratique sous la Révolution française », Annales historiques de la Révolution française, mars 2004, no 335, p. 1-17.

\section{NOTES}

1. G. Lefebvre, La grande peur de 1789.

2. Dans la préface de l'édition de 2014, Hervé Leuwers et Michel Biard rappellent que les toutes premières recensions de l'ouvrage ne laissaient pas forcément présager ce futur statut de grand classique.

3. L'historien américain Clay Ramsay considère que cette « intuition psychologique » de Lefebvre résiste à une analyse détaillée. Voir C. Ramsay, The ideology of the Great Fear: the Soissonnais in 1789.

4. G. Lefebvre, La grande peur de 1789, p. 172.

5. G. Lefebvre, Quatre-vingt-neuf.

6. C'est ainsi que Lefebvre interprète la convocation des États généraux dans les formes de 1614 , le conflit autour du doublement du tiers état et du vote par tête.

7. G. Lefebvre, Quatre-vingt-neuf, p. 68.

8. Ibid, p. 113.

9. G. Lefebvre, Quatre-vingt-neuf, p. 127.

10. T. Tackett, «La Grande Peur et le complot aristocratique sous la Révolution française », § 3 .

11. E. Lavisse et A. Rambaud (dir.), Histoire générale du IV siècle à nos jours. tome VIII, La Révolution française, 1789-1799, p.68-69. Alphonse Aulard a par ailleurs largement contribué à imposer le nom de "Grande Peur " (un temps «Grand'Peur » sous sa plume) comme référent aux paniques de l'été 1789 ; bien avant Georges Lefebvre.

12. A. Soboul, La Révolution française, p. 158.

13. F. Furet et D. Richet, La Révolution française, p. 86-87. La Grande Peur y est qualifiée « d'insurrection complexe ».

14. C. Ramsay, The ideology of the Great Fear: the Soissonnais in 1789. Voir également, C. Ramsay, «L'idéologie de la Grande Peur : le cas du Soissonnais ». 
15. T. Tackett, «La Grande Peur et le complot aristocratique sous la Révolution française ».

16. Ibid, $\S 25$. Cette hypothèse n'est pas sans rappeler l'interprétation de Hippolyte Taine sur les paniques de l'été 1789 (que l'on ne désignait pas encore sous le nom de Grande Peur).

17. C. Ramsay, The ideology of the Great Fear: the Soissonnais in 1789, F. Mège, La dernière année de la province d'Auvergne. La Grande Peur, H. Delpont La victoire des croquants: les révoltes paysannes du Grand Sud-Ouest pendant la Révolution 1789-1799.

18. La lutte très actuelle contre les «fake news » n'est pas à l'abri de cette posture par laquelle les milieux autorisés s'arrogent le privilège de dire le vrai et le faux.

19. Arch. Dép. Tarn (ADT), 4 EDT BB 45 . Nous sommes en capacité d'affirmer que ces corrections n'ont pas été faites au moment de la rédaction, car les autorités municipales, associées à de nombreux notables de la ville, ont rédigé le $1^{\mathrm{er}}$ août une circulaire pour alerter les communautés voisines de la menace des brigands et des mesures à prendre (voir le registre des délibérations consulaires de Réalmont, ADT 222 EDT BB 11).

20. F. Pasquier, Notes et réflexions d'un bourgeois de Toulouse au début de la Révolution, d'après des lettres intimes, p. 28.

21. Arch. Dép. Haute-Garonne, 1 L 323, arrêt du parlement de Toulouse du $1^{\mathrm{er}}$ août 1789.

22. Voir G. Fournier, Journées révolutionnaires à Toulouse.

23. P. Froissart, La rumeur : histoire et fantasmes.

24. Nous reprenons les substantifs «rumorologue» "rumorancie» ou encore « rumorisme » que P. Froissart a utilisé dans un but sensiblement polémique.

25. L'exemple le plus déterminant est celui de G. Allport et L. Postman, "Les bases psychologiques des rumeurs ».

26. G. Le Bon, Psychologie des foules auquel répond G. Lefebvre, «Foules révolutionnaires ». On peut retrouver ce dernier texte dans les éditions de 1988 et de 2014 de La Grande Peur de 1789.

27. Lefebvre n'ignorait pas que des groupes sociaux non-paysans aient participé à la Grande Peur. Il écrivait «le rôle le plus curieux fût à coup sûr celui des autorités ", jugeant implicitement cette participation plus anormale que celle des paysans et il ne la commentait pas pour elle-même. G. Lefebvre, La grande peur de 1789, p. 183.

\section{RÉSUMÉS}

La Grande Peur est très souvent regardée à travers le seul prisme paysan, évacuant, par un a priori problématique, la participation de «l'élite». La Grande Peur est pleinement identifiée à l'intervention paysanne dans la Révolution française. L'article se propose d'essayer de comprendre comment et pourquoi cette identification s'est produite. L'historiographie de la Grande Peur, autour d'une discussion sur le rôle de l'œuvre de Georges Lefebvre, peut être utilement comparée aux analyses ayant pour objet les rumeurs, considérées implicitement comme populaires ou comme symptômes de l'état social. Cette analogie permet de repenser la 
Grande Peur à travers la culture et l'action des élites sociales : les conceptions qui sous-tendent le contenu des fausses nouvelles sont loin d'être étrangères aux discours et aux idées qui structurent l'ordre social.

\section{AUTEUR}

\section{HENRI VIGNOLLES}

Doctorant, Université Toulouse - Jean-Jaurès, laboratoire FRAMESPA 


\title{
Les fausses nouvelles et leurs
} conséquences en Révolution : le cas des massacres de septembre 1792 en province

\author{
Côme Simien
}

1 Du 2 au 4 septembre 1792, d'immenses massacres ensanglantent Paris. En trois jours et trois nuits, quelque 1100 à 1400 victimes perdent la vie, essentiellement des prisonniers tirés de leurs geôles par des foules émeutières s'abandonnant à un déchaînement de violences collectives. Fruits d'une " préparation mentale collective " dont les rouages principaux sont mieux connus des historiens depuis le maître ouvrage de Pierre Caron ${ }^{1}$, ces événements macabres sont rendus possibles par l'état d'émotivité permanent dans lequel évolue alors Paris, et la conviction que de multiples complots contre la Révolution sont sur le point de se déclencher dans la capitale. Dans la montée des peurs collectives qui préparent ainsi le massacre, les rumeurs - entendues comme des nouvelles sans certitude se répandant en semant de l'inquiétude - jouent un rôle essentiel, que les recherches de $\mathrm{T}$. Tackett et $\mathrm{L}$. Porter sont récemment venues rappeler ${ }^{2}$. Une, en particulier, s'avère décisive dans le déclenchement des massacres, celle d'un complot des prisons, que l'on disait alors pleines de détenus (15000 à 30000 , quand on n'y trouve en réalité guère plus de 2500 à 2600 prisonniers $^{3}$ ) prêts à se soulever pour livrer la ville aux ennemis austro-prussiens de la nation révolutionnaire.

2 Il a moins souvent été noté, en revanche, que les violences meurtrières qui frappent la capitale s'inscrivent dans le contexte plus large d'une vague de massacres (soixantecinq au moins ${ }^{4}$ ) traversant la France de la mi-juillet au début du mois d'octobre 1792. Si ces événements provinciaux n'atteignent jamais l'ampleur du drame parisien (onze victimes à Lyon, six à Marseille, quarante-quatre à Versailles...), ils n'en touchent pas moins près de quatre départements sur dix et sont directement responsables de la mort d'une centaine de personnes à travers le pays ${ }^{5}$. Prendre en considération cette « saison des massacres de septembre ${ }^{6} "$ par le biais des bruits et fausses nouvelles qui travaillent alors la province, à l'aide de documents produits « à chaud » (correspondance privée, 
rapports administratifs, presse...), apparaît pourtant comme un moyen de saisir d'un peu plus près le climat général d'un pays qui vit alors le dernier été de la monarchie.

\section{Un enchevêtrement rumoral}

3 À l'instar de Paris, les espaces provinciaux qui connaissent des massacres entre juillet et septembre 1792 paraissent tous avoir été traversés par une accumulation de rumeurs, la plupart pessimistes quant à l'avenir de la Révolution et de ses partisans. Parmi elles, une, en particulier, finit par dominer toutes les autres, par son intensité comme par son potentiel anxiogène, contribuant alors de manière décisive à la saturation des tensions qui précède de peu le déclenchement des massacres. Ainsi en va-t-il à Lyon, où onze prisonniers perdent la vie le 9 septembre 1792. La rumeur qui finit par précipiter les événements concerne les officiers nobles du régiment RoyalPologne, en stationnement depuis peu dans la ville et sur le point de la quitter, le 22 août, pour rejoindre le poste qui leur a été indiqué par le général en chef de l'armée du Midi ${ }^{7}$. Loin de cette réalité, somme toute banale, d'un mouvement de troupes par temps de guerre, le bruit public accuse ces officiers de vouloir rejoindre le royaume sarde, afin de s'engager, avec leurs soldats, aux côtés de son roi et du comte d'Artois (alors à Turin), contre la Révolution. Placés pour cette raison en détention dans la prison de Pierre-Scize par les autorités municipales et militaires de la ville, c'est là que la foule les trouve le 9 septembre, et les passe par les armes. C'est de là, ensuite, que les émeutiers décideront de se porter dans les deux autres prisons de la ville, y faisant trois victimes supplémentaires, toutes prêtres réfractaires, semble-t-il regardés comme impliqués dans un complot contre-révolutionnaire de plus grande envergure lié aux officiers du régiment de cavalerie ${ }^{8}$.

4 À cette date, et depuis un mois au moins, quatre grandes catégories de rumeurs avaient toutefois déjà largement travaillé la ville de Lyon. Des rumeurs frumentaires, tout d'abord: alors que le prix des céréales double sur les marchés en quelques jours, les bruits d'un accaparement orchestré par les ennemis de la Révolution dans le but d'affamer le peuple lyonnais se répandent dans toute la ville dès la fin du mois d'août ${ }^{9}$. Des rumeurs concernant le front militaire, ensuite: dans les derniers jours du même mois, la ville croit par exemple savoir (il n'en était en fait rien) que les Piémontais et les Suisses s'apprêtaient à attaquer de concert la France, en prenant d'abord le chemin de Lyon $^{10}$. Des rumeurs à répétition impliquant un hypothétique complot de l'intérieur, également : vers la mi-août, on murmure que les ennemis du nouvel ordre des choses sont sur le point de s'emparer de l'arsenal et des principaux postes militaires de la ville ${ }^{11}$, tandis qu'un autre bruit annonce la formation d'une légion contrerévolutionnaire de mille cinq cents hommes armés et vêtus de l'uniforme national, dont le chef se cacherait à Lyon ${ }^{12}$. Durant la première semaine de septembre, une nouvelle rumeur enfle selon laquelle des conjurés devaient se voir remettre des signes de reconnaissance, avant de se soulever contre la Révolution et ses partisans lyonnais ${ }^{13}$. Enfin, les rumeurs de collusion des autorités avec les ennemis de la Révolution se multiplient: le fait même d'avoir placé les officiers du régiment Royal-Pologne non dans les prisons de la ville, sous la surveillance populaire, mais dans le fort de PierreScize, à l'écart du centre, est interprété par toute une partie au moins des patriotes comme une preuve manifeste de la volonté de faciliter leur évasion ${ }^{14}$. 
$5 \quad$ L'intensité et la multitude des rumeurs qui traversent ainsi le pays durant l'été 1792 ne doit pas surprendre. Si l'on admet, à la suite des travaux sur les phénomènes rumoraux, que les moments les plus favorables à l'épanouissement et à la propagation des rumeurs sont les périodes de crise, ces instants particuliers où «le sentiment de la proximité du danger crée une atmosphère d'attente inquiète » qui voit « la population réagir au moindre signal ${ }^{15}$ », si l'on admet également que l'incertitude politique, mêlée à l'attention au politique et à la défiance vis-à-vis des autorités est de nature à les stimuler ${ }^{16}$, alors force est d'admettre que l'été 1792 fut un moment particulièrement propice à la naissance et à la diffusion rapide des fausses nouvelles. Car, comme le remarque Tackett, il n'y eut sans doute guère, durant toute la Révolution, de période plus effrayante et plus troublante que ces trois mois de juillet, août et septembre $1792^{17}$. À la suite d'une colère de moins en moins contenue contre la monarchie (qui traverse l'ensemble du pays) le trône a été renversé le 10 août. Pour la première fois depuis plus de mille ans, la France se trouve sans roi. Des élections ont été convoquées afin qu'une assemblée puisse donner une nouvelle Constitution à la France et une autre forme à l'État. Pour l'heure, la patrie avance dans une voie inconnue ${ }^{18}$, tandis que la Révolution tout entière apparaît (à raison) en péril, face à l'avancée rapide et, semble-t-il, inexorable des armées austro-prussiennes qui, dès juillet, ont promis aux patriotes les pires tourments et une subversion totale s'il était touché à la famille royale. La patrie est alors bel et bien « en danger ».

6 Dans ces moments de tensions extrêmes, les rumeurs ont à vrai dire d'autant plus aisément proliféré que les informations sûres et officielles sont devenues très rares, une rareté qui alimente elle-même de manière décisive la montée de l'inquiétude. Elle crée en effet un vide que le besoin de comprendre et de savoir nourrit aussitôt de " on dit ». Si le phénomène n'est pas propre aux mois de juillet à septembre 1792, mais constitue l'un des substrats les plus favorables à l'épanouissement des rumeurs ${ }^{19}$, force est en revanche d'admettre qu'il est particulièrement affirmé durant cet arc chronologique. À Lyon, toujours, le maire, Louis Vitet, rapporte au Conseil général de la commune, le 2 septembre 1792, une semaine tout juste avant les massacres qui ensanglantèrent sa ville, que " plusieurs gens malintentionnés avoient répandu le bruit de différents échecs » essuyés par les armées françaises ${ }^{20}$. S'il condamne ces rumeurs, force lui est surtout de constater qu'elles surviennent dans une ville qui n'a nulle « connaissance par lettre ou par courrier extraordinaire de nouvelles qui put y donner lieu ». Et pour cause! Vitet lui-même, pourtant premier édile de la ville, est bien obligé d'admettre, pour le regretter, qu'aucune «nouvelle certaine sur les mouvements de nos armées et ceux des armées combinées de Prusse et d'Autriche » ne parvient entre Saône et Rhône ${ }^{21}$. Devant le manque total d'information et face à l'évidence des périls que l'on imagine fondre de toutes parts, la ville cède alors aux rumeurs les plus inquiétantes.

7 Lorsque la nouvelle des premières victoires militaires arrivera, au début de l'automne 1792, et que la Convention commencera à exercer ses fonctions, levant ainsi quelquesunes des incertitudes qui pesaient sur le devenir politique du pays et l'exercice de la souveraineté, le contexte favorable à l'éclosion de ces rumeurs disparaîtra et, avec lui, pour un temps, les bruits les plus alarmants. La vague rumorale de l'été 1792 doit donc bien être comprise, d'abord, comme le symptôme d'une période de peurs, d'angoisses et de ressentiments collectifs déjà là, que les rumeurs ont tout à la fois cristallisés et amplifiés. À ce titre, elles ne peuvent être présentées comme le seul ingrédient, ni 
même comme l'ingrédient premier, qui devait conduire au déclenchement de la geste massacrante ${ }^{22}$.

8 Le cas de rumeurs sans massacre permet de le confirmer. Car s'il n'y eut pas de massacre sans rumeur durant l'été 1792, force est en revanche d'admettre que les six dixièmes des départements qui ne connaissent pas de violences populaires meurtrières n'en furent pas moins traversés de fausses nouvelles inquiétantes. À Rennes par exemple, le bruit d'un « complot qui fait frissonner » se répand à la fin août. Selon les interlocuteurs locaux du Moniteur, il serait fomenté par des «monstres» qui, pour plusieurs d'entre eux, trameraient leurs noirs desseins depuis les prisons de la ville ${ }^{23}$. Tel bruit, qui devait apporter leur justification à tant de violences, ne se transforme pourtant pas, ici, en expédition punitive. Si de multiples facteurs peuvent expliquer ce massacre qui n'eut pas lieu, remarquons surtout que les départements touchés par les violences, entre juillet et octobre 1792, ne sont pas distribués de manière aléatoire dans l'espace national. Soit ils se situent à proximité immédiate de la guerre ou des frontières (donc de la possibilité de la guerre), soit au cœur ou au voisinage de zones agitées par des conspirations royalistes bien réelles (Ardèche, Cévennes), soit enfin, aux abords de la capitale et de ses combats à très haute implication émotionnelle ${ }^{24}$. Dès lors qu'on s'éloigne de Paris, du bruit de la guerre et des prises d'armes, et même si des volontaires s'engagent au même moment dans toute la France pour sauver la Révolution, le degré de tensions et de peurs qui travaillent le tissu social est peut-être moindre, et donc moins propice à transformer en pulsions paniques les fausses nouvelles en circulation.

\section{Des rumeurs descriptives et prescriptives}

9 L'efficacité des rumeurs qui travaillent les zones de massacre durant l'été 1792 tient à ce qu'elles sont tout autant descriptives que prescriptives ${ }^{25}$. Elles désignent en effet des coupables clairement identifiés, qui non seulement donnent un sens aux difficultés que l'on suppose, à tort ou à raison, éprouvées par la patrie, mais qui rendent aussi possible leur résolution par l'élimination des responsables désignés de la peur ressentie.

À Châlons-sur-Marne, par exemple, les émeutiers, en procédant à la mise à mort d'un détenu, prévenu d'assassinat, le 10 septembre, entendent châtier ceux dont la rumeur dit qu'ils complotent dans l'ombre des prisons de la ville ${ }^{26}$. Ils acceptent en revanche la remise en liberté d'un humble détenu, proposée par Prieur de la Marne. Retenu dans les geôles châlonnaises pour une modique dette de 50 livres, ce malheureux échappe d'évidence aux contours de la rumeur et donc aux périls guettant ceux qu'elle désigne. Il peut même, par la suite, être porté en triomphe dans la ville par une foule qui manifeste ainsi sa conviction d'avoir rétablit une justice qui avait momentanément fait défaut ${ }^{27}$. À Castres, les tensions de l'été 1792, elles aussi nourries par les bruits de multiples conjurations, sont plus particulièrement avivées par la question primordiale des vivres, dont le cours ne cesse de croitre ${ }^{28}$. Alors que les gardes nationaux volontaires sont sur le point de quitter la ville pour rejoindre les frontières envahies, la rumeur se répand qu'un marchand de blé spécule à la hausse sur les prix des grains au détriment du peuple. Les mesures prises pour protéger cet homme qui, soudain, donne sens aux maux populaires, ne suffisent pas: le corps de garde où il a été placé en détention préventive est forcé, avant que la foule ne se livre sur lui à un déchaînement spectaculaire de brutalités dont la nature exprime, à elle seule, l'ampleur du 
ressentiment éprouvé. Défenestré, le marchand est ensuite assommé de coups de bâtons et traîné mort dans les rues. Son corps est finalement jeté dans l'Agout, la rivière traversant la ville. Nulle autre victime n'est à déplorer par la suite. L'affameur supposé du peuple, qui n'aurait pourtant jamais spéculé sur les céréales ${ }^{29}$, n'est plus. Cédant à la rumeur née des inquiétudes planant sur la survie des classes populaires, la foule a agi dans le sens que la fausse nouvelle lui prescrit afin d'assurer ses lendemains, et pas plus que cela.

\section{Des rumeurs cloisonnées et toujours en lien avec le réel}

Les rumeurs qui participent à la "préparation mentale collective » des massacres ont encore une autre particularité essentielle : leur ancrage local. Celui-ci regarde tant leur objet (le complot qu'elles mettent en jeu) que son rayon d'action. Le foisonnement intense des bruits qui traversent le pays durant l'été 1792 , s'il décline sans cesse des thèmes identiques (complot de famine, complot des prisons, avancée des armées ennemies), n'en met pas moins en jeu des rumeurs cloisonnées, sans articulation entre elles $^{30}$. Quoique les bruits qui prennent naissance à Paris soient d'ordinaire de ceux qui se propagent le plus aisément sur l'ensemble du territoire national, la rumeur d'un complot des prisons de la capitale n'a d'effet que dans d'étroits horizons géographiques, limités à Paris et à ses environs immédiats ${ }^{31}$. Qu'on s'en éloigne et alors, soit un épais silence l'emporte, soit les observateurs s'étonnent du crédit dont a bénéficié ce bruit étrange jusque sur les âmes d'ordinaires les plus pondérées de la capitale ${ }^{32}$.

12 En tout état de cause, les rumeurs parisiennes ne sauraient expliquer la mobilisation des foules émeutières, puis leur passage à l'acte, à Rethel, Castres, Toulon, Couches... D'autant plus que la moitié de ces massacres provinciaux ont eu lieu avant même ceux de Paris, en juillet-août 1792. Pour ceux-là aussi, la rumeur qui précipite le massacre est circonscrite dans d'étroits horizons géographiques. À Limoges, c'est le bruit selon lequel on aurait trouvé chez le prêtre Chabrol "un dépôt d'armes chargées", qu'il aurait refusé de remettre aux gardes nationaux venus les lui réclamer, qui sème la colère et la peur au sein de la population, au point qu'une foule finit par s'emparer de lui, le traînant dans les rues, l'assommant et le rouant de coups jusqu'à ce que mort

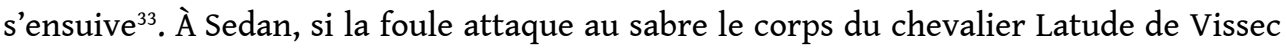
avant de promener sa tête dans la ville, le 5 septembre, c'est parce qu'on affirme qu'il se rendait clandestinement dans le camp des Autrichiens afin de leur signaler les maisons des patriotes de la ville - et non ceux d'une autre localités ${ }^{34}$.

Cette réalité locale de la rumeur contribue sans doute à son efficacité. La peur ressentie est d'autant plus vive que le péril est perçu comme proche, concret, imminent, incarné, et le passage à l'acte d'autant plus aisé que les responsables de ces peurs vivent dans le pays, dans le quartier, dans la ville concernée par ces inquiétudes. Ces rumeurs sont d'autant plus crédibles, enfin, qu'elles entretiennent toujours un lien plus ou moins étroit avec la réalité. Celui-ci peut-être direct, comme à Florac (Lozère) où, le 9 août 1792, le sieur Giberne de La Martinerie est fusillé par un attroupement. Cet événement intervient dans un espace régional particulier, celui des Cévennes, travaillé, au début du mois d'août 1792, par la rumeur d'une conjuration des ennemis intérieurs et extérieurs de la Révolution ${ }^{35}$. Or ce bruit insistant n'est pas dénué de tout fondement, 
loin s'en faut, la région ayant connu au cours des deux années précédentes trois camps contre-révolutionnaires à Jalès (Ardèche), dont le dernier a été vaincu un mois seulement avant le massacre de Florac $^{36}$. Il avait été convoqué par les princes émigrés qui entendaient donner au Vivarais une place de premier ordre dans la contrerévolution, en lançant durant l'été 1792 une offensive dont le but est le renversement tout entier du nouvel ordre des choses. L'entreprise, mal exécutée, échoue finalement en quelques jours, au début du mois de juillet, suite à la déroute de la petite armée contre-révolutionnaire du comte de Saillans. Des papiers sont saisis à cette occasion. Ils permettent de mettre à jour l'ensemble du projet ainsi que les ramifications du complot (authentique cette fois), en indiquant tant les noms des principaux chefs de la conjuration que l'implication de nombreuses autorités municipales de la région, dans sa partie d'obédience catholique du moins. Les rebelles sont, dans les jours et les semaines suivants, poursuivis avec acharnement par des patriotes désireux « d'en finir avec le péril royaliste et d'exorciser les peurs générées par les menaces d'une guerre civile ", ainsi que l'analyse V. Sottocasa ${ }^{37}$. La conjuration n'avait toutefois plus guère de substance, en août, lorsque les patriotes cévenols lui prêtent encore un avenir.

Ailleurs, le lien entre rumeur et réalité peut être un peu moins accentué, sans cesser d'exister pour autant. À Lyon, les officiers nobles qui seront exécutés le 9 septembre, après que la rumeur publique les a accusés de vouloir prendre la fuite à la tête de leur régiment, n'ont aucunement le projet de livrer la guerre à la France depuis le royaume de Piémont-Sardaigne. Force est en revanche d'admettre qu'ils ont remis leurs démissions depuis déjà deux mois, par rejet d'une Révolution à l'égard de laquelle ils n'éprouvent plus aucune espèce de sympathie ${ }^{38}$. De facto, ils ont pu paraître suspects d'émigration, quand bien même leur déplacement est en fait ordonné par l'état-major de l'armée du Midi - qui refusait depuis deux mois d'accepter les démissions desdits officiers.

En de nombreux cas, l'attitude des autorités locales contribue de manière décisive à rattacher au réel les bruits en circulation. Ainsi en va-t-il à Marseille où la rumeur se répand, le 20 juillet, qu'un marchand drapier du nom de Boyer tramait un complot contre la municipalité, le Club et les patriotes de la ville, lesquels doivent être égorgés dans la rue, le lendemain, après que Boyer et ses partisans, vêtus de vert et de fleurs de lys, se seront emparés de toute l'artillerie de la ville et aient mis le feu au port ${ }^{39}$. Gagnée par le doute, la municipalité ordonne la fouille de la maison dudit Boyer par la garde nationale, le 20 juillet. Or, venant d'autorités que l'on peut à bon droit supposer mieux renseignées que les simples citoyens, ces investigations et l'arrestation préventive de Boyer ont surtout pour effet d'accréditer l'imminence de la conjuration ${ }^{40}$. La colère populaire peut alors enfler sans que plus rien ne puisse l'apaiser, y compris le résultat des fouilles du domicile de Boyer, qui ne révèlent pourtant rien de compromettant. Aussitôt, des rassemblements se constituent pour s'emparer de sa personne afin que "justice fût faite» au peuple ${ }^{41}$. Moins de deux heures après son placement sous les écrous, il périt sous les coups de la foule, devant sa prison, son cadavre étant peu après pendu à un réverbère. 


\section{BIBLIOGRAPHIE}

Michel BIARD, Philippe BOURDIN, Hervé LEUWERS et Pierre SERNA (dir.), 1792. Entrer en République, Paris, Armand Colin, 2013.

Haïm BURSTIN, L'invention du sans-culotte. Regards sur le Paris révolutionnaire, Paris, Odile Jacob, 2005.

Pierre CARON, Les massacres de septembre 1792, Paris, Maison du Livre français, 1935.

Anarchasis cOMBES, Histoire de la ville de Castres et de ses environs pendant la Révolution française, Castres, Lucien Granier, 1875.

Natalie Z. DAVIS, Les cultures du peuple. Rituels, savoirs et résistances au XVI siècle, Paris, Aubier, 1979, p. 284.

Arlette FARGE, La vie fragile. Violence, pouvoirs et solidarités à Paris au XVIII ${ }^{e}$ siècle, Paris, Le Seuil, 1986.

Alfred FRAY-FOURNIER, Le département de la Haute-Vienne : sa formation territoriale, son administration, sa situation politique pendant la Révolution, Limoges, Henri Charles-Lavauzelle Imprimeur, 1908, t. 2. Janine GARRISSON, Tocsin pour un massacre : la saison des Saint-Barthélemy, Paris, Éd. d'Aujourd'hui, 1975.

Oscar HAVARD, Histoire de la Révolution dans les ports de guerre. Toulon, Paris, Nouvelle Librairie Nationale, 1912-1913.

François de JOUVENEL, « Les camps de Jalès (1790-1792), épisodes contre-révolutionnaires ? ", Annales Historiques de la Révolution française, 2004-3, vol. 337, p. 1-20.

Steven KAPLAN, Le complot de famine, histoire d'une rumeur au XVIII e siècle, Paris, A. Colin-EHESS, 1982. Antoine LAPIERRE, Campagne des Emigrés dans l'Argonne en 1792, Sedan, Librairie Genin, 1911.

Charles-Antoine LOURDE, Histoire de la Révolution à Marseille et en Provence, t. 2, Marseille, Senès, 1839.

Pierre-Victor MALoUËT, Mémoires, t. 2, Paris, Plon, 1874.

Jean-Clément MARTIN, Violence et Révolution. Essai sur la naissance d'un mythe national, Paris, Le Seuil, 2006.

François PLOUX, De bouche à oreille. Naissance et propagation des rumeurs dans la France du XIXe siècle, Paris, Aubier, 2003

François PLoux, « La ville des "libelles parlés". Rumeurs et bruits publics à Paris sous la Première Restauration », dans Philippe Bourdin et Stéphane Le Bras (dir.), Les fausses nouvelles. Un millénaire de bruits et de rumeurs dans l'espace public français, Clermont-Ferrand, PUBP, 2018, p. 83-103.

Lindsay PORTER, Popular Rumour in Revolutionary Paris, 1792-1794, Basingstoke, Palgrave Macmillan, 2017.

Marcel REINHARD, 10 août 1792. La Chute de la Royauté, Paris, Gallimard, 1969.

Côme SIMIEN, Les massacres de septembre 1792 à Lyon, Lyon, Éd. Aléas, 2011.

Valérie SOTTOCASA, Mémoires affrontées. Protestants et catholiques face à la Révolution dans les montagnes du Languedoc, Rennes, PUR, 2004. 
Donald SUTHERLAND, « Justice and Murder. Massacres in the Provinces. Versailles, Meaux and Reims in 1792 », Past and Present, vol. 222, 2014, p. 129-163.

Timothy TACKETT, « Rumor and Revolution: The Case of the September Massacres », French History and Civilization, 2011, vol. 4, p. 54-64.

Timothy TACKETT, Anatomie de la terreur. Le processus révolutionnaire, 1787-1793, Paris, Le Seuil, 2018.

Paolo VIOLA, « Violence révolutionnaire ou violence du peuple en révolution », dans Michel

Vovelle (dir.), Recherches sur la Révolution française, Paris, La Découverte, 1991, p. 95-102.

Maurice WAHL, Les premières années de la Révolution à Lyon, 1788-1792, Paris, A. Colin, 1894.

Sophie WAHNICH, La longue patience du peuple. 1792, la naissance de la République, Paris, Payot, 2008.

\section{NOTES}

1. P. Caron, Les massacres de septembre 1792. Plus récemment, H. Burstin, L'invention du sans-culotte. Regards sur le Paris révolutionnaire, p.195-226; ou encore J.-C. Martin, Violence et Révolution. Essai sur la naissance d'un mythe national, p. 140.

2. T. Tackett, «Rumor and Revolution: The Case of the September Massacres », p. 54-64.

L. Porter, Popular Rumour in Revolutionary Paris, 1792-1794.

3. P. Caron, Les massacres de septembre 1792, p. 24.

4. Selon le recensement qu'en propose, ibid.

5. T. Tackett est parmi les rares à intégrer ces violences provinciales à l'analyse des tensions extrêmes qui conduisent à une nouvelle accélération du processus révolutionnaire durant l'été 1792, Anatomie de la terreur. Le processus révolutionnaire, 1787-1793, p. 226. D. Sutherland, "Justice and Murder. Massacres in the Provinces. Versailles, Meaux and Reims in $1792 »$, p. 129-163 ; C. Simien, Les massacres de septembre 1792 à Lyon.

6. De même qu'il y avait eu, naguère, une « saison des Saint-Barthélemy ». J. Garrisson, Tocsin pour un massacre : la saison des Saint-Barthélemy.

7. C. Simien, Les massacres de septembre 1792 à Lyon, p. 40 et suivantes.

8. Ibid., p. 64.

9. Arch. mun. Lyon, 784 WP 034 1, Pétition de la société populaire de Pierre-Scize, 10 septembre 1792 et Adresse des citoyennes de la section Saint-Georges au ministre de l'Intérieur, s.d.

10. Procès-verbaux des délibérations des séances des Corps municipaux de la ville de Lyon, vol. 3, p. 274. Service historique de la Défense (SHD), B ${ }^{3} 1$, Lettre de Vitet à Servan, ministre de la Guerre, 28 août 1792.

11. Bibl. mun. Lyon, 116 252, Journal de Lyon ou Moniteur du département de Rhône-et-Loire, 15 août 1792.

12. Arch. mun. Lyon, 1401 WP 133, Lettres de Vitet aux procureurs généraux syndics des département de l'Isère et de Rhône-et-Loire, 11 août 1792.

13. Arch. nat., $\mathrm{F}^{7} 4575^{10}$, Lettre de Saint-Charles au ministre des Affaires étrangères, 6 septembre 1792 . 
14. Journal de Lyon ou Moniteur du département du Rhône et Loire, édition du 10 septembre 1792.

15. F. Ploux, De bouche à oreille. Naissance et propagation des rumeurs dans la France du XIX siècle, p. 122.

16. Id., « La ville des "libelles parlés". Rumeurs et bruits publics à Paris sous la Première Restauration ", p. 85-86.

17. T. Tackett, « Rumor and Revolution: The Case of the September Massacres », p. 62.

18. La solution monarchique est condamnée, de même que la famille régnante. La République n'est pourtant guère évoquée avant le 22 septembre 1792. Voir M. Biard, Ph. Bourdin, H. Leuwers et P. Serna (dir.), 1792. Entrer en République.

19. T. Tackett, "Rumor and Revolution: The Case of the September Massacres », p. 56. Voir également F. Ploux, De bouche à oreille. Naissance et propagation des rumeurs dans la France $d u$ XIXe siècle, p. 62, qui rappelle que la rumeur est une sorte d'interprétation collective et improvisée d'une situation de crise venant en quelque sorte combler la pénurie d'informations diffusées par les canaux institutionnels.

20. Procès-verbaux des délibérations des séances des Corps municipaux de la ville de Lyon, vol. 3, p. 278.

21. SHD, $\mathrm{B}^{3} 2$, Lettre de Vitet à Servan, ministre de la guerre, 9 septembre 1792.

22. Il faudrait également prendre en compte des ingrédients qui prolongent l'effet de la rumeur et rendent possible le déclenchement des mises à mort, tel que le rôle de la parole violente et de la déshumanisation rhétorique de l'adversaire, (voir N. Z. Davis, Les cultures du peuple. Rituels, savoirs et résistances au XVI siècle, p. 284). Les imaginaires populaires pérennes de la violence souveraine et du crime de lèse-majesté, ou la patience déçue des militants patriotes à l'égard des autorités. Voir P. Viola, «Violence révolutionnaire ou violence du peuple en révolution » et $\mathrm{S}$. Wahnich, La longue patience du peuple. 1792, la naissance de la République.

23. Réimpression de l'Ancien Moniteur, vol. 13, p. 460 (numéro du 26 août 1792).

24. Sont principalement concernés par les massacres, outre Paris, les abords de la capitale, la Champagne et les Ardennes, la vallée du Rhône, la Provence ainsi que le Bordelais. Voir T. Tackett, Anatomie de la terreur. Le processus révolutionnaire, 1787-1793, p. 224-227.

25. T. Tackett, «Rumor and Revolution: The Case of the September Massacres », p. 58.

26. Arch. nat., $\mathrm{F}^{1 \mathrm{C}} \mathrm{II}$ Marne 4, Rapport des commissaires du pouvoir exécutif à Châlons au Conseil exécutif provisoire, 11 septembre 1792. Voir aussi la Réimpression de l'Ancien Moniteur, t. XIII, p. 698.

27. C'est là une dimension essentielle et durable des foules émeutières, comme le souligne Arlette Farge pour le XviII ${ }^{e}$ siècle parisien, lorsque les émotions populaires étaient moins mues par une volonté de rupture qu'elles ne se pensaient comme un point de jonction entre un ordre qui faisait défaut et un avenir mal assuré. A. Farge, $L a$ vie fragile. Violence, pouvoirs et solidarités à Paris au XVIII e siècle, p. 296. Sur ce sentiment de souveraineté des foules de septembre 1792, déjà identifiée par Pierre Caron, on se reportera également à P. Viola, "Violence révolutionnaire ou violence du peuple en révolution », et S. Wahnich, La longue patience du peuple. 1792, la naissance de la République.

28. Arch. nat. $\mathrm{F}^{7} 3691^{1}$, Procès verbal, dressé par les administrateurs du département du Tarn, des événements survenus dans la ville de Castres les 21 et 22 juillet 1792. 
29. C'est en tout cas ce qu'avance A. Combes, Histoire de la ville de Castres et de ses environs pendant la Révolution française, p. 82.

30. On retrouve de semblables phénomènes au cours du siècle suivant. F. Ploux, De bouche à oreille. Naissance et propagation des rumeurs dans la France du XIXe siècle, p. 116.

31. Malouët rapporte en ces termes le propos que lui aurait tenu un paysan de Gennevilliers, où il se cachait alors, le 3 septembre 1792, à propos des massacres des prisons parisiennes alors en cours: "Aussi, c'est bien terrible que ces aristocrates voulussent tuer tout le peuple en faisant sauter la ville !». P.-V. Malouët, Mémoires, t. 2, p. 243-244.

32. Voir par exemple la réaction perplexe du pasteur genevois Étienne Dumont à la lecture d'une lettre de son ami Cabanis, début septembre 1792, lequel affirmait que les événements dramatiques qui venaient d'ensanglanter la capitale avaient permis de déjouer une conspiration qui aurait sinon livré Paris à l'ennemi. Memoirs of the Life of sir Samuel Romilly, written by himself with a selection from his Correspondence., vol. 2, p. 7-8.

33. A. Fray-Fournier, Le département de la Haute-Vienne: sa formation territoriale, son administration, sa situation politique pendant la Révolution, p. 186-201.

34. A. Lapierre, Campagne des Émigrés dans l'Argonne en 1792, p. 40.

35. Arch. nat. $\mathrm{F}^{7} 3681^{14}$, Lettre des administrateurs du département de la Lozère au ministre de l'Intérieur, 13 août 1792.

36. F. de Jouvenel, «Les camps de Jalès (1790-1792), épisodes contrerévolutionnaires?», p. 1-20.

37. V. Sottocasa, Mémoires affrontées. Protestants et catholiques face à la Révolution dans les montagnes du Languedoc, p. 85-116.

38. C. Simien, Les massacres de septembre 1792 à Lyon, p. 33-37.

39. Arch. nat $\mathrm{F}^{7} 3659^{3}$, Extrait du registre des délibérations de la municipalité de Marseille, 21 juillet 1792.

40. Sur le rôle des autorités dans l'accréditation des rumeurs, voir A. Farge, La vie fragile. Violence, pouvoirs et solidarités à Paris au XVIII siècle, p. 274.

41. Arch. nat $\mathrm{F}^{7} 3659^{3}$, Extrait du registre des délibérations de Marseille, 21 juillet 1792.

\section{RÉSUMÉS}

Du 2 au 4 septembre 1792, d'importants massacres ensanglantent Paris, à l'issue d'un processus de "préparation mentale collective» dans lequel les rumeurs ont joué un rôle majeur, mieux connu des historiens depuis les travaux récents de Timothy Tackett et Lindsay Porter. Il a moins souvent été noté, en revanche, que ces massacres parisiens s'inscrivent dans une vague plus générale de violences collectives meurtrières qui traverse la France du mois de juillet au début du mois d'octobre 1792. Prendre en considération cette « saison des massacres de septembre » par le biais des bruits et fausses nouvelles qui travaillaient alors la province apparaît pourtant comme un moyen de saisir d'un peu plus près le climat général d'un pays qui vivait alors le dernier été de la monarchie. C'est ce à quoi s'emploie le présent article. 
AUTEUR

CÔME SIMIEN

Maitre de conférences en Histoire moderne à l'Université université Paris I - Panthéon-Sorbonne, membre de l'Institut d'Histoire moderne et contemporaine (IMAC) 


\title{
Le fédéralisme girondin : une fausse nouvelle à la vie dure
}

\author{
Anne de Mathan
}

1 La Révolution française, qui tend à construire un ordre démocratique, crée aussitôt débats et opposition. Le "marché » politique ouvert en 1789 suscite la concurrence en vue de l'obtention du monopole de la capacité à énoncer la volonté du peuple ${ }^{1}$. La confrontation des diverses propositions est propice à la circulation de rumeurs disant l'immémoriale crainte populaire à l'égard des puissants ${ }^{2}$ ou la peur de ces derniers face à la modification de l'ordre traditionnel. Des combats d'image publique motivent, comme en d'autres périodes de désectorialisation ${ }^{3}$ des assignations sociales et politiques, le recours à la désinformation, voire la calomnie ${ }^{4}$. La créativité rhétorique et de patients usages de la propagande parviennent parfois à disqualifier certains compétiteurs. Ainsi en va-t-il des Girondins, aussi fédéralistes que Robespierre fut royaliste en thermidor. On observera comment et pourquoi fut créée la peur d'un complot qui n'existait pas, ainsi que les raisons du succès de cette fausse nouvelle du fédéralisme girondin ${ }^{5}$. On suivra les étapes de la création d'une information controuvée qui réussit à éliminer les Girondins. Parce que les Montagnards ont le dernier mot, l'artefact du fédéralisme se fige en catégorie politique structurant l'imaginaire national, comme le montrent de surprenants usages contemporains.

\section{Aux sources d'une fausse nouvelle}

\section{De la rivalité personnelle à la concurrence révolutionnaire}

Entre Brissot et Robespierre, l'inimitié surgit dans le débat sur la guerre. Le premier se convertit à une intervention militaire contre deux souverains allemands, afin de tester la fiabilité de l'exécutif et de républicaniser l'Europe ; le second privilégie la révolution dans un seul pays par la distribution de piques à tous les bons citoyens, soit la guerre civile $^{6}$. Ces patriotes soupçonnent tous ceux que la divergence masque en l'autre des intentions perfides. Le conflit s'amplifie par la médiatisation de la presse et l'appui sur l'opinion publique, dans le Défenseur de la Constitution, alors monarchique, et Le Patriote 
Français ${ }^{7}$. Le puits sans fond des interrogations sur la pureté du civisme de l'adversaire, de la traque des masques imposteurs et des effets de dévoilement d'une vérité trouvée à sa seule porte se creuse, sans qu'il soit possible de déterminer la proportion entre sincérité et diffamation.

\section{Une trouvaille rhétorique}

L'acrimonie de Robespierre, journaliste, envers Brissot, député, se teinte d'antiparlementarisme. Le Défenseur de la Constitution affirme que :

[la] «principale cause de nos maux est à la fois dans le pouvoir exécutif et dans la

législature qui ne peut pas, ou qui ne veut pas le sauver8."

Proposer comme palliatif de tous les maux l'inéligibilité des législateurs laisse supposer des motifs peu avouables dirigés contre Brissot et ses amis9. La reconfiguration politique après le 10 Août produit de nouvelles stratégies et l'utilisation des émotions populaires ${ }^{10}$ comme levier contre des "mandataires infidèles", dont Robespierre, membre de la Commune, réclame :

"Qu'ils tombent tous sous le glaive des lois ${ }^{11}$."

Il prête à Brissot une défiance vis-à-vis de Paris, reprenant les procédés des feuilles contre-révolutionnaires ${ }^{12}$ qui, lors des élections de 1791, réactualisent contre Brissot la vieille hantise du fédéralisme, à l'époque où les républiques hollandaise ou suisse effrayaient le pouvoir absolu. Robespierre accuse Brissot et ses amis «d'avoir envoyé des courriers dans tous les départements pour leur persuader que la Convention nationale ne serait pas libre à Paris et pour déterminer les nouveaux représentants de la nation à fixer leur séjour dans une autre ville ${ }^{13}$ ».

6 Pendant les massacres de septembre, il affirme leur implication dans le complot contrerévolutionnaire dont les sans-culottes parisiens entendent protéger leurs familles avant de partir aux frontières. Vergniaud ne dort plus chez lui et ces précautions ne sont pas vaines, comme le montre la perquisition sans mandat, et sans résultat, de la maison de Brissot. Jaurès est net :

«Dans la nuit du 2 au 3 septembre, une accusation pareille de trahison est une provocation au meurtre ${ }^{14}$. »

7 La fausse nouvelle du fédéralisme trouve des relais, comme Chabot qui fabule le 10 septembre :

«Autant je suis ennemi des rois, autant je me déclare l'ennemi du gouvernement fédératif, depuis que, lors de la journée du 10, j'ai vu tous les côtés droits de l'Assemblée venir me flagorner et me dire: "Maintenant, nous sommes aussi républicains, mais il nous faut un bon gouvernement fédératif”. Dès ce moment, je me suis dit: "il y a anguille sous roche"15."

Elle trouve une audience en raison du climat de peur qui se répand après la fuite du roi le 21 juin 1791, effrayante par la trahison d'une figure paternelle. La suspicion apparaît, tel un héritage empoisonné laissé aux Français par le royal traître. La peur, décuplée lors de l'invasion étrangère en août 1792 qui paraît corroborer le complot contrerévolutionnaire, empoisonne le débat politique où la diversité d'opinions est volontiers attribuée à la malveillance. La croyance en ce fédéralisme girondin n'est pas le fait de la bêtise ou de l'insincérité, mais révèle une des structures d'un imaginaire politique traversé de tensions entre espoir et incertitude des lendemains. 


\section{Un sillon patiemment creusé} coup de force au scénario parfaitement exécuté. La Convention est cernée par une foule armée qui effraie les députés. Barère demande à ses collègues :

"Comment vos lois seraient respectées si vous ne les faisiez qu'entourés de baïonnettes ${ }^{22}$ ?»

Sortant à la rencontre du peuple, les élus entendent Hanriot, commandant de l'armée révolutionnaire, donner cet ordre laconique :

«Canonniers, à vos pièces ${ }^{23}$."

17

Couthon pousse le cynisme jusqu'à déclarer que les députés, rassurés sur leur liberté, peuvent céder à l'opinion. On vote que «les députés, ses membres, dont les noms suivent, seront mis en état d'arrestation chez eux ». Il n'y a aucun débordement, parce que le tribunal révolutionnaire, créé le 10 mars 1793 pour prendre en charge les 
émotions vindicatives du peuple, et qui a déjà montré ses inclinations en acquittant Marat le 24 avril, garantit au mouvement populaire parisien que les députés seront jugés, sinon condamnés.

\section{Le piège du fédéralisme} jeu de miroirs déformants ${ }^{24}$, l'un et l'autre camp opposent leurs arguments politiques. Pour les uns, les Girondins assujettissaient la Convention en s'opposant au recours à l'exception, présenté comme la seule façon de sauver la République en guerre. Pour les Girondins, l'arrestation d'élus du peuple sans motif d'accusation a rompu le lien national. Mais tous prennent avec la légalité des aises qu'ils justifient par la légitimité de leur vision de la Révolution. Pour les Montagnards, l'intention fédéraliste prêtée aux Girondins aurait nécessité le 2 juin. Pour les Girondins, la mobilisation des départements n'est pas la cause, mais la conséquence de l'atteinte faite le 2 juin à l'ordre légal de la première République ; elle vise à restaurer la centralité législative, assurer la sécurité des élus et défendre la démocratie parlementaire. Mais la révolte, contre-productive, paraît fournir à point nommé la preuve jusque-là manquante du fédéralisme pour justifier la condamnation des Girondins.

\section{Un procès perdu d'avance}

Le 8 juillet, Saint-Just s'efforce de motiver le décret du 2 juin, sans pouvoir prouver la culpabilité des Girondins ${ }^{25}$. Il avoue que «les conjurés ont laissé peu de traces », mais certifie l'existence d'un «complot formé contre l'établissement et l'unité de la République » qui aurait abouti à la " dislocation du corps politique ». Billaud-Varennes bute aussi, le 15 juillet 1793 , sur le défaut de sources :

«Sans doute, il n'est pas de forfait plus difficile à prouver que ceux des conspirateurs. Travaillant dans l'ombre et méditant leurs crimes à loisir, les traces matérielles manquent presque toujours [...] il faut s'en tenir forcément, à leur égard, à la simple conviction morale ${ }^{26}$. "

Le 3 octobre, Robespierre s'oppose à la demande d'Amar d'imprimer les preuves de la "conspiration", craignant que "cette impression ne retarde l'instruction ${ }^{27}$ ». La Convention vote l'accusation de 40 députés, passibles du tribunal révolutionnaire. Le fédéralisme, désormais considéré comme suffisamment documenté par les révoltes départementales et les trahisons de Toulon et de la Corse, est devenu le nouveau nom du mal. Amar dit de ces boucs émissaires : 
«Nos maux passés, nos maux présents, ceux que l'avenir nous prépare, voilà leurs

crimes. ${ }^{28} »$ procès politique. Invité à accélérer la procédure, le jury délibère le 30 octobre qu' «il a existé une conspiration contre l'unité, l'indivisibilité de la République ${ }^{29}$ » et que les accusés sont condamnés à mort. En tout, 45 députés périssent en l'an II - exécutés, suicidés ou morts en prison - et 106 représentants, incarcérés ou réduits à la clandestinité, voient leur vie mise entre parenthèses. En province, environ 1500 citoyens montent à l'échafaud. Dans les geôles de la République ou les affres de la proscription, plusieurs milliers expient un crime imaginaire, désormais gravé en lettres de sang dans l'imaginaire politique français.

\section{Le psittacisme des discours politiques}

\section{Des usages circonstanciels du passé}

Les modalités de la sortie du gouvernement révolutionnaire après Thermidor achèvent la rigidification de la catégorie du fédéralisme. Parce que certains Girondins survivants entendent - comme Louvet dans le contexte des journées populaires de germinal et prairial an III -, proscrire le droit de résistance justifiant l'insurrection, ils empêchent la reconnaissance du sens des révoltes de $1793^{30}$. L'hommage funèbre aux Girondins est si bâclé, le 11 vendémiaire an IV ( 5 octobre 1796), alors que la contestation royaliste place la Convention face à d'autres urgences, qu'il tient lieu d'un deuxième enterrement à la sauvette ${ }^{31}$. Ainsi demeure ouverte la rivalité politique des discours sur la légitimité à énoncer la volonté du peuple pendant tout le $\mathrm{XIX}^{\mathrm{e}}$ siècle, où histoire ${ }^{32}$ et mémoire ${ }^{33}$ ont partie liée.

Dans les combats politiques de leur temps, nombre de plumes libérales ${ }^{34}$, néojacobines ${ }^{35}$, démocratiques et romantiques ${ }^{36}$, socialistes $^{37}$ ou communardes, reprennent le discours du salut public plaidant la nécessité de l'élimination des Girondins. En revanche, la critique libérale se montre sceptique sur le fédéralisme girondin, soulignant la modernité démocratique des Girondins pour dénoncer dans le gouvernement révolutionnaire l'héritage de l'arbitraire absolutiste ${ }^{38}$. Une fois la république acquise, la méthode positiviste ${ }^{39}$ démasque l'inanité du fédéralisme girondin. Mais le fédéralisme opère au $\mathrm{xx}^{\mathrm{e}}$ siècle un retour facilité par le contexte international. L'école jacobine redonne vie aux intentions centripètes des Girondins. Mathiez les dit mus par le "particularisme local en lutte contre le pouvoir central ${ }^{40}$ ", de même que Lefevre ${ }^{41}$ ou Soboul qui va jusqu'à écrire que «le fédéralisme eut un contenu social plus marqué que son aspect politique ${ }^{42}$ ». Relisant le conflit entre ces Républicains à l'aune de la comparaison avec la révolution bolchevique ${ }^{43}$, ils en proposent une lecture classiste afin de justifier l'élimination de ces " culottes dorées " qui s'opposaient au salut public, même si quelques francs-tireurs du colloque de 1975 montrent que les Girondins étaient loin de contester la centralisation ${ }^{44}$.

\section{La fin du fédéralisme?}

L'école critique sort les Girondins de leur relégation historiographique, même si le traitement réservé à ceux qui contribuèrent à la chute de la monarchie 
constitutionnelle se fait sévère ${ }^{45}$. Mona Ozouf, élevée dans un régionalisme qu'elle dit bon teint ${ }^{46}$, montre bien, pour avoir réfléchi à l'opprobre de la proposition fédérale en France, ce qu'est le fédéralisme de 1793: «un monstre à l'existence purement polémique ", sans rapport avec une quelconque revendication séparatiste ${ }^{47}$. C'est aussi que la désincarcération des passions franco-françaises a commencé dans les années 1960, grâce à des regards étrangers venus d'États ignorant le tabou du fédéralisme, car organisés en structures confédérées. Le colloque de Marseille témoigne de ce renouveau ${ }^{48}$ animé par des chercheurs étrangers ${ }^{49}$ et français ${ }^{50}$. À telle enseigne qu'il serait difficile aujourd'hui aux historiens de prendre au pied de la lettre le discours jacobin sur le fédéralisme girondin ${ }^{51}$.

\section{Des clichés usés}

Les hommes politiques sont rarement historiens, et les références historiques de leurs discours montrent que la fausse monnaie du fédéralisme girondin est toujours redistribuée pour argent comptant, selon un cours connaissant parfois de spectaculaires rebonds, comme le note Françoise Fressoz dans Le Monde le 7 février 2018:

« Le girondisme est furieusement à la mode. »

27 Le 22 mars 2017, le candidat à la présidence de la République, Emmanuel Macron, annonce en effet un "pacte girondin avec nos collectivités ${ }^{52}$ », dont, président, il précise le contenu: "davantage de liberté» en compensation de 13 milliards d'économie budgétaire ${ }^{53}$. Cette instrumentalisation historique habille du manteau de la confiance que doit inspirer le savoir, la paupérisation programmée des collectivités locales. Ce discours, à mille lieues des ambitions girondines en matière d'instruction ou de démocratie participative, n'a pas prévenu la colère des périphéries.

Jean-Christophe Cambadélis s'empare aussitôt de l'allusion historique pour allumer des contre-feux et donner un titre évocateur à son programme alternatif: La gauche de demain sera girondine. Le vice-président du Parti socialiste Européen a beau jeu de brocarder les références présidentielles :

«À vrai dire, le terme "jacobin" est assez mal choisi. D'une part, le centralisme était hérité de la longue période absolutiste, et, d'autre part, lesdits Jacobins n'avaient pas le monopole du centralisme et les Girondins auxquels on les oppose par tradition n'étaient pas forcément des décentralisateurs féroces ${ }^{54}$. ”

En revanche, quand Christian Estrosi réclame une politique de décentralisation plus ancrée sur les territoires - « Nous sommes un parti de citoyens, un parti girondin ${ }^{55}$ »et martèle sur France Inter "je suis girondin », celui-ci s'avère plus royaliste, si l'on peut dire, que le roi. Pas plus que François Bayrou détaillant sur France Inter le 4 novembre 2018 sa "sensibilité girondine ", il ne semble avoir conscience du fait que les Girondins formaient non pas une droite royaliste constitutionnelle attachée au libéralisme économique, mais bien une autre gauche, émancipatrice et cosmopolite. De Nice à Pau, l'on ne voit pas que reprendre le discours du fédéralisme girondin, c'est afficher ses inclinations... robespierristes et jacobines! 
La déesse Fama est un vrai Janus, aussi friande de ragots frelatés que productrice de renommées éternelles. Ainsi les Girondins ont-ils été figés dans les discours à charge par leurs vainqueurs. Le fédéralisme n'est pourtant qu'une fausse nouvelle forgée pour des raisons de rivalités personnelle et politique afin de justifier l'élimination des Girondins, qui n'ont jamais articulé le moindre projet de structure fédérale pour la France, mais furent éliminés pour avoir défendu une autre vision de la République, quoique indubitablement une et indivisible.

1 Cet antagonisme entre Girondins et Jacobins, s'il recouvre l'existence de deux familles bien distinctes de la gauche française - l'une réformiste, gîtant la démocratie dans le libre accès au débat parlementaire, l'autre révolutionnaire, privilégiant l'égalisation des conditions de vie - se résume souvent à la confrontation infondée du fédéralisme et de la centralisation. Cette lecture biaisée, répétant le discours politique des vainqueurs, demeure aujourd'hui en butte témoin des conflits du passé et assure aux vaincus ironie de l'histoire - une étrange omniprésence dans un imaginaire politique travaillé par les héritages d'une Révolution matricielle.

La destinée des Girondins rappelle la dimension héritée des représentations et la nécessité pour les comprendre de la prise en compte de leurs contextes de production. L'impérative réflexivité des historiens sur leurs mises en récit du passé garantit seule que leurs discours ne soient pas de simples opinions, sans prétention illusoire à l'énonciation de la Vérité, ni « rumorancie $»^{56}$ surplombante ${ }^{57}$. Si le fédéralisme est un mythe en ce qu'il se trouve, avant l'été 1793 , dépourvu de tout référent documenté, la peur que suscite la dénonciation de ce danger fabriqué, ainsi les réactions au fait, bien réel, de l'éviction des Girondins le 2 juin, et leurs lectures méritent d'être historicisés.

\section{BIBLIOGRAPHIE}

Frank ATTAR, Aux armes citoyens! Naissance et fonction du bellicisme révolutionnaire, Paris, Le Seuil, 2010.

Alphonse AULARD, La société des Jacobins, t. 3, Paris, Jouaust, Noblet, Quantin, 1892.

Alphonse AULARD, Histoire politique de la Révolution française, Paris, A. Colin, 1901.

Michel BIARD, 1793, Le siège de Lyon : entre mythes et réalités, Clermont-Ferrand, Lemme, 2013.

Michel BIARD, Jean-Numa DUCANGE, Jean-Yves FRETIGNÉ (dir.), Fédéralisme et centralisation. Les modèles et leur circulation dans l'espace européen francophone, germanophone et italophone, Mont-Saint-Aignan, Presse Universitaire de Rouen et du Havre, 2018.

Louis BLANC, Histoire de la Révolution, Paris, Langlois et Leclerc, (12 vol.), 1847-1862.

Louis BlANC, Doctrine de l'État. Plus de Girondins. La République une et indivisible, Uzès, Inclinaison, 2008.

Frédéric BRAESCH, La Commune du dix août 1792, Paris, Hachette, 1911. 
Laurent BRASSART, « Les voies enchevêtrées de la mobilisation politique : l'échec de la révolte antimontagnarde dans un département modéré (juin 1793) ", Revue d'histoire moderne et contemporaine, 2010-1, n 57, p. 25-46.

Gérald BRONNER, La démocratie des crédules, Paris, PUF, 2013.

Philippe BOURDIN (dir.), La Révolution, écriture d'une histoire immédiate, Clermont-Ferrand, Presses de l'Université Blaise-Pascal, 2008, p. 111-128.

Philippe BUONARROTI, Conspiration pour l'égalité, dite de Babeuf $(1828,1957)$, Paris, La Fabrique, 2015. Jean-Christophe CAMBADÉLIS, La gauche de demain sera girondine, Paris, Fondation Jaurès, février 2018.

Roland CARRAZ, « Girondins et Montagnards, le cas chalonnais », dans Albert SOBOUL (dir.), Girondins et Montagnards, Paris, SER, 1980, p. 167-192.

Benjamin CONSTANT, De la force du gouvernement actuel de la France et de la nécessité de s'y rallier, Paris, Flammarion, 2013 (1796).

Benjamin CONSTANT, Des effets de la terreur, (s.n.), (1796).

Benjamin CONSTANT, Des réactions politiques, (s.n.), (1796).

Bernard cousin (dir.), Les fédéralismes. Réalités et représentations, 1789-1874, Aix, PUP, 1995.

Camille DESMOULINS, Histoire des Brissotins, ou fragments de l'histoire secrète de la Révolution, et des six premiers mois de la République, Paris, De l'imprimerie patriotique et républicaine, 1793.

Michel DOBRY, Sociologie des crises politiques, Paris, Presse de la Fondation Nationale des Sciences Politiques, 1987.

Marcel DORIGNY, « Pouvoir central et pouvoirs locaux dans les projets constitutionnels girondins de 1793. Unité et indivisibilité républicaine », dans Bernard cousin (dir.), Les fédéralismes. Réalités et représentations, 1789-1874, p. 321-329.

Roger DUPUY, « Du pseudo-fédéralisme breton au pseudo-anarchisme parisien : révolution et structures », dans Albert SOBOUL (dir.), Girondins et Montagnards, Paris, SER, 1980, p. 193-218.

Pierre-Toussaint DURAND de MAILLANE, Histoire de la Convention nationale suivie d'un fragment sur les 31 mai, $1^{\text {er }}$ et 2 juin 1793 par le comte Lanjuinais, Paris, Baudouin, 1825.

Alphonse ESQUIROS, Histoire des martyrs de la liberté, Paris, Bry, 1851.

Arlette FARGE et Jacques REVEL, Logiques de la foule : l'affaire des enlèvements d'enfants, Paris, 1750, Paris, Hachette, 1988.

Alan FORREST, Society and Politics in Revolutionary Bordeaux, London, Oxford UP, 1975.

Antonino de FRANCESCO, Il governo senza testa. Movimento democratico e federalismo nella Francia rivoluzionaria, 1789-1795, Naples, Morano, 1992.

Antonino de FRANCESCO, « Thiers' Muses : redepicting the Crime of Federalism in postRobespierrist Revolutionary France ", When shooting is over. The order and the Memory, $6^{\text {th }}$ Biennal Symposium of Milan Group on Early United State History, Milan, 1998, p. 107-131.

Pascal FROISSART, La rumeur. Histoire et fantasmes, Paris, Belin, 2002.

François FURET et Mona Ozouf (dir.), La Gironde et les Girondins, Paris, Payot, 1991. 
Paul HANSON, The Jacobin Republic Under Fire. The Federalist Revolt in the French Revolution, Pennsylvania State UP, 2003.

Jean JAURÈs, Histoire socialiste de la Révolution Française, tome III, Paris, Éd. Sociales, 2014 (1901, 1968).

Alphonse de LAMARTINE, Histoire des Girondins, Paris, Laffont, (2 vol.), 2014 (1847).

Georges LEFEBVRE, La grande peur, Paris, Alcan, 1932.

Georges LEFEBVRE, La Révolution française, Paris, PUF, 1968 (1930), p. 285 et 356.

Hervé LEUWERS, Robespierre, Paris, Fayard/Pluriel, 2016 (2014).

Marisa LINTON, Choosing Terror: Virtue, Friendship and Authenticity in the French Revolution, Oxford UP, 2013.

Anne de MATHAN, Le fédéralisme girondin. Histoire d'un mythe national, mémoire inédit de recherche pour l'HDR, Paris 1, 2017, 2 vol.

Anne de MATHAN, «Le fédéralisme girondin », position d'HDR, Annales historiques de la Révolution française, $\mathrm{n}^{\circ}$ 393, 2018-3, p. 195-206.

Anne de MATHAN (dir.), Mémoires de la Révolution française. Enjeux épistémologiques, jalons historiographiques et exemples inédits, Rennes, PUR, 2019.

Albert mathiez, Le bolchévisme et le jacobinisme, Paris, Librairie du Parti socialiste et de l'Humanité, 1920 ; La Révolution française, Paris, UGE, 1978, (1922), vol. II, p. 135.

Jean-Clément MARTIN, « Approches du fédéralisme pendant la Révolution française, entre coïncidence, cristallisation et lecture téléologique ", dans Bernard cousin (dir.), Les fédéralismes. Réalités et représentations, 1789-1874, p. 63-71.

Jules MicheLET, Histoire de la Révolution française (1847-1853), Paris, Gallimard, Pléiade, 2019.

François-Auguste MIGNET, Histoire de la Révolution française, Paris, Didot et Ladvocat, 1824.

Michel OFFERLÉ, Les partis politiques, Paris, PUF, 2012 (1987).

Mona ozouf, Composition française. Retour sur une enfance bretonne, Paris, Folio, 2010.

Mona ozouf, « Fédéralisme », Dictionnaire critique de la Révolution française, Paris, Flammarion, 1988, p. 85-95.

Mona ozouf, «La Révolution française et la perception de l'espace national : fédérations, fédéralisme et stéréotypes régionaux », L'école de la France, Paris, Gallimard, 1994, p. 27-54. Alison PATRICK, The men of the first French Republic, Baltimore and London, John Hopkins UP, 1972. Natalie PETITEAU, Écrire la mémoire. Les mémorialistes de la Révolution et de l'Empire, Paris, Les Indes Savantes, 2012.

Thibaut POIROT, « "L'enceinte sacrée des lois” sous les armes : les mobilisations armées autour des assemblées parlementaires de la Révolution (1792-1799) », Annales historiques de la Révolution française, 2018-3, p. 57-76.

Edgar QUINET, La Révolution, Paris, Belin, 2000 (1865).

Maximilien ROBESPIERRE, CEuvres complètes, tome IV, Le Défenseur de la Constitution, Paris, SER/Alcan, 1939.

SAINT-JUST, Euvres complètes, Paris, Gallimard, 2004. 
Albert SOBOUL, Histoire de la Révolution française, Paris, Éd. Sociales, (2 vol.), 1962, I, p. 363.

Germaine de STAËL, Des circonstances actuelles, Paris, H. Champion, 2016 (1906).

Timothy TACKETT, « La Grande Peur et le complot aristocratique sous la Révolution française », Annales historiques de la Révolution française, $\mathrm{n}^{\circ} 335,2004-1$, p. 1-17.

Adolphe THIERS, Histoire de la Révolution française, Paris, Lecointre et Durey, 1823-1827, (10 vol.).

Charles WALTON, La liberté d'expression en Révolution. Les mœurs, l'honneur, la calomnie, Rennes, PUR, 2014.

Sophie WAHNICH, Les émotions, la Révolution française et le présent : exercices pratiques de conscience historique, Paris, CNRS, 2009.

Gérard WALTZER, Actes du tribunal révolutionnaire, Paris, Mercure de France, 1986, p. 247.

\section{NOTES}

1. M. Offerlé, Les partis politiques. M. Linton, Choosing Terror.

2. A. Farge et J. Revel, Logiques de la foule; G. Lefebvre, La grande peur ; T. Tackett, « La Grande Peur et le complot aristocratique sous la Révolution française ».

3. M. Dobry, Sociologie des crises politiques.

4. C. Walton, La liberté d'expression en Révolution.

5. A. de Mathan, Le fédéralisme girondin ; position d'HDR.

6. J.-P. Brissot, Maximilien Robespierre, Discorsi sulla guerra.

7. $\mathrm{N}^{\mathrm{o}} 1035$ du 10 juin 1792.

8. M. Robespierre, Euvres complètes, t. 4, p. 521.

9. Id., p. 533.

10. S. Wahnich, Les émotions, la Révolution française et le présent.

11. M. Robespierre, Défenseur de la Constitution, $\mathrm{n}^{\circ} 12$, p. 569 ; 581-582.

12. J.-P. Brissot, Le Patriote Français, 8 juillet 1791.

13. $1^{\mathrm{er}}$ septembre 1792, F. Braesch, La Commune du 10 août 1792, p. 458.

14. J. Jaurès, Histoire socialiste de la Révolution française, vol. 2, p. 97.

15. A. Aulard, La société des Jacobins, IV, p. 275-276.

16. H. Leuwers, Robespierre, p. 219.

17. AP LII, 25 septembre 1792, p. 134.

18. AP LVII, 15-19 janvier 1793 et A. Patrick, The men of the first French Republic.

19. C. Desmoulins, Histoire des Brissotins.

20. A. Aulard, La société des Jacobins, V, p. 213.

21. AP LXV, 31 mai 1793, p. 655.

22. AP LXV, 2 juin 1793, p. 706.

23. P.-T. Durand de Maillane, Histoire de la Convention nationale p. 300-309, et T. Poirot, " "L'enceinte sacrée des lois" sous les armes: les mobilisations armées autour des assemblées parlementaires de la Révolution (1792-1799)». 
24. M. Biard, 1793, Le siège de Lyon.

25. Saint-Just, Euvres complètes, p. 588 et suiv.

26. AP LXIX, 15 juillet 1793, p. 21.

27. AP LXXV, 3 octobre 1793, p. 537.

28. AP LXXXV, p. 520 et suiv.

29. G. Waltzer, Actes du tribunal révolutionnaire, p. 247.

30. A. de Francesco, "Thiers' Muses », p. 107-131; Réimpression du Moniteur, XXIV, 14 prairial an III, p. 607 et suiv ; La Sentinelle, 8 messidor an III, p. 2.

31. Réimpr. du Moniteur, XXVI, p. 114.

32. P. Bourdin (dir.), La Révolution, écriture d'une histoire immédiate.

33. N. Petiteau, Écrire la mémoire; A. de Mathan (dir.), Mémoires de la Révolution française.

34. A. Thiers, Histoire de la Révolution française; François-Auguste Mignet, Histoire de la Révolution française.

35. P. Buonarroti, Conspiration pour l'égalité, dite de Babeuf; É. Cabet, Histoire populaire de la Révolution Française, Paris, 4 vol. 1839 ; A. Esquiros, Histoire des martyrs de la liberté.

36. J. Michelet, Histoire de la Révolution française; A. de Lamartine, Histoire des Girondins.

37. L. Blanc, Histoire de la Révolution; Doctrine de l'État ; Plus de Girondins ; La République une et indivisible.

38. G. de Staël, Des circonstances actuelles ; B. Constant, De la force du gouvernement actuel ; Des effets de la terreur ; Des réactions politiques; E. Quinet, La Révolution.

39. A. Aulard, Histoire politique de la Révolution française ; J. Jaurès, Histoire socialiste de la Révolution française.

40. A. Mathiez, La Révolution française.

41. G. Lefebvre, La Révolution française, p. 285 et 356.

42. A. Soboul, Histoire de la Révolution française, p. 363.

43. A. Mathiez, Le bolchévisme et le jacobinisme.

44. R. Carraz, "Girondins et Montagnards, le cas chalonnais » et R. Dupuy, « Du pseudofédéralisme breton au pseudo-anarchisme parisien: révolution et structures », A. Soboul (dir.), Girondins et Montagnards, p. 167-192 et 193-218.

45. F. Furet et M. Ozouf (dir.), La Gironde et les Girondins ; F. Attar, Aux armes citoyens !.

46. M. Ozouf, Composition française.

47. M. Ozouf, « Fédéralisme »; «La Révolution Française et la perception de l'espace national».

48. B. Cousin (dir.), Les fédéralismes.

49. A. de Francesco, Il governo senza testa ; A. Forrest, Society and Politics in Revolutionary Bordeaux; P. Hanson, The Jacobin Republic Under Fire.

50. J.-C. Martin, «Approches du fédéralisme pendant la Révolution française, entre coïncidence, cristallisation et lecture téléologique »; M. Dorigny, " Pouvoir central et pouvoirs locaux dans les projets constitutionnels girondins de 1793. Unité et indivisibilité républicaine»; L. Brassart, «Les voies enchevêtrées de la mobilisation politique $»$.

51. M. Biard, J.-N. Ducange, J.-Y. Fretigné (dir.), Fédéralisme et centralisation. 
52. https://twitter.com/emmanuelmacron/status/844497891846750208.

53. Le courrier des maires, 17/07/2017.

54. J.-Chr. Cambadélis, La gauche de demain sera girondine.

55. Libération, 20/12/2017 ; France 3 Alpes-Provence-Côte d'Azur, 20/12/2017.

56. P. Froissart, La rumeur. Histoire et fantasmes.

57. G. Bronner, La démocratie des crédules.

\section{RÉSUMÉS}

Sur le «marché » politique ouvert en 1789 , la concurrence en vue du monopole de la capacité à énoncer la volonté du peuple suscite des combats d'image publique où les réputations créditent les compétiteurs. La focalisation de l'opinion sur des thématiques plus ou moins véridiques peut faciliter la défaite politique, voire la condamnation judiciaire, et une rumeur, créée de toutes pièces, devenir un mythe. La rivalité entre deux hommes, Brissot et Robespierre, et entre deux gauches, produit en 1792 la peur d'un complot qui n'existe pas. Parce que les Montagnards ont le dernier mot, l'imputation calomnieuse du fédéralisme se fossilise en une catégorie politique structurant l'imaginaire national, gravée dans le marbre de l'opprobre judiciaire de l'an II, de deux siècles de passions historiographiques et d'usages politiques contemporains, où les oripeaux des Girondins habillent parfois drôlement les revendications ou flatteries provinciales.

\section{AUTEUR}

\section{ANNE DE MATHAN}

Professeur d'Histoire moderne, Université Caen-Normandie 


\title{
" La peste est parmi eux »: contagions et guerre civile dans l'Ouest de la France (1793-1796)
}

\author{
Anne Rolland-Boulestreau
}

1 Une inquiétante rumeur se propage entre l'été et l'hiver 1793 en France : la peste aurait fait son apparition dans l'Ouest et la contagion menacerait l'ensemble de la Nation. En cette fin $\mathrm{du} \mathrm{XVIII}^{\mathrm{e}}$ siècle, évoquer cette terrible maladie prend une résonance toute particulière. Les Français, et plus particulièrement les Provençaux, ont déjà vécu la triste expérience de ses effets, lorsqu'en 1720, le Grand Saint Antoine débarque ballots de marchandises, tissus, rats et puces mortelles à Marseille ${ }^{1}$. Par des mesures drastiques, dont l'établissement d'un cordon sanitaire dans le sud de la France, la peste disparaît, non sans avoir provoqué la mort de 120000 personnes, dont la moitié de cité phocéenne en six mois ${ }^{2}$. Soixante-dix ans après, la peste risque de nouveau de se répandre, cette fois-ci par l'Ouest de la France.

2 Circonstance aggravante : la guerre civile accompagne l'épidémie. En effet, depuis mars 1793, cette région française est entrée en insurrection essentiellement contre la Constitution civile du clergé et la conscription militaire ${ }^{3}$. Face à l'impéritie et aux fortes divisions républicaines, les Vendéens - contre-révolutionnaires surnommés les « Blancs »- emportent des victoires éclatantes, soudaines et inattendues durant tout le printemps et une bonne partie de l'été $1793^{4}$. Dans le cadre de cet article, nous ne reviendrons pas sur le récit de la guerre de Vendée, car il s'agira plutôt de montrer que la rumeur est un outil politique redoutable autant pour la République que pour ses ennemis, en temps de guerre. Nous montrerons comment se propage une rumeur, quelles fonctions politiques elle joue dans ce contexte particulier de guerre civile dans l'Ouest français et combien il est difficile de la contrer. 


\section{À la source de la rumeur}

L'histoire compte nombre d'événements aux effets importants, provoqués par des rumeurs développées par un climat de crise $^{5}$. Le point de départ des rumeurs est généralement mal connu des contemporains. Dans le contexte de la Révolution française, la Grande Peur l'illustre parfaitement. Partie de plusieurs régions françaises, elle se nourrit de rumeurs aussi diverses que fantaisistes - étrangers menaçant le territoire, brigands cupides et organisés prêts à fondre sur les communautés désarmées, espions à la solde de puissances étrangères inquiètes devant les événements révolutionnaires. Dans le contexte anxiogène de 1789, elle provoque des réactions en chaîne dans les villes et les campagnes. Des châteaux sont attaqués, des archives et chartriers brûlés, des agents de l'État forcés de fuir... Pourtant, l'insurrection s'arrête tout aussi brutalement qu'elle a commencé. Rien de plus imprévisible et inconstant, mais terriblement efficient, que ces faux bruits de l'été 1789 sortis de nulle part.

En mars 1793, à l'inverse, on sait précisément d'où vient la rumeur de la peste : de Paris, de la Convention, c'est-à-dire du centre névralgique du pouvoir révolutionnaire. Elle est engendrée à dessein par un discours, celui de Barère, membre du comité de Salut public.

5 «Expert » de la Vendée ${ }^{6}$, il prend régulièrement la parole à la barre de la Convention nationale pour donner des nouvelles de l'armée de l'Ouest. À deux reprises, les $1^{\text {er }}$ août et $1^{\text {er }}$ octobre 1793, Barère présente la République assiégée par une coalition intérieure et étrangère. S'il adopte d'abord la rhétorique classique des hordes de barbares déferlant sur la France, ou des "brigands » cachés dans leurs " repaires » et «leurs forêts ", il convoque aussi la biologie pour alarmer la Convention :

«C'est dans les plaies gangréneuses que la médecine porte le fer et le feu. C'est à Mortagne, à Cholet, à Chemillé que la médecine politique doit employer les mêmes moyens et les mêmes remèdes. »

Barère encourage les Conventionnels à :

«Extirper les deux plus grandes maladies des nations, le fanatisme religieux et la superstition royale. »

Bien connue des hommes du XVIII ${ }^{e}$ siècle, la gangrène inspire une crainte réelle. Elle suppose la pourriture des chairs conduisant à une mort inéluctable si aucune mesure n'est prise à temps. C'est pourquoi, en août 1793, la gangrène est la métaphore qui correspond à la situation vendéenne. Barère encourage l'armée de l'Ouest à mener la guerre de Vendée, comme un médecin ampute un malade infecté, violemment et radicalement.

Deux mois plus tard, Barère récidive en usant, cette fois, d'une autre métaphore médicale plus redoutable encore : la Vendée est le «charbon politique qui dévore le cœur de la République ». Le charbon cutané est une forme d'anthrax qui donne au patient fièvres et nausées. Tout comme la gangrène, le charbon finit par ronger la peau et appartient à ces affections visibles, abrasives et mortelles sur le long terme. La médecine du XVIII ${ }^{e}$ siècle est encore incapable de traiter de telles lésions. Mais plus inquiétant, le charbon est une affection que l'on confond souvent avec la peste bubonique $^{7}$. Si Barère se garde bien de parler explicitement de la peste, il associe à dessein la Vendée au charbon "politique ». C'est un acte politique lourd de sens et de conséquences pour l'Ouest de la France et pour la République elle-même. L'objectif est 
bien de persuader les dirigeants républicains à prendre des mesures prophylactiques extrêmes à l'encontre d'un territoire et d'une communauté sécessionnistes.

Comparer la guerre fratricide à des symptômes médicaux n'est guère original. Dans un autre contexte, celui des guerres de religion $\mathrm{du} \mathrm{xvI}^{\mathrm{e}}$ siècle, les écrits de Montaigne évoquaient déjà des «humeurs peccantes » quand ceux de Claude Huot décrivent des "guerres intestines ${ }^{8}$ ». Barère ici n'innove donc pas dans le contexte risqué d'une dislocation du corps social et politique, mais les références à la gangrène et au charbon constituent une amplification métaphorique très nette entre l'été et octobre 1793. Si tous connaissent les effets de la gangrène, la "peste politique » constitue une menace autrement plus grave : la Vendée est cette peste à l'œuvre dans la nation qui ne peut se conjurer qu'avec un geste chirurgical décisif.

Par la radicalité de son discours, et en aggravant son diagnostic en l'espace de quelques semaines, Barère accompagne l'évolution de la guerre: loin d'être circonscrite, à l'automne 1793, l'insurrection est au contraire à son apogée. Pour les républicains, le contexte militaire s'est dégradé. Les Vendéens se sont rendus maîtres d'Angers et de Saumur (pour quelques jours en juin 1793), de Cholet, de Montaigu, de Mortagne, de Chemillé et d'un territoire de plus en plus étendu et difficile à réinvestir. La Vendée est donc le péril suprême pour la République, comme la peste peut l'être pour une population à la merci du germe mortel.

\section{Le succès d'une métaphore}

11 Les sources permettent de suivre la réception des discours de Barère sur le terrain de la Vendée. Plus que la gangrène, c'est surtout le thème de la peste qui est généralement adopté et ce, à cause d'un événement précis qui accrédite la rumeur: la Virée de galerne. Il s'agit de la tragique marche de 50000 à 100000 Vendéens qui gagnent Granville entre octobre et décembre 1793, dans l'espoir de prendre un port et recevoir les secours des Anglais. L'entreprise est un échec. Lors de leur retour vers la Loire, à la fin de l'année 1793, les Vendéens sont physiquement épuisés. Le typhus, la dysenterie et la malnutrition font des ravages dans leurs rangs ${ }^{9}$. Les républicains relaient alors auprès du comité de Salut public les craintes des populations au contact des rebelles à la République. Certains officiers préconisent des mesures drastiques, comme le général Tribout:

«Je ne veux pas de prisonniers, ils mettraient la peste dans nos armées ${ }^{10}$. "

Les rapports militaires rendent compte de façon quasi obsessionnelle de la présence de la peste dans les secteurs traversés par les Vendéens en débâcle. Les civils eux-mêmes relaient ces rumeurs, d'autant plus facilement qu'ils sont souvent chargés de ramasser les cadavres après des massacres ou des affrontements particulièrement violents. Les habitants du Mans en font la dramatique expérience, eux qui doivent enterrer les corps trois ou quatre jours après les terribles combats de rue des 13 et 14 décembre 1793. Ici, comme ailleurs, le jugement est catégorique :

«La peste est parmi eux; ils ne sont pas plutôt morts que la putréfaction s'empare

de leurs cadavres ${ }^{11}$. "

13 Vivant ou mort, le Vendéen constitue une menace directe. La rumeur se nourrit alors de la rumeur, et il ne fait plus aucun doute que la peste est de retour en France et que la Vendée insurgée est le vecteur de contamination. 
La femme vendéenne est désignée comme agent privilégié de la maladie et de la contagion. À cet égard, les lettres de Le Petit, secrétaire des représentants du peuple à Hentz et Francastel, sont éclairantes. En février 1794, il est en poste à Blois, ville située à $200 \mathrm{~km}$ à l'arrière du front, où sont envoyées les prisonnières vendéennes raflées par les colonnes du général Turreau. Ce républicain se plaint régulièrement à ses collègues du comité révolutionnaire de Saumur de l'odeur pestilentielle de ces femmes. Il les accuse de porter des miasmes putrides et mortifères:

«Une d'elles m'ayant écrit ce matin pour d'inutiles réclamations, sa lettre a failly

me faire tomber à la renverse, quand je l'ai développée ${ }^{12}$. »

Côtoyer leurs geôles risque de rendre malades les gardiens. Affecté à Chartres, Le Petit avoue son soulagement, la fatigue s'éloigne et la maladie marque le pas. Au-delà de son expérience personnelle, Le Petit traduit parfaitement le danger mortel auquel s'expose le républicain au contact des Vendéennes. À une époque où les odeurs sont associées très fortement à la bonne ou mauvaise santé des individus, celle nauséabonde de la femme vendéenne est un symptôme évident de morbidité ${ }^{13}$.

D'après les républicains, même les chefs rebelles seraient conscients de cette corruption féminine. Comme on introduit un pestiféré dans une communauté saine, ils forceraient les femmes à se réfugier "sur les terres de la République». Elles souilleraient ainsi, par leur "esprit plus pervers encore que fanatique", le sang des républicains, comme l'affirme le représentant Garnier. Aux yeux des républicains en guerre, les Vendéens représentent bien alors la "race impure ${ }^{14}$ » ou la "caste impure $^{15}$ » par excellence et leurs femmes attestent d'une ligne de démarcation entre la "Vendée encore pure et la Vendée encore esclave ${ }^{16}$ ».

Les Nantais eux-mêmes vivent dans cette même crainte. Ils accréditent et relaient ces rumeurs. La peste proviendrait des prisons surchargées et malsaines. Le comité de surveillance de Nantes écrit au comité de Salut public que la ville connaît « depuis deux ans la peste, la famine et la guerre ${ }^{17}$ ». Ces trois fléaux immémoriaux, qui font écho à cette prière médiévale : "A fame, peste, bello libera nos Domine ${ }^{18}$ ", sont en lien direct avec la Vendée.

La Vendée constitue une menace interne à la France républicaine qui corrompt tout le corps social et politique. Au moment où la régénération de la société par la Révolution est un concept central du nouveau régime, il est vital pour lui de combattre et d'éradiquer une Vendée pestilentielle. Cet exemple montre clairement le transfert du registre médical au registre idéologique, puis au réel politique ${ }^{19}$. La Vendée devient, pour longtemps, un lieu « empesté20 $»$.

\section{Contrer la rumeur}

Par sa dangerosité extrême et sa puissance de contamination des masses, la référence à la peste s'adapte parfaitement à la Vendée. La rumeur possède en soi cette force d'admettre pour vérité ce qui n'était au départ qu'une analogie puis un soupçon. En témoigne le rapport de Villiers, membre du district d'Angers, au ministre de l'Intérieur, en mars 1794 :

«L'administration n'ignore pas qu'il sest répendu le bruit tant dans Paris que dans different département que la peste faisait de grand ravage a angers, a nantes et autre lieu circonvoisin. De pareils bruits étoient capables d'exciter les plus vives alarmes mais heuresemen il netoit pas fondé ${ }^{21}$. » 
Villiers sait bien que la peste n'est pas une maladie bénigne pour les Français de son temps et que la propagation de la rumeur risque de coûter cher aux départements de l'Ouest. D'ailleurs, depuis les débuts de la guerre civile, les foires et les marchés ne peuvent plus se tenir en Vendée militaire ni à sa périphérie. Ainsi en est-il du marché de Chalonnes, pourtant essentiel dans le ravitaillement en bovins et céréales d'Angers, de Saumur, voire de Paris $^{22}$. Les foires de Beaupréau et de Cholet, elles aussi déterminantes dans ce commerce, approvisionnaient, à la fin du XVIII ${ }^{e}$ siècle, le port de Nantes en produits manufacturés - les fameuses toiles de Cholet notamment - en partance vers les Antilles ou l'Afrique. Là encore, depuis les débuts de la guerre civile, les relations commerciales y sont quasiment inexistantes. L'isolement guette autant les rebelles que les républicains de la région. La dénégation de Villiers prouve, s'il en était besoin, combien l'instrumentalisation $d u$ registre épidémiologique peut être préjudiciable à la République elle-même. À la peste, il faut, selon lui, préférer d'autres images, comme celle de la chasse, moins connotée mais tout aussi efficace pour rendre compte du danger vendéen, le saltus, à l'assaut de la civilisation, l'ager.

21 Les officiers de santé sont les grands absents de ce débat national. S'ils sont convaincus que le climat de la Vendée est mortifère et favorise les fièvres, en affaiblissant les corps et les esprits, ils ne se prononcent pas sur cette question qui agite conventionnels, civils et militaires. Il leur serait pourtant facile de nier l'efficience de ce couple infernal de la Vendée et de la peste. Mais, affaiblis, divisés, régulièrement attaqués sur leur mauvaise gestion des hôpitaux, la lâcheté de leurs personnels devant l'ennemi, plus prompts à abandonner les blessés sur le champ de bataille qu'à conduire à bon port les ambulances, ces experts médicaux sont incapables d'intervenir dans les débats et de contrer la rumeur.

Après l'amplification des combats, vient enfin le temps de la déflation de la guerre. Au printemps 1794, le général en chef Turreau est d'abord muté à Belle-île, puis arrêté et emprisonné. Pour juguler la menace vendéenne toujours installée, la Convention nationale décide une politique pacificatrice dans laquelle l'allusion à la peste n'est plus de mise $e^{23}$. Au contraire, elle fait son possible pour rétablir les productions agricoles et le commerce dans la zone insurgée. Les traités de La Jaunaye et de Saint-Florent-leVieil, de février et mai 1795, le montrent assez: sur 18 articles, 9 concernent le rétablissement de l'économie. De même, les Vendéens sont ré-humanisés et la Vendée quitte définitivement les registres cynégétiques et épidémiologiques. Pour évoquer le conflit vendéen, plus aucun militaire ou civil républicain n'utilise l'image de la maladie. Vaincue, la Vendée ne risque plus de rendre malade le corps national.

La dernière mention de la peste date du 20 mars 1796 lorsque les dirigeants vendéens encore en vie, Puisaye, d'Autichamp et Bernier, demandent de l'aide aux " puissances belligérantes ${ }^{24} »$. Ils estiment alors que la République française a fait lever « un souffle pestilentiel » sur l'Europe, en ayant corrompu les mœurs et "gangréné » le pays. La métaphore médicale a changé de camp, mais ici, inefficace, peut-être anachronique, elle disparaît des archives. rumeur, elle s'inscrit dans une situation particulièrement favorable: la guerre de Vendée engagée en mars 1793 affaiblit la Nation. La soi-disant contagion par la 
gangrène et la peste attribuées aux Vendéens est un acte politique proportionnel au danger vendéen, intimement lié à un contexte de crise mortelle pour les républicains. Les succès vendéens jusqu'à l'été 1793 menacent le corps social tout entier, tout comme la peste disloque les familles, les villages, les régions.

L'analogie de la contagion appliquée à la Vendée est liée à l'empoisonnement du sang, selon les connaissances médicales de l'époque. Elle convient parfaitement à l'image des rebelles qui représentent un danger mortel pour les républicains, en lutte permanente et inextricable contre les contre-révolutionnaires. C'est ce qui rend la Vendée si menaçante.

C'est ce qui explique aussi le succès de la rumeur qui se diffuse rapidement dans tous les cercles de la nation. La rumeur pose donc la question de la réception, de la radicalisation, de l'altération même d'un discours politique en réalité sociale dans un contexte prédisposé à l'admettre. Barère a été dépassé par sa chimère ${ }^{25}$, au point que les autorités républicaines mettront plusieurs semaines pour éteindre cette fausse nouvelle. Il faudra attendre les traités de pacification de l'hiver et du printemps 1795 pour que la Vendée soit enfin fréquentable ${ }^{26}$. La fabrication de la rumeur a bel et bien ajouté aux malheurs de l'Ouest.

\section{BIBLIOGRAPHIE}

Micah ALPAUGH, « Les émotions collectives et le mouvement des fédérations (1789-1790) », Annales historiques de la Révolution française, $\mathrm{n}^{\circ}$ 372, 2013.

Frédérique AUDOIN-ROUZEAU, Les chemins de la peste, Le rat, la puce et l'homme, Tallandier, 2007.

Élisabeth BELMAS, « Pouvoir politique et catastrophe sanitaire : la "publication" des épidémies de peste dans la France moderne », Parlement[s], Revue d'histoire politique, $\mathrm{n}^{\circ}$ 25, 2017.

Philippe BossIs, « La foire aux bestiaux en Vendée au XVIII ${ }^{\mathrm{e}}$ siècle, une reconstruction du monde rural », Études rurales, n 78-79-80, 1980.

Maïté BOUYsSY, Une histoire culturelle de la Révolution. Le salon imaginaire de Bertrand Barère, Éditions de la Sorbonne, Paris, 2016.

Élodie CABOT, « Archéo-anthropologie de la bataille du Mans (décembre 1793), la mémoire des os », dans A. Rolland-Boulestreau et B. Michon (dir.), Mémoires des guerres civiles, construction des mémoires, $d u \mathrm{XVI}^{e}$ siècle à aujourd'hui, Presses Universitaires de Rennes, à paraître en 2022.

Jean-Claude CARON, Frères de sang. La guerre civile en France au XIX siècle, Seyssel, Champ Vallon, 2009.

Charles-Louis CHASSIN, Les pacifications de l'Ouest, 1794-1801, Juven, Paris, 1896.

Alain CORBIN, Le miasme et la jonquille, l'odorat et l'imaginaire social, XVIII ${ }^{e}$-XIX ${ }^{e}$ siècles, Paris, Champs Flammarion, 1986. 
Annie CRÉPIN, Défendre la France, les Français, la guerre et le service militaire, de la guerre de Sept Ans à Verdun, PUR, Rennes, 2005.

Annie CRÉPIN, Vers l'armée nationale. Les débuts de la conscription en Seine-et-Marne (1798-1815), Rennes, Presses Universitaires de Rennes, 2011.

Janine GARRISSON, «Deux vieilles France en échauguette, les guerres de religion ", Vingtième siècle, revue d'histoire, $\mathrm{n}^{\circ} 5,1985$.

Jean-Pierre GOUBERT, Roselyne REY, Jacques BERTRAND, Alexandra LACLAU, Atlas de la Révolution française, tome 7 : Médecine et santé, Éditions de l'École des Hautes Études en Sciences Sociales, Paris, 1993.

Simon Jean GRUGET (abbé), Mémoires et journal de l'abbé Gruget, curé de La Trinité d'Angers, Angers, Germain et Grassin, 1902.

Philippe JOUTARD, Histoire de Marseille en treize événements, Éditions Jeanne Laffitte, 1988.

Jean-Clémnet MARTin, La Vendée et la France, Seuil, Paris, 1987.

François PLOUX, « Rumeurs et expériences collectives de la discontinuité temporelle (1814-1815) », Revue d'histoire du XIX ${ }^{e}$ siècle, $\mathrm{n}^{\circ}$ 49, 2014.

Anne ROLLAND-BOULESTREAU, Les colonnes infernales, violences et guerre civile en Vendée militaire (1794-1795), Fayard, 2015.

Anne RolLAND-BOUlestreaU, Guerre et paix en Vendée (1794-1796), Paris, Fayard, 2019.

Jean-Julien Michel SAVARY, Guerres des vendéens et des chouans, ou Annales des départemens de l'Ouest pendant ces guerres, d'après les Actes et la Correspondance du comité de Salut public, des Ministres, des Représentans du peuple en mission, des Agens du gouvernement, des Autorités constituées; des généraux Berruyer, Biron, Canclaux, Rossignol, Santerre, L'Échelle, Kleber, Marceau, Turreau, Moulin, Hoche..., et d'après les Règlemens, Proclamations et Bulletins du conseil supérieur et des chefs des Vendéens et des Chouans ; par un officier supérieur des Armées de la République, habitant dans la Vendée avant ces troubles, Paris, Baudouin frères, 1824 (6 vol.).

Éric SCHNAKENBOURG, «Les chemins de l'information : la circulation des nouvelles depuis la périphérie européenne jusqu'au gouvernement français au début du XVIII ${ }^{\mathrm{e}}$ siècle », Revue historique, 2006/2 ( $\left.\mathrm{n}^{\circ} 638\right)$.

Pierre SERNA, « Barère, penseur et acteur d'un premier opportunisme républicain face au directoire exécutif », Annales historiques de la Révolution française, n 332, avril-juin 2003.

Côme SIMIEN, Les massacres de septembre 1792 à Lyon, Lyon, Éd. Aléas, 2011.

Linda SIMON, Les rumeurs, « Le point sur... Psychologie », De Boeck Supérieur, 2015.

Timothy TACKETT, « La Grande Peur et le complot aristocratique sous la Révolution française », Annales historiques de la Révolution française, $\mathrm{n}^{\circ}$ 335, 2004.

Georges VigaRello, Le propre et le sale, l'hygiène du corps depuis le Moyen Âge, Paris, Seuil, 1985.

\section{NOTES}

1. P. Joutard, Histoire de Marseille en treize événements. F. Audoin-Rouzeau, Les chemins de la peste, le rat, la puce et l'homme. 
2. Soit 50000 morts sur une population de 100000 habitants, entre janvier et novembre 1720.

3. A. Crépin, Défendre la France. Les Français, la guerre et le service militaire, de la guerre de Sept Ans à Verdun. Et du même auteur, Vers l'armée nationale. Les débuts de la conscription en Seine-et-Marne (1798-1815).

4. J.-C. Martin, La Vendée et la France.

5. F. Ploux, «Rumeurs et expériences collectives de la discontinuité temporelle (1814-1815) », p. 21-35. T. Tackett, « La Grande Peur et le complot aristocratique sous la Révolution française", p.1-17. Sur le rapport entre rumeurs et émotions, voir M. Alpaugh, «Les émotions collectives et le mouvement des fédérations (1789-1790) ». É. Schnakenbourg, "Les chemins de l'information: la circulation des nouvelles depuis la périphérie européenne jusqu'au gouvernement français au début du XVIII ${ }^{\mathrm{e}}$ siècle ", p. 291.

6. Barère expert avec son collègue Carnot qui, lui, est plutôt chargé des affaires militaires. P. Serna, «Barère, penseur et acteur d'un premier opportunisme républicain face au directoire exécutif ». M. Bouyssy, Une histoire culturelle de la Révolution: le salon imaginaire de Bertrand Barère.

7. E. Belmas, «Pouvoir politique et catastrophe sanitaire: la "publication" des épidémies de peste dans la France moderne ", p. 34.

8. J. Garrisson, « Deux vieilles France en échauguette, les guerres de religion », p. 91. J.C. Caron, Frères de sang, La guerre civile en France au XIX ${ }^{e}$ siècle.

9. J.-P. Goubert, R. Rey, J. Bertrand, A. Laclau, Atlas de la Révolution française, t. 7 : médecine et santé, p. 12. Voir les conclusions de l'archéologue Élodie Cabot sur les fouilles des charniers du Mans et l'état sanitaire des squelettes. E. Cabot, «Archéoanthropologie de la bataille du Mans (décembre 1793), la mémoire des os ».

10. J.-J. M. Savary, Guerres des vendéens et des chouans, ou Annales des départemens de l'Ouest pendant ces guerres, d'après les Actes et la Correspondance du comité de Salut public, des Ministres, des Représentans du peuple en mission, des Agens du gouvernement, des Autorités constituées; des généraux Berruyer, Biron, Canclaux, Rossignol, Santerre, L'Echelle, Kleber, Marceau, Turreau, Moulin, Hoche..., et d'après les Règlemens, Proclamations et Bulletins du conseil supérieur et des chefs des Vendéens et des Chouans; par un officier supérieur des Armées de la République, habitant dans la Vendée avant ces troubles, vol. II, p. 459, Lettre du général Tribout au ministre de la Guerre, 24 décembre 1793.

11. Arch. Vincennes, SHD, B 5/7, Angers, le 7 décembre 1793.

12. Arch. dép. Maine-et-Loire, 1 L 1225, lettre de Le Petit au comité révolutionnaire de Saumur, $1^{\text {er }}$ ventose an II, 19 février 1794.

13. A. Corbin, Le miasme et la jonquille, l'odorat et l'imaginaire social, XVIII ${ }^{e}-\mathrm{XIX}{ }^{e}$ siècles. G. Vigarello, Le propre et le sale, l'hygiène du corps depuis le Moyen Âge.

14. Arch. Vincennes, SHD, B 5/7, Lettre du général Commaire au ministre de la Guerre, Saumur, le 26 décembre 1793 ; ou Arch. Vincennes, SHD, B 5/7, Lettre de Perreau au comité de Salut public, Les Sables, 9 décembre 1793.

15. Arch. dép. Maine-et-Loire, $2 \mathrm{~L} 31$, Lettre des administrateurs du district d'Ancenis à ceux d'Angers, le 18 prairial an II, 6 juin 1794.

16. C.-L. Chassin, Les pacifications de l'Ouest, 1794-1801, p. 156, Lettre du général Cordellier à Turreau, le 6 février 1794, Tiffauges. 
17. J.-J. M. Savary, Guerres des vendéens et des chouans..., 2 septembre 1795.

18. « De la famine, de la peste, de la guerre, libérez-nous, Seigneur ».

19. L. Simon, Les rumeurs, «Le point sur... Psychologie », plus particulièrement p. 53 et suivantes.

20. J.-J. M. Savary, Guerres des vendéens et des chouans..., 3 janvier 1794.

21. Arch. dép. Maine-et-Loire, 2 L 5 bis, $1^{\text {er }}$ germinal an II, 21 mars 1794. Gruget, un curé resté sur sa paroisse de la Trinité à Angers, évoque cette peste angevine, plus particulièrement dans les prisons, Mémoires et journal de l'abbé Gruget, curé de la Trinité d'Angers, p. 18.

22. Arch. Vincennes, SHD, B 5/12, 18 septembre 1795. P. Bossis, « La foire aux bestiaux en Vendée au XVIII ${ }^{e}$ siècle, une reconstruction du monde rural ».

23. A. Rolland-Boulestreau, Guerre et paix en Vendée (1794-1796).

24. J.-J. M. Savary, Guerres des vendéens et des chouans..., 20 mars 1796.

25. Barère évoque la peste et la gangrène avant la Virée de galerne et les problèmes d'hygiène que posent les traitements des cadavres. Est-il incitateur de la rumeur? L'excite-t-il avant même les événements qui confirmeront durablement les métaphores ? Le comble de cette histoire est que Barère ne va cesser, à la barre de la Convention nationale, de déplorer les faux bruits, les «nouvelles exagérées », les " faux rapports ", les «fausses relations ", les «faussetés de ce genre ». Il menace même ceux qui «trompent sciemment la Convention nationale » «dans un moment où toutes les âmes sont ouvertes à toutes les impressions, où l'inquiétude publique est exaspérée et peut avoir des résultats fâcheux; de pareils hommes, dis-je, sont répréhensibles et seront désormais punis ", Décret du $1^{\mathrm{er}}$ octobre 1793, Moniteur Universel, tome XVIII.

26. A. Rolland-Boulestreau, Guerre et paix en Vendée, 1794-1796.

\section{RÉSUMÉS}

En mars 1793, l'Ouest de la France entre en guerre civile. Batailles et «chocs " se succèdent jusqu'en octobre 1793, date à laquelle les insurgés vendéens entreprennent l'hasardeuse Virée de galerne jusqu'à leur échec devant Granville en Normandie. Commence alors un lent repli vers la Loire où, affaiblis et harcelés, ils sont écrasés dans les marais de Savenay à la veille de Noël 1793. Une rumeur circule alors dans les rangs de l'armée républicaine : les ennemis étaient malades de la peste et leurs cadavres risquent de contaminer les patriotes. L'analogie entre la Vendée militaire, les maladies et la contagion est tellement efficace que cette «nouvelle » est relayée par les administrations départementales jusqu'au Comité de Salut public. Nous nous proposons de mesurer à quel point la rumeur anxiogène d'une diffusion de la peste dans l'Ouest se nourrit du contexte de guerre civile et justifie la résolution prophylactique du problème par l'élimination des Vendéens. 
AUTEUR

ANNE ROLLAND-BOULESTREAU

Professeure en Histoire moderne à l'université catholique de l'Ouest (Angers), Centre Histoire

« Espaces et Cultures » (CHEC) - Université Clermont-Auvergne 


\title{
La théâtralité révolutionnaire des fausses nouvelles
}

\author{
Philippe Bourdin
}

1 De la Grande Peur de l'été 1789 jusqu'aux prophéties de Rigomer Bazin sous le Directoire, sûr d'un soulèvement populaire final, en passant par les massacres de septembre 1792 ou les affirmations de complots successifs contre la République, propres à justifier du Tribunal révolutionnaire puis des tribunaux criminels, la Révolution française n'a cessé de prouver sa sensibilité aux on-dit. Art de l'illusion et du paraître, de masques démasqués, le théâtre, si fréquenté par les contemporains et si attentif à se saisir des affres de l'actualité, pouvait-il échapper aux bruits, rumeurs et nouvelles falsifiées qui firent aussi l'événement? Produit d'une tradition et de règles, dont il tend à s'affranchir de plus en plus au cours de la décennie révolutionnaire, il affiche volontiers en argument faux semblants et quiproquos comme le sel de l'existence, et cache de plus profondes duperies dans de classiques tragédies, tout en usant $\mathrm{du}$ répertoire patriotique pour rappeler les grandes affaires qui construisent la mémoire populaire ou les normes de la réaction thermidorienne. La liste des succès et des échecs permis par les circonstances serait longue; nous nous contenterons de quelques exemples significatifs.

\section{Jeux de salon, recours aux antiques}

Le faux est traditionnellement affirmé sur les affiches et sur les scènes pour attirer un spectateur friand des retournements de la comédie, ces travestissements d'identité, ces bruits de placards où s'enferme l'amant contrit ou le mari inquiet que démultiplieront au XIX ${ }^{e}$ siècle vaudevilles et opérettes (là est pour l'heure l'un des arguments du Tartuffe révolutionnaire de Népomucène Lemercier, créée le 21 prairial an III - 9 juin 1795 - au théâtre de la République). Le temps est à la sidération, à laquelle invitent les entrepreneurs de spectacle des boulevards issus de la Foire, d'Audinot à Nicolet. La fin justifiant les moyens, dans l'économie comme dans les intrigues, nulle honte à exposer les illusions et les menteries d'Arlequin. Les premières s'incarnent au Vaudeville, en février 1793, dans Colombine mannequin, cette statue de cire aimée par un Arlequin 
s'abîmant dans les gestes tendres et les déclarations de fidélité volubiles devant ses amis esbaudis, avant qu'une Colombine de chair et d'os ne vienne remplacer sa copie. Les secondes atteignent leur apogée en floréal an VI dans Les Revenans, du citoyen Ségur aîné :

«Gilles et Scapin ont fait passer Arlequin pour mort. Gilles veut épouser la fille de Cassandre, promise à Arlequin. Scapin veut s'approprier un dépôt d'argent que le prétendu mort lui a confié. Cassandre a peur des revenans. Gilles lui apparaît comme l'ombre d'Arlequin, et lui ordonne de donner sa fille à Gilles, lorsqu'Arlequin, travesti comme son rival, oppose revenant à revenant, déconcerte les fripons, recouvre son argent et sa maîtresse ${ }^{1}$.»

$3 \quad$ Mais le XVIII ${ }^{\mathrm{e}}$ siècle a aussi pour modèle Les Fausses confidences de Marivaux, portée sur scène en 1737 par la Comédie-Italienne, qui, rencontre entre le drame et la comédie, disserte sur la possibilité de provoquer l'amour par la manipulation. Les mêmes ressorts sont ensuite réutilisés. En 1791, on va encore écouter au théâtre parisien du Cirque national La Fausse peur ${ }^{2}$, comédie en un acte mêlée d'ariettes de Marsollier des Vivetières (1750-1817), créée par les Italiens en 1774. « En donnant cette bagatelle, je n'ai pas prétendu avoir fait une bonne pièce ${ }^{3}$ ", précise inutilement l'auteur dans son avant-propos, où ce protégé de Carmontelle rappelle qu'il emprunte, ce faisant, à ce dernier son proverbe du Feint empoisonnement. En des scènes qu'il reconnaît lui-même comme "décousues", et dont il a ôté quelques-unes pour l'édition de nature à faire taire tout "préjugé défavorable », tant " le théâtre est une carrière où l'on ne marche qu'en tremblant ${ }^{4}$ ", il fait s'agiter entre cour de château et salon un aéropage de la société nobiliaire d'Ancien Régime (comtesse, baron, marquis, chevalier) et sa domesticité. Chacun, entre deux migraines, disserte de l'esclavage des sentiments, du choix de l'hymen, de l'amour-propre, du courage et de la fatuité, de l'honneur et de la vengeance, de la timidité et de l'assurance, tout ce qui va faire, si l'on peut dire, de l'arroseur l'arrosé. La comtesse est souveraine : tout est objet pour elle de moqueries courtisanes, de sarcasmes, d'ironie, déclinés en toutes langues dans un sabir qui rend chuintant l'allemand, gouleyant l'italien, voltigeant l'anglais. Travestissant ses penchants à l'homme le plus probe, elle intrigue, badine, usant des services et des déguisements d'un certain Raille, nom évidemment sans ambiguïté. Elle persifle et signe, par lettres interposées, s'offrant un divertissement émollient qui prolonge interminablement l'attente de l'amant, mais ne pousse pas l'audace jusqu'aux Liaisons dangereuses.

4 L'élixir du mensonge peut-il jamais échapper au boudoir, si présent dans les nombreuses reprises qui alimentent les programmations? À dire vrai, l'historien est quelque peu démuni devant des sources apparemment alléchantes que l'éphémère d'une soirée théâtrale n'a pas portées jusqu'à l'édition. On a bien joué à Paris La Fausse contre-révolution, ou la Ruse patriotique en 1792, par deux fois au Lycée dramatique ${ }^{5}$. Mais rien ne nous permet d'accéder au contenu des textes, pas même un court compte rendu dans les journaux qui se limitent à mentionner le titre de l'œuvre. Argument publicitaire, celui-ci est souvent un piège, et mieux vaut compter avec les métaphores et sous-entendus d'un répertoire a priori plus classique, moins immédiatement patriotique. Les complots, les conspirations ne manquent pas dans les tragédies tirées des faits antiques, et avec eux leur cortège de duperies en tout genre : dans la pièce éponyme de Delrieu donnée en l'an VII au théâtre de l'Odéon, Asynoüs, roi de Mycènes détrôné, ne fait-il pas croire à sa mort, et ne se déguise-t-il pas dans les habits d'un général persan tué par son frère pour mieux reconquérir son trône, "action lente et 
compliquée » selon l'Almanach des Muses de l'an VIII (p. 288) ? En l'an II, le théâtre de la République bruit des répliques d'Épicharis et Néron, de Legouvé, ou de celles du Timoléon de Chénier, et l'on sait combien, à chaque représentation, des spectateurs cherchent les allusions qui trahissent la suspicion vécue à l'heure des comités de surveillance, ou l'hostilité que suscitent des membres du comité de Salut public comme Robespierre. Comme le dit, non sans un certain sens de la litote, l'Almanach des Muses pour l'an III à propos de la seconde pièce: "Grand succès. De nombreuses allusions sortant naturellement du sujet, et toutes fort applaudies. ${ }^{6}$ " Le numéro de l'année suivante trouvera quelque intérêt à Pausanias, de Claude-Joseph Trouvé, l'un des rédacteurs du Moniteur, car Pausanias devient le pseudonyme de Robespierre, et l'auteur s'emploie à justifier le 9 Thermidor :

«On voit [...] la convention, les tribunes, la commune, le tribunal révolutionnaire, les complices du tyran, et jusqu'au général Henriot. [...] Description énergique de la tyrannie décemvirale ${ }^{7}$."

Écriture officielle, surtout, d'une histoire trahie par le besoin de justification des Thermidoriens, cherchant en "l'Incorruptible » un éminent bouc-émissaire, imposant le mot de «Terreur » pour disqualifier les institutions d'exception qu'ils ont servies, et fuyant les responsabilités individuelles et collectives dont ils sont comptables... D'emblée, Trouvé nourrit les répliques d'un discours formaté, indéfiniment reproduit dans les textes d'époque: "trame criminelle», délateurs, un tribunal "aveugle instrument/D'injustice, de haine et de ressentiment», des "terreurs stupides», des " complots » hantent la scène 1 de l'acte I; «la terreur ", "l'échafaud » apparaissent dans les scènes de l'acte II. Clé de l'intrigue, la scène 2 de l'acte I dit tout des craintes soulevées par le 8 Thermidor, Robespierre annonçant sans pouvoir la lire une liste de futurs proscrits :

«La liberté dans Sparte est désormais éteinte ;

L'horreur et l'épouvante ont rempli cette enceinte,

Et par l'impunité l'oppresseur enhardi

Consterne un peuple entier sous le joug abruti.

J'ai vu, j'ai vu la liste impie, abominable,

Où de sang altéré, de meurtre insatiable,

Il proscrit à la fois, avec tout le sénat,

Tous les noms honorés et fameux dans l'État. »

La peur comme arme de gouvernement: telle est bien l'accusation portée contre Pausanias, qui s'explique scène 6 de l'acte II sur les manières de manipuler l'opinion :

«Montrer Lacédémone à son dernier instant,

La vertu dans les fers, le crime triomphant ;

Dans les convulsions des discordes civiles,

La liberté mourante et les lois inutiles;

Peindre à quelques esprits, par la peur énervés,

Les désastres prochains qui leur sont réservés;

Pour prévenir les maux que je vois prêts à naître,

Les effrayer au point de souhaiter un maître,

Voilà ce que ma voix va tenter aujourd'hui. »

7 Flétri par les réserves dramaturgiques accablant son œuvre, Trouvé, ami de Barras et de Fouché, dont on sait l'immarcescible honnêteté, attendra cependant quinze ans avant de la publier8. Au théâtre Feydeau, où exerçaient en l'an III les ComédiensFrançais, le succès public de sa prose opportune, douze fois représentée, n'était pas allé sans quelques maux : 
«L'impression qu'elle produisit fut terrible, et agit tellement sur l'acteur (Mr. Larive) qui remplissait le premier rôle, qu'il en tomba malade, et mit vingt jours d'intervalle entre la première et la seconde représentation ${ }^{9}$. » répertoire classique qui se combinait mal avec les attentes politiques, le modéré Larive, protégé des dames Montansier et Clairon, et éternellement supplanté par Talma, voyait-il là les limites de son art? Trouvé, en 1810, désormais auréolé de sa carrière diplomatique en République cisalpine et au Wurtemberg, récompensé du Tribunat et d'une carrière préfectorale, ranime encore le souvenir des "monstres" sanglants de l'an II pour docilement exalter « le génie protecteur » révélé par le 18 Brumaire. Celui qui finira par rejoindre les Bourbons restaurés sait combien un succès littéraire peut faciliter les promotions.

\section{Le souvenir de Calas}

9

Mais, à l'heure où la France proclame les droits de l'Homme, lorsqu'elle édifie des codes de procédures judiciaires, un temps oubliés en l'an II dans des tribunaux d'exception, il est aussi bon de rappeler les grandes affaires du siècle. Elles ont construit, avec l'aide de Voltaire et d'une kyrielle d'avocats obtenant en 1765 la réhabilitation de Calas et de Sirven, la conviction que l'erreur judiciaire, que la preuve falsifiée sont toujours possibles. Tel est bien le sujet du Calas, ou le Fanatisme, de Lemierre d'Argy, porté quinze fois sur la scène des Variétés dans l'hiver 1790-1791, du Jean Calas de Jean-Louis Laya, une tragédie donnée sept fois au théâtre de la Nation dans la même période, et de la pièce éponyme de Marie-Joseph Chénier, représentée six fois sur le théâtre de la République dans l'été 1791. Enfin, La veuve Calas à Paris, ou le Triomphe de Voltaire, de Jean-Baptiste Pujoulx, que joue à six reprises à partir du 31 juillet 1791 le Théâtre Italien, invente un dialogue entre la veuve Calas, Voltaire et son équipe. Bien sûr, la reviviscence des actions publiques du philosophe de Ferney, mort en 1778, anticipe ou accompagne sa panthéonisation, le 13 juillet 1791, en présence de la veuve Calas et de l'une de ses filles au premier rang du cortège. Cette commémoration contribue à en faire, aux côtés de Rousseau, l'incarnation des Lumières ${ }^{10}$. Au demeurant, le nombre de représentations ne sanctifie pas de grands succès théâtraux: quelle que soit la réputation des auteurs, il s'agit bien là de créations de circonstance. Lorsque Chénier produit son œuvre, le thème, remarque Palissot : «Commençait à inspirer une espèce de satiété ${ }^{11}$.»

10 Mais il nous en apprend quand même sur l'inconscient collectif et la place qu'y tiennent les combats du siècle et les stéréotypes. Laya rappelle d'emblée les bûchers de l'Inquisition, l'homme usurpant le pouvoir de Dieu et niant la liberté de penser, et d'autre part l'opinion irréductible des Toulousains :

«L'ignorance est toujours fière, dure, intraitable :

Tel est le catholique à Toulouse aujourd'hui

Et la raison encore n'est pas mûre pour lui ${ }^{12}$.» (acte I, scène 1)

11 Lemierre renchérit, le Toulousain :

«Est superstitieux et emporté; il regarde comme des monstres ses frères qui ne sont pas de la même religion que lui. [...] Cette ville solennise encore tous les ans, par une procession et par des feux de joie, le jour où elle massacra quatre mille citoyens hérétiques il y a deux siècles. En vain six arrêts du conseil ont défendu 
cette odieuse fête, les Toulousains l'ont toujours célébrée comme les jeux

floraux ${ }^{13}$. » aussi au spectateur une visite sensible de la famille Calas, du fils aîné Louis converti au catholicisme à Marc-Antoine qui marche vers le suicide malgré l'amour et la tolérance de son entourage, des sentiments qui rendent impossible le meurtre dont on accable le père. Ses accusateurs et ses juges sont confondus :

« Ils ont pu soupçonner qu'un respectable père

Pleurât un sang chéri qu'eût versé sa colère. » (acte II, scène 1)

Comme est tentée une analyse sociale pointant la trop grande réussite des protestants, facteur de jalousie, le poids des bruits colportés par les catholiques, soutenus par les capitouls de Toulouse, l'achat de témoins, sont dénoncés :

« De l'intérêt du ciel couvrant leurs calomnies,

Ils osent se parer, pour les voir impunies,

Du voile respecté de la religion!

"Mon fils devoit le soir faire abjuration",

Disent-ils, "\& son père aveugle et fanatique

N'a plus dans son enfant rien vu qu'un catholique :

Et du sang égaré détruisant le saint nœud,

Il a tué son fils croyant plaire à son dieu !"

Quelques voix vont plus loin ; “c'est la famille entière,

Qui leva sur ce fils une main meurtrière"

Disent-ils, \& frappés d'un délire insensé,

Ils courent, promenant partout son corps glacé. » (acte II, scène 3)

$\mathrm{M}^{\mathrm{me}}$ Calas rappelle la puissance du mensonge :

«La preuve se détruit, et non pas le soupçon;

L'un semant les erreurs \& la prévention,

Laisse après lui souvent une trace infidelle ;

L'autre ne permet plus de douter après elle. » (acte II, scène 6)

Lemierre est outré par les vices de la procédure, comme par les pompes funèbres de Marc-Antoine célébrées par des pénitents blancs, dont plusieurs magistrats, qui l'élevèrent en martyr : les crédules tentent d'arracher au défunt des dents pour en faire des reliques; d'autres crient au miracle (une dévote sourde entend les cloches, un prêtre apoplectique guérit); les derniers, enfin, voient dans l'échafaud sur lequel on rouerait Calas père l'ornement de la fête annuelle voulue par la Providence. Loin de cet irrationnel antithétique des Lumières, qui participe du combat que leur livrent leurs adversaires, Lemierre, en sa préface, rappelle le contenu des fausses nouvelles sur lesquelles on décide du sort de Calas père :

«Les esprits une fois émus ne s'arrêtent point. On imagina que les protestans du Languedoc s'étoient assemblés la veille; qu'ils avoient choisi, à la pluralité des voix, un bourreau de la secte; que le choix étoit tombé sur le jeune Lavaisse [ami du fils Calas, l'un des derniers à l'avoir vu vivant, NA] ; que ce jeune homme, en vingtquatre heures, avoit reçu la nouvelle de son élection, et étoit arrivé de Bordeaux pour aider Jean Calas, sa femme et leur fils Pierre à étrangler un ami, un fils, un frère. [...] On n'avoit, on ne pouvoit avoir aucune preuve contre la famille ; mais la religion trompée tenait lieu de preuve ${ }^{14}$. "

Ne rechignant pas lui non plus à faire l'analyse psychologique de Marc-Antoine, ce sont les faits, le procès, que reprend Lemierre dans son propos liminaire et dans le long drame qui suit. La conclusion revient au magistrat La Salle, défenseur de Calas, pourfendeur « des bruits vagues et incertains » sur lesquels se construit l'affaire : 
«Rien de si dangereux, rien de si injuste que de hasarder un jugement sur des conjectures. Toute affaire où la preuve consiste en indices, et ne va qu'à former un doute, doit être réservée au souverain jugement de Dieu, et les hommes doivent savoir que quand il ne leur a pas donné le parfait éclaircissement d'un crime, c'est une marque qu'il n'a pas voulu les en faire juges. » (acte III, scène 5)

Chénier, à son tour, refait le procès, se concentrant sur ses derniers jours, loin cependant de la précision de Lemierre. Il « écarte aussi bien la fiction que les passions particulières, notamment familiales, pour s'emparer d'un événement historique chargé d'enjeux collectifs ", et en faire une tragédie plébéienne - un renouvellement du cadre et des personnages tragiques qui est une conquête de la Révolution ${ }^{15}$. Il dénonce une nouvelle fois (après son Charles IX) les funestes effets de la révocation de l'édit de Nantes, encense toujours Voltaire à l'édition des œuvres complètes duquel il a largement contribué, mais se tait sur les bruits. Toute son attention est tournée vers la confrontation entre deux magistrats aux points de vue opposés : La Salle, personnalité éclairée et sensible, qui est convaincu de l'innocence du prévenu, et Clérac, qui fait condamner celui-ci, partageant l'hostilité commune contre les protestants sans avoir conscience de ses préjugés. Le dramaturge en reste au plan des principes.

« Pour condamner un homme, rappelle-t-il simplement scène 3 de l'acte II, il faut que l'évidence ait de son attentat démontré l'existence ${ }^{16}$. »

La tragédie ne néglige qu'en apparence le contexte politique contemporain lorsqu'elle décrit un pouvoir judiciaire ancillaire du politique, marquant davantage la continuité que la rupture, dans l'attente de nouveaux codes et dans la crainte de l'intervention d'un peuple ici présenté comme "égaré », insensible au sort de Calas. Comme le remarque le Journal de la Cour et de la Ville:

«Au moment où Calas marche vers le supplice, l'auteur l'a ingénieusement fait suivre par une foule de peuple, qui, après avoir assisté à l'exécution, revient froidement faire baisser le rideau ${ }^{17}$. »

«La mort de Calas semble suspendue dans les esprits, comme la menace d'un passé qui pourrait revenir, ou d'un avenir que la stabilisation repoussée de la Révolution rend toujours plus incertain ${ }^{18}$.»

19 Pujoulx, justement, s'emploie à réhabiliter le peuple, nombreux aux funérailles de Voltaire.

\section{Les affres de la suspicion}

La réaction thermidorienne amène nombre de pièces prétendant analyser les ressorts du gouvernement révolutionnaire, insistant fortement sur la répression judiciaire et tout autant sur l'un de ses fondements : la suspicion. N'est-elle pas la traduction la plus brutale des faux bruits? C'est en tout cas ce que semblent avancer Picard, Duval et Lemierre dans Les Suspects, comédie créée à Paris le 12 avril 1795, une satire politique féroce. Au-delà de la défense des proscrits girondins, dont les survivants viennent de regagner leurs bancs à la Convention, Picard entame alors une reconversion politique. Il dénonce la Terreur comme il l'a fait des Muscadins (La_Perruque blonde, août 1794) et se retrouve ainsi dans le juste milieu prôné par le Directoire, à l'heure (l'an $\mathrm{V}$ pour ce qui concerne la publication) où les royalistes connaissent de grands succès électoraux. Duval est un proche, qui a partagé avec lui l'écriture de plusieurs textes; Lemierre est un auteur régulier de chants patriotiques depuis 1792, qui a déjà glorifié La Révolution du 9 Thermidor. Les municipalités cantonales ont été rehaussées dans leur rôle par la 
Constitution de l'an III, au détriment des districts: les comptes décadaires des commissaires du gouvernement ne cessent de dénoncer les limites des hommes qui les composent, critique sur laquelle rebondit Picard.

Ignorante des mœurs urbaines qu'elle importe avec retard, la municipalité rurale au sein de laquelle se déroule l'intrigue ne fonderait-elle pas un comité révolutionnaire (scène 3) ? Il s'agit bien, en effet, de «mettre la Terreur à l'ordre du jour » en différé, et l'on s'interroge sur la notion de " suspect », qui semble aux villageois être un titre et un emploi de reconnaissance offert par la République (scène 4). Le maire, Leroux, pense que beaucoup d'honnêtes gens - et l'on joue sur ce qualificatif qu'on accrochait en l'an II à la veste des modérés et des contre-révolutionnaires - en ont été pourvus. Il propose d'en honorer Damis, le héros de la pièce, qui se récuse (scène 5), lui qui voit dans les représentants en mission, des «messieurs courant les départemens pour les dépeupler et les déchirer " - allusion à la Vendée (scène 6). Le tambour du cru bat soudainement la caisse (scène 8). Un chœur de commères s'interroge sur la raison de cette convocation: élections? Contingent de suspects à réunir (scène 9)? Elles disputent de la définition des suspects (scène 10). Gillin, riche propriétaire foncier, se vante d'en faire partie (scène 11). Le tambour est tout fier, car il vient à son tour d'être nommé suspect, ce qui lui permet de traiter Gillin, qui lui a refusé sa fille, en " collègue " et de lui jurer de ne rien faire sans son " excommunication ", qu'il confond avec la communion (scène 12). Gillin se demande cependant quelles occupations, quelles marques distinctives, quels déplacements éventuels se rattachent à son statut (scène 13).

Arrive l'agent du gouvernement Courantin, un jacobin qui s'étonne que tout le village ne l'accueille pas en armes et promet de raser ce repaire de "fédéralistes", de " contre-révolutionnaires", d'" aristocrates", rappelant les nombreuses arrestations qu'il a ordonnées dans la ville voisine tandis que lui-même festoyait et profitait de son statut. "Je voyage en poste, dans une bonne limonière, j'ai plein mon portefeuille d'assignats, je bois le vin des aristocrates. »

Gillin lui avoue qu'il n'y a que deux suspects dans la place, et Courantin se fait fort de les envoyer à Paris, ce dont se réjouit le benêt qui l'invite à sa table (scène 14). "Gracchus » Courantin - qui a visiblement donné son écot à la déchristianisation - se régale à l'idée du bon vin qu'il va boire, des filles qu'il va réquisitionner, des beaux meubles et des bijoux sur lesquels il va déposer les scellés (scène 15). Croisant Damis, il en fait un Muscadin : linge blanc, cravate, habit fin, le contraire de sa moustache et de son pantalon; il croit l'avoir vu défendre des fédéralistes en Picardie - rappel des regroupements girondins à Caen en 1793. Damis, ne se dégonflant pas, nie y avoir été mais défend la mémoire des proscrits et de leurs idéaux. «La république forte par son gouvernement, forte de ses lois, forte de ses finances, forte de sa justice, et forte enfin de l'amour et de l'union des citoyens. »

Il attaque Courantin sur sa mise, son ivrognerie, et oppose son pistolet à son sabre (scène 16). Courantin se promet de le faire arrêter (scène 17). Gillin annonce l'arrivée des municipaux (scène 18). Courantin vient dîner chez lui, se répand sur les plaintes que son action a suscitées, se moquant des malheurs des familles, tandis que la mère Gillin et sa fille se vantent d'être femme et fiancée de suspects (scène 19). Courantin, accueilli par la municipalité, découvre que les suspects ne correspondent guère à l'idée qu'il s'en fait et qu'il n'y a pas de prison; Gillin propose de transformer sa maison; Nicolas refuse de se laisser enfermer, et Gillin à son tour donne sa démission de 
« suspect» (scène 20). Damis demande à Courantin de montrer ses autorisations; elles sont signées de Robespierre, Couthon et Saint-Just, et il lui annonce alors que "l'incorruptible et ses dignes ministres sont morts sur l'échafaud qu'ils avaient élevé pour la nature entière ", que l'on recherche désormais leurs complices, que la notion de « suspect » ne va plus avoir cours, qu'une constitution républicaine va être donnée à la France, mais que les plaies seront longues à se refermer. Courantin choisit la fuite (scène 21) ${ }^{19}$.

Sur cette même fuite des "terroristes" de la veille, "les brigands", les mêmes dénonciations de concussion et de prévarication, d'accusations falsifiées, Ducancel échafaude l'une des pièces maîtresses de la réaction thermidorienne, L'Intérieur des comités révolutionnaires, ou les Aristides modernes, représentée pour la première fois à Paris, au théâtre de la Cité-Variétés, le 8 floréal an III (27 avril 1795), et publiée la même année chez Barba. Il fait de nombreux emprunts à la réalité contemporaine : l'évocation des dénonciations devant les sociétés populaires, les hésitations sur les imputations politiques et leurs sens (" accapareur ", " aristocrate ", "fanatique ", "fédéraliste ", " Coblentz », " agent de Pitt et de Cobourg », « ennemi prononcé de l'égalité », " propos contre-révolutionnaires" avilissant les autorités constituées et la représentation nationale), les interrogatoires, les mandats d'amener collectivement signés - autant que l'analphabétisme le permette -, les arrestations nocturnes de citoyens hébétés, les bâtiments religieux devenus prisons. Les Jacobins du 9 Thermidor et les brigands, ou les Synonymes, de Fabien Pillet, pièce qui tient peu de temps l'affiche au théâtre CitéVariétés puis aux Variétés-Égalité au cours du premier semestre 1795, va trouver dans une caverne de la forêt de Fontainebleau des jacobins réfugiés, qui y tiennent une forme de comité de surveillance. Gueulebordet propose derechef une épuration pour passer au crible les faux frères. Et chacun de faire valoir ses titres: le premier est assassin, le second banqueroutier, le troisième massacreur (ayant obtenu ses lettres de noblesse en septembre 1792), le quatrième empoisonneur, etc. À chaque "confession politique et révolutionnaire», la Société chante en chœur: «Bon, bon, c'est un coquin !/C'est un excellent Jacobin », un refrain qui vaut certificat de civisme ${ }^{20}$.

Cette réalité théâtralisée ne pouvait qu'émouvoir les spectateurs, tant étaient nombreuses les familles de près ou de loin touchées par la suspicion - Albert Mathiez évaluait en 1929 la part de la population française suspectée à 0,35\%, Donald Greer six ans plus tard montait le chiffre à $1,9 \%$, les enquêtes les plus récentes oscillant entre les deux chiffres ${ }^{21}$. Mais ils sont aussi nombreux à savoir que si ces épurations ont pu un temps fragiliser les renommées, ont valu inscription sur la liste des suspects, elles avaient tout autant un caractère probatoire qui a permis à beaucoup de leurs victimes de regagner, et parfois très rapidement, leur rang parmi les militants - un service régulier dans la garde nationale, un engagement et des dons patriotiques non équivoques dans une France en guerre valaient reconnaissance. Avant la fermeture du club parisien, en novembre 1794, les sociétés populaires provinciales vivent ces phénomènes de rejet et de réintégration sur un rythme accéléré.

27 Si Pillet n'offre pas de répit à ceux qui fuient vers les profondeurs de la ruralité, L'Intérieur des comités révolutionnaires se construit aussi sur une critique des mœurs urbaines très inscrite dans le XVIII ${ }^{\mathrm{e}}$ siècle, plus morale qu'aériste cependant. À la ville, creuset des vices recomposé par les sections révolutionnaires, doit être préféré « un asyle solitaire et champêtre », peuplé d'« honnêtes cultivateurs ", où le rousseauiste fils Dufour, le héros positif de l'intrigue, presse ses parents de se réfugier; encore doit-il 
s'agir d'un espace aux perspectives dégagées, qui n'ait pour seul juge que la voûte céleste, car Dufour père emprunte aux peurs de l'enfance pour filer la métaphore politique :

«La France n'est plus qu'une immense forêt fermée de murs, habitée par des loups qui dévorent, et des brebis qu'ils massacrent. » (acte I, scène 12)

La caverne, les sombres futaies pour autre horizon de la schizophrénie, la clairière comme ouverture sur la liberté, tels sont bien les lieux que privilégiera aussi Le Brigand d'Hoffman et Kreutzer, publié à Paris, chez Huet, en l'an III22 .

Lassé de ces combats, de ces déchirements, Hyacinthe Dorvo imagine la même année Le Faux député, création à succès : 39 représentations à partir du 14 février 1795, 26 au théâtre Molière, 13 au théâtre du Lycée des $\operatorname{Arts}^{23}$. La pièce a pour épigramme :

"Nous ne vous craignons plus, beaux oiseaux de passage ${ }^{24}$."

Quelle confiance avoir dans des politiques, s'interroge l'un des personnages :

"Qui sans cesse prêchaient les supplices, les haines;

Qui faisaient des Français un peuple de bourreaux,

En ne voyant le bien que sur des échafauds. »

Auquel son compère répond :

« Accuser! Citoyen, c'est une bonne recette.

Qui plus est, le Contrat social... le... décrète. » (acte I, scène 2)

Le titre tient dans une confusion due à une homonymie entre un député et un habitant du village dans lequel il séjourne, qui n'est autre que son neveu et s'est complu dans trop de promesses. Mais le vrai dénouement tient dans la sérénité retrouvée: le représentant du peuple ouvre les portes des prisons, comme l'ont effectivement fait sur le terrain nombre des nouveaux envoyés après Thermidor (acte II, scène 4). Il méprise les allégations d'un ancien membre du comité de surveillance, qui, par jalousie amoureuse, lui dénonce encore quelques " aristocrates ", puis dans la même personne un « accapareur » (acte III, scène 1), un « royaliste » (acte III, scène 2), en lui rappelant ses manières de faire :

«Sur des listes,

Nous les enregistrons d'abord, et puis après,

Du bien public toujours servant les intérêts,

Mes collègues et moi, sans daigner les entendre,

À petit bruit chez eux, nous les envoyons prendre.

On les mène en prison. Alors sans différer

Nous mettons les scellés ; on fait administrer

Leurs biens ; leurs revenus, ; dont nous touchons la rente,

Sont par nous répartis à la classe indigente.

Le tout en attendant des indices nouveaux,

Et leur traduction devant les tribunaux. » (acte II, scène 7)

Faire taire la calomnie, créer la propagande, telle est l'équivoque que le théâtre engendre. Théâtre de l'instant, faussement camouflé sous des atours antiques ; théâtre historique, usant des temps récents pour mesurer l'erreur humaine toujours possible ; théâtre de la réaction, construisant la Terreur en pointant ses seules dérives judiciaires. Dans tous les cas, le présent offre suffisamment d'éléments dramaturgiques, ballotant l'individu dans le grand bain d'un collectif qui s'épuise en religion, en suspicion, en nation même, puisque celle-ci semble se construire moins sur un lien universel que sur 
des exclusions successives, des épurations maladives. Le théâtre est témoignage, au gré des carrières des auteurs, des renversements idéologiques que leur survie artistique et financière, autant que leurs convictions, leur dictent. Jouant des peurs, comme le fait sur les scènes privées et élitistes de l'enfance son double éducatif, il est pédagogie pour adultes. Les élèves, somme toute, ne sont pas toujours des plus assidus, à en juger par le faible nombre de représentations de quasiment chacune des pièces qui précèdent, à l'exception notable de celles de Ducancel, portée de surcroît par une longue carrière provinciale, et de Dorvo, qui frappent chacune par leur qualité d'écriture. Simplement, les tréteaux sont l'un des moyens et des espaces d'un discours plus généralement diffusé, qui use de tous les supports disponibles pour faire croire à une raison retrouvée chez des hommes de pouvoir qui ne veulent surtout pas le quitter et n'assument aucunement leur passé.

\section{BIBLIOGRAPHIE}

Almanach des Muses pour l'an IV, Paris, Louis, an IV.

Almanach des Muses pour l'an VII, Paris, Louis, an VII.

Gauthier AMBRUS, Marie-Joseph Chénier, un poète en temps de Révolution (1788-1795), thèse de doctorat en Littérature et civilisation française, université Paris IV - Paris-Sorbonne, 2018.

Alphonse AULARD, Paris pendant la réaction thermidorienne et sous le Directoire, t. 1 (du 10 thermidor an II au 21 prairial an III), Paris, Cerf-Noblet-Quantin, 1898.

Philippe BouRDIN, « La Terreur et les trois brigands ", Études théâtrales, « La Terreur en scène ", 2014, n 59, p. 61-72.

Marie-Joseph CHÉNIER, Jean Calas, Paris, Moutard, 1793.

Hyacinthe DORVo, Le Faux député, Paris, Imprimerie des Droits de l'Homme, an III.

Ducancel, L'Intérieur des comités révolutionnaires, ou les Aristides modernes, Paris, Barba, an III.

Donald GREER, The incidence of the terror during the French Revolution. A statistical interpretation, Cambridge, Harvard University Press, 1935.

Jean-Louis LAYA, Jean Calas, Avignon, Garrigan, 1791.

Jean-Louis LEMIERRE, Calas, ou le Fanatisme, Paris, Bureau des révolutions, 1791.

Albert MATHIEZ, «Quel fut le nombre des suspects? ", Annales historiques de la Révolution française, $1929, \mathrm{n}^{\circ} 1$, p. $75-77$.

Ling-Ling SHEU, Voltaire et Rousseau dans le théâtre de la Révolution française (1789-1799), Bruxelles, Éditions de l'Université, « Études sur le XVIII ${ }^{\mathrm{e}}$ siècle », 2005.

Benoît-Joseph MARSOLLIER Des VIVETIÈRES, La Fausse peur, Paris, Valade, 1777.

PICARD, DUVAL (paroles) et LEMIERRE (musique), Les Suspects, Paris, Barba, an VI.

André TISSIER, Les spectacles à Paris pendant la Révolution, Genève, Droz, t. 1, 1992 ; t. 2, 2002. 
Claude-Joseph TRouVÉ, Pausanias, Carcassonne, Gabriel Gareng, 1810.

\section{NOTES}

1. Almanach des Muses pour l'an VII, p. 309.

2. A. Tissier, Les spectacles à Paris pendant la Révolution, t. 1, p. 312.

3. B.-J. Marsollier des Vivetières, La Fausse peur, p. V.

4. Ibidem, p. VI et 60 .

5. A. Tissier, Les spectacles à Paris pendant la Révolution, t. 1 p. 302.

6. Page 15 de la notice des ouvrages de poésie.

7. Almanach des Muses pour l'an IV, p. 263-264.

8. C.-J. Trouvé, Pausanias, préface.

9. Idem.

10. L.-L. Sheu, Voltaire et Rousseau dans le théâtre de la Révolution française (1789-1799).

11. M.-J. Chénier, Jean Calas, p. VI.

12. J.-L. Laya, Jean Calas.

13. J.-L. Lemierre, Calas, ou le Fanatisme, p. III et VIII.

14. Ibidem, p. V.

15. G. Ambrus, Marie-Joseph Chénier, un poète en temps de Révolution (1788-1795), p. 102.

16. M.-J. Chénier, Jean Calas, p. 32.

17. Journal de la Cour et de la Ville, $\mathrm{n}^{\circ}$ 33, 2 août 1791.

18. G. Ambrus, Marie-Joseph Chénier, un poète en temps de Révolution (1788-1795), p. 106.

19. Picard, Duval et Lemierre, Les Suspects.

20. A. Aulard, Paris pendant la réaction thermidorienne et sous le Directoire, tome 1 (du 10 thermidor an II au 21 prairial an III), p. 639 : Annales patriotiques, 30 germinal an III.

21. A. Mathiez, «Quel fut le nombre des suspects?», Annales historiques de la Révolution française ; D. Greer, The incidence of the terror during the French Revolution.

22. Ph. Bourdin, «La Terreur et les trois brigands », Études théâtrales.

23. A. Tissier, Les spectacles à Paris pendant la Révolution, tome II, p. 234.

24. H. Dorvo, Le Faux député. La pièce a été donnée au théâtre de la rue Saint-Martin le 29 pluviôse an III (17 février 1795).

\section{RÉSUMÉS}

Produit d'une tradition et de règles, dont il tend à s'affranchir de plus en plus au cours de la décennie révolutionnaire, le théâtre affiche volontiers en argument faux semblants, quiproquos et mensonges comme le sel de l'existence. Il use aussi d'un répertoire patriotique qui rappelle les 
grandes affaires constitutives d'une mémoire populaire: ainsi du procès Calas, porté devant l'opinion par Voltaire, qui marque les limites d'une justice conduite par des témoignages sans preuve, de faux aveux, parfois obtenus sous la torture. Sous la réaction thermidorienne, ce sont les normes de la suspicion et des tribunaux révolutionnaires que l'on interroge : accusations construites sur la rumeur, termes valises qui déconsidèrent l'adversaire social ou politique, falsifications biographiques.

\section{AUTEUR}

\section{PHILIPPE BOURDIN}

Professeur d'Histoire moderne, Université Clermont-Auvergne, Institut universitaire de France, Centre d'Histoire « Espaces et Cultures » 


\title{
Les rumeurs dans l'espace public au commencement de la Restauration (1814-1816)
}

\author{
François Ploux
}

1 La période de transition chaotique entre le Premier Empire et la Restauration bourbonienne constitue un moment remarquable dans l'histoire de la propagation des rumeurs. Entre avril 1814 et mars 1816, l'espace public fut sans discontinuer parcouru en tous sens par des «fausses nouvelles» politiques. Il était notamment question de complots (complot aristocratique, conjuration bonapartiste ou jacobine, pacte de famine...), de la rétrocession des biens nationaux à leurs anciens propriétaires, du rétablissement des rentes féodales. Sous la Première comme sous la Seconde Restauration, on s'entretenait encore de la reprise des guerres européennes; et du possible démantèlement de la France par les Alliés. Mais ce qui fait la particularité de cette séquence, c'est l'extraordinaire prolifération des nouvelles relatives à Napoléon Bonaparte. Elles annonçaient, dans leur immense majorité, sa prochaine reconquête du pouvoir $^{1}$. Les circonstances de cet exploit pouvaient varier à l'infini. Selon l'une des rumeurs les plus répandues, Napoléon aurait pris le commandement d'une vaste armée de soldats turcs. Bien souvent, on se bornait à indiquer dans quelle contrée ou dans quelle ville il avait été aperçu. Mais l'information principale que délivraient ces récits, c'est qu'il fallait s'attendre à ce qu'il réapparaisse dans un délai très court.

Ces bruits se propageaient pour l'essentiel en empruntant les canaux ordinaires de la communication orale. Pour tenter d'endiguer ce véritable déferlement de rumeurs, qui maintenait les habitants dans un état d'agitation permanente, le pouvoir finit par adopter un arsenal inédit de mesures répressives. Deux lois d'exception (loi du 9 novembre 1815 sur les cris et écrits séditieux, loi de sûreté générale du 29 octobre de la même année) permirent aux tribunaux d'engager des poursuites contre les colporteurs de bruits alarmants. Des centaines d'hommes et de femmes, accusés d'avoir répété une fausse nouvelle, furent condamnés à des peines de prison ${ }^{2}$, systématiquement assorties d'une amende et d'une mise en surveillance de haute police. Tout aussi nombreux furent celles et ceux qui, pour le même motif, furent placés 
en détention par simple décision du préfet $^{3}$. Mais on se préoccupa aussi de démentir ces bruits. À la demande du ministre de la Police Decazes, ou de leur propre initiative, les préfets firent afficher des placards stigmatisant l'absurdité de ces nouvelles clandestines. Les maires, les curés, furent mis à contribution dans cette vaste opération de neutralisation des rumeurs. Dans certains départements, on mit en circulation de petits journaux rédigés dans un style à la portée du peuple, où l'on présentait la véritable situation du royaume. Certains préfets, désemparés, n'hésitèrent pas à interdire aux populations de s'entretenir des affaires politiques.

3 Pour les autorités, l'affaire était entendue. L'origine de toute cette agitation était à chercher dans les sourdes menées des factieux - qu'on accusait d'exploiter sans vergogne la crédulité des masses. Si les preuves positives de cette instrumentalisation de la rumeur sont ténues, il ne fait guère de doute que la mise en circulation de faux bruits a pu constituer une forme rudimentaire de propagande. Pendant les Cent-Jours, par exemple, les royalistes, des membres du clergé, répandaient des nouvelles propres à décourager les plus fidèles partisans de Napoléon. Autre exemple: l'annonce du prochain retour de Napoléon était parfois placardée. Mais cette interprétation policière de la rumeur est loin d'en livrer toute l'intelligibilité. On s'efforcera de montrer comment, dans les circonstances particulières de cette période de transition politique, a pu s'installer une atmosphère tout à la fois d'incertitude, de peur et d'espérance messianique dont la rumeur était la principale manifestation.

\section{En régime d'incertitude}

4 Commençons par un constat. La plupart des rumeurs qui circulaient dans le public avaient un caractère prédictif. À tout le moins prospectif. La chose va sans dire si l'on pense à la fausse annonce du retour de Napoléon en France. Cette dernière rumeur revêtait même, parfois, une dimension prophétique, lorsque celui ou - beaucoup plus souvent - celle qui annonçait l'événement prétendait posséder un pouvoir de divination (pour la police comme pour les préfets, il ne faisait aucun doute qu'il s'agissait de charlatans). Mais, de manière générale, ces informations faisaient entrevoir des bouleversements dans l'ordre politique ou institutionnel, ou révélaient un fait - un complot, l'assassinat du roi - dont les conséquences futures ne pourraient qu'être considérables. C'est en cela qu'elles étaient prédictictives.

5 Un climat d'incertitude générale régnait en France au commencement des deux Restaurations. Mais aussi pendant l'«interrègne» des Cent-Jours. C'est dans ce contexte anxiogène que les fausses nouvelles se propagèrent. Nous ferons l'hypothèse que c'est le sentiment collectif de l'instabilité des institutions politiques qui engendra cette atmosphère de tension expectative. Et rendit possible - ou provoqua - la multiplication des rumeurs anticipatrices. L'incertitude est sans doute le propre des périodes de crises politiques ou diplomatiques majeures. Mais il faut se demander pour quelles raisons particulières, dans le contexte du début des deux Restaurations bourboniennes, les publics - dont il serait nécessaire de prendre en considération la diversité - ont pu admettre si facilement les représentations alternatives du réel que véhiculaient ces rumeurs, malgré les démentis répétés du pouvoir.

6 Rappelons d'abord qu'en l'espace d'un peu plus d'un an, entre avril 1814 et juin 1815, les Français avaient été témoins de trois changements de régime successifs. L'État n'apparaissait plus comme ce qui garantissait à la vie collective un minimum de 
stabilité. Bien au contraire, c'est parce que le pouvoir, à son plus haut niveau, semblait fragile, menacé, que les Français éprouvaient ce sentiment d'insécurité dont la rumeur était le symptôme. On s'attendait à chaque instant à ce qu'une violente commotion ébranle les institutions. À Paris, dès le printemps 1814, il n'était question, dans les différentes «sociétés» qu'espionnait la police, que de l'imminence d'une grande secousse politique ${ }^{4}$. Malgré tous ses efforts pour effacer les traces matérielles et la mémoire des régimes post-révolutionnaires, la monarchie ne parvint que très progressivement à installer la croyance collective dans son caractère définitif. L'épisode des Cent-Jours - qui ne fit que confirmer ce que mille rumeurs annonçaient depuis des mois - n'arrangea évidemment pas les choses.

$7 \quad$ Le déficit de légitimé dont souffraient les Bourbons explique sans doute en partie que l'on put si aisément penser la possibilité de l'effondrement de la monarchie. Les mécontents, en particulier - ils étaient nombreux - n'éprouvaient aucune gêne à se référer, dans leurs plaintes, à d'autres expériences politiques. L'histoire récente en offrait toute une panoplie.

8 Et puis, le régime était en proie à des contradictions internes qui renforçaient cette impression d'instabilité. Le caractère libéral des institutions était inscrit dans la Charte. Mais le protocole, l'organisation de la Cour, la symbolique royale, pouvaient donner le sentiment d'une volonté de retour à l'Ancien Régime. Et les royalistes « exaltés » (c'est ainsi que l'on désigna d'abord les ultras), qui étaient installés au cœur du pouvoir, ne cessaient de dénoncer la ligne politique modérée du Ministère. On racontait par exemple qu'il était de bon ton, dans les salons du faubourg Saint-Germain, de jeter à la corbeille des exemplaires de la Charte. Les provocations des émigrés rentrés, l'expression publique de leurs prétentions (au sujet notamment des biens nationaux), non seulement inquiétaient beaucoup de monde, mais en outre donnaient du régime une image ambiguë. On commentait, dans Paris, les prétendues dissensions au sein de la famille royale. Et ce n'est sans doute pas un hasard si le déferlement de fausses nouvelles du début de la Restauration atteignit son point culminant au plus fort du conflit entre le Ministère et la Chambre introuvable (entre janvier en mars 1816).

Cette impression d'un État miné par ses contradictions se trouvait renforcée par l'intense concurrence que se livraient, dans la course aux places et aux récompenses honorifiques, les nobles rentrés d'émigration d'une part, les généraux de Napoléon d'autre part. Une véritable psychose du complot s'empara de ces groupes. Les uns comme les autres se croyant menacés, physiquement, par leurs adversaires ${ }^{5}$. La police observait que cette agitation au sein de groupes proches du pouvoir inquiétait beaucoup les Parisiens. On signalait en province des bruits inquiétants qui n'étaient que de lointains échos des rumeurs parisiennes.

10 La monarchie, pour toutes ces raisons, donnait l'impression d'être constamment menacée. On s'interrogeait naturellement sur l'avenir. Sans développer ce point qui mériterait d'être approfondi, on peut ajouter que cette disposition, dont la rumeur prédictive était le symptôme, devait sans doute beaucoup au sentiment, qui habitait un grand nombre de Français, de l'instabilité de leur position personnelle, de l'incertitude de leur avenir. Tous les hommes (employés des administrations impériales, militaires) dont les ressources, l'existence, le futur, dépendaient directement de l'État, se trouvaient dans une position très inconfortable. Les rapports de police, cette fois encore, signalaient chaque jour le désespoir de ces hommes, en attente d'une place, d'une pension, d'une information sur leur avenir'. L'incertitude sur ce dernier était au 
principe d'une disposition attentiste. C'est parmi les militaires que les bruits de retour de Napoléon commencèrent à circuler, au cours de l'été 1814 (on racontait que l'Autriche, mécontente du règlement du conflit, avait fait appel à lui pour prendre le commandement de ses armées). Cette fable autrichienne se répandit ensuite parmi les ouvriers, qui côtoyaient les soldats casernés dans Paris. Elle circulait aussi en province.

\section{Peurs et rancœurs}

Dans la rumeur s'exprimaient aussi les peurs et les rancœurs des sujets du roi. Ceux-ci avaient, il est vrai, bien des raisons de s'inquiéter. On redoutait, à juste titre ${ }^{7}$, une violente réaction politique ${ }^{8}$. Mais les royalistes eux-mêmes ne se sentaient pas en sécurité. Et les événements de mars 1815 semblèrent donner raison aux plus pessimistes d'entre eux. Par ailleurs, la crainte d'un démembrement de la France, ou d'une nouvelle invasion, taraudait les Français. Mais c'est surtout la question des biens nationaux, de la dîme et des rentes féodales qui était source d'angoisse 9 .

Il n'y a pas lieu de s'étonner de ce que les propriétaires ${ }^{10}$ se soient sentis menacés, en dépit des déclarations et des textes qui garantissaient l'irrévocabilité des transactions ${ }^{11}$. C'est que la question des biens nationaux fut abondamment débattue, notamment durant la Première Restauration. Elle constituait l'un des points de fixation de l'opposition des deux France, dont la Charte était censée encourager la fusion. Duvergier de Hauranne affirmait que, de toutes les questions « que la Révolution avait légué » à la monarchie restaurée, c'était « la plus difficile », la " plus brûlante ${ }^{12}$ ». On en débattait dans la littérature pamphlétaire, à la Chambre des députés, dans la presse... En province, les acquéreurs baignaient dans un climat hostile. La correspondance administrative signalait des restitutions forcées. Des propriétaires furent victimes d'actes de brigandage ${ }^{13}$. Certains étaient menacés. Plus fréquemment encore, ils étaient insultés, pris à partie par le clergé (notamment dans l'arrondissement de Mamares, dans le Rhône, dans le Pas-de-Calais). C'est bien sûr surtout dans l'Ouest et dans le Midi blanc que leur situation était inconfortable. Dans l'arrondissement de Béthune (très royaliste), les acquéreurs se trouvaient, "par le fait de l'opinion, dans une sorte d'interdiction sociale». La "Petite Église » paraît avoir été assez active dans cette croisade. L'incertitude entourant le devenir de ces biens entrainnait une forte dépréciation de leur valeur.

13 La circulation des rumeurs entretenait, au sein de cette catégorie aux effectifs nombreux ${ }^{14}$, un climat d'angoisse. On rapportait des histoires terrifiantes. Par exemple que le roi, à l'approche de Noël, avait promis à son confesseur d'ordonner une restitution générale ${ }^{15}$. Ou que le duc de Berry, à qui le monarque avait confié son chagrin de ne pouvoir procéder à cette rétrocession, aurait rétorqué :

"Confiez-moi deux compagnies de cavaliers, et j'arrangerai l'affaire ${ }^{16}$. "

Ce même duc de Berry aurait encore déclaré :

"Aussitôt que mon père sera sur le trône, on s'occupera de la chose ${ }^{17}$. "

Les fanfaronnades des émigrés, leur hostilité déclarée à la Charte, contribuaient à ce climat d'angoisse. Mais, davantage encore, la diffusion, jusque dans les villages les plus reculés, de brochures prétendant démontrer la possibilité légale d'une restitution. Deux opuscules, en particulier, eurent un retentissement considérable. Le premier était dû à l'avocat Dard. On y lisait que les actes des assemblées révolutionnaires étant frappés de nullité, les ventes « nationales » étaient invalides. Une restitution générale présenterait 
en outre l'avantage politique de ruiner les acquéreurs, ou au moins de les priver de la possibilité de participer à la désignation des députés (le cens électoral étant fixé à 500 francs). Le texte de Falconnet était plus violent encore. Les deux auteurs furent arrêtés par ordre du directeur de la police du royaume. Mais les milieux de l'émigration se récrièrent. Le roi ordonna la remise en liberté, et l'abandon des poursuites.

Cependant, des exemplaires des deux brochures circulaient en province. On en signalait jusque dans les villages les plus reculés (notamment dans le Pas-de-Calais, l'Ille-etVilaine, la Loire-Inférieure, les Pyrénées-Orientales, etc.). Les acquéreurs, inquiets, étaient à l'affût du moindre indice qui accréditerait les bruits de restitution. Ils s'inquiétèrent beaucoup du mépris avec lequel le comte d'Artois, en voyage officiel dans l'Est, traita deux évêques ayant appartenu à l'Église constitutionnelle.

Simultanément se propageaient un peu partout des rumeurs de rétablissement de la dîme et des rentes féodales.

\section{Rumeur et charisme napoléonien} laquelle se trouvaient beaucoup de Français quant au sort qui leur serait réservé, un sentiment diffus d'insécurité... Autant de facteurs qui, combinés, installèrent un climat d'attente. Dans cette conjoncture instable, l'indécision du futur rendait possible la circulation des pronostics. Les conditions étaient réunies d'un déferlement de rumeurs. Et notamment de rumeurs anticipatrices.

Mais tout cela n'explique pas pourquoi, en contrepoint des bruits annonciateurs de troubles, de violences, de spoliation, de souffrances, se propageait la rumeur d'une restauration impériale. À moins que l'espérance du surgissement miraculeux d'un sauveur ne se soit constituée comme une sorte de correctif du sentiment d'angoisse.

Les rumeurs napoléoniennes précédèrent les événements de mars 1815. À Paris, ville placée sous étroite surveillance policière, et sur laquelle nous sommes par conséquent très bien renseignés, on s'entretenait du retour de l'Empereur dès le mois de juillet 1814. Les militaires en particulier, qui vivaient très mal le retour à la vie civile, et rêvaient d'une reprise de la guerre contre l'Autriche, allaient répétant que l'empereur François avait ou allait faire appel à Napoléon pour prendre la tête de ses armées. La rumeur ne cessa d'enfler jusqu'en mars. Dans les semaines qui suivirent la bataille de Waterloo, les Français se préoccupèrent moins du souverain déchu (la correspondance administrative, en tout cas, ne mentionnait nulle rumeur à son sujet). Mais dès le début de l'automne, ces bruits se multiplièrent de nouveau; et, de plus en plus, jusqu'en janvier et février 1816. Dans les campagnes surtout, on s'entretenait de l'évasion de Napoléon, du fait qu'il avait reconstitué une immense armée composée d'Ottomans... Ce n'est qu'au cours du second semestre de cette année que le calme se rétablit progressivement.

21 Jusqu'à quel point les paysans s'attendaient-ils vraiment à voir resurgir Napoléon parmi eux ? Voilà une question qui mérite au moins d'être soulevée. Quelle signification accordaient-ils à cette nouvelle transmise de bouche à oreille? S'agissait-il pour eux d'une information crédible ? D'un conte qu'on prenait plaisir à entendre et à répéter? Était-ce l'expression d'un rêve ? Ou encore une manière détournée (mais quand même très risquée) de provoquer le régime? Ou de dire son mépris du monarque? Des 
rapports de police semblent indiquer que l'information était souvent prise au premier degré. À l'annonce de l'approche des armées napoléoniennes, des paysans pris de panique se dépêchaient de prendre femme pour échapper à la conscription.

On peut également déchiffrer, dans ces rumeurs napoléoniennes, toutes sortes d'expressions d'une représentation populaire du monarque ${ }^{18}$. Pour ne prendre qu'un seul exemple, au plus fort de la terrible disette de 1816, alors que circulaient des rumeurs d'un pacte de famine (on accusait le roi, l'Église, les nobles, d'être responsables de la pénurie de blé), on associait le retour de Napoléon au rétablissement de l'abondance.

On pourrait, bien entendu, interpréter cette attente quasi messianique du sauveur comme le produit décalé du culte napoléonien orchestré depuis 1796-1797. Mais ce serait à la fois évident et très insuffisant ${ }^{19}$. Il faut rappeler que la défaite militaire et l'effondrement de l'Empire avaient beaucoup entamé le capital de sympathie dont bénéficiait Napoléon. Peu de gens le regrettaient en avril $1814^{20}$. Alors, comment expliquer ce brusque retour de fortune?

C'est dans les époques de grands bouleversements, écrivait Weber, qu'on voit habituellement surgir la figure du chef charismatique ${ }^{21}$. Les années 1814-1816 furent assurément des années de détresse psychologique et matérielle, que la mémoire sélective des ouvriers et des paysans opposait à la prospérité et à la gloire du règne de Napoléon ${ }^{22}$. L'installation durable de ce climat d'attente messianique fut certes le produit de ce qu'avait accompli Napoléon. Mais pas seulement au sens où on l'entend habituellement. Je vois dans le déferlement de rumeurs sous le règne de Louis XVIII un effet à retardement de la " glaciation démocratique » (Jean-Paul Bertaud ${ }^{23}$ ) consécutive au coup d'État de Brumaire. L'État napoléonien avait organisé, ou parachevé, la destruction systématique de tout ce qui aurait pu former l'armature d'un espace public autonome. L'Empire avait tout fait pour reléguer les Français dans le rôle de simples adorateurs du grand homme. Le pouvoir s'efforçait en particulier de contrôler l'information. Les journaux ne bénéficiaient plus d'aucune liberté, la correspondance privée était régulièrement inspectée, les conversations espionnées par des milliers de «mouches»... Le pouvoir prétendait contrôler tous les flux de diffusion de l'information.

Cependant, avec l'accumulation des difficultés à la fin du règne, la défiance et l'inquiétude s'installèrent progressivement. Et les rumeurs se mirent à proliférer ${ }^{24}$. La demande sociale d'information se faisait plus pressante : les nouvelles circulaient par le bouche-à-oreille. Le phénomène ne fit que s'amplifier par la suite.

Sous le règne des Bourbons, ce n'était plus seulement l'incertitude du lendemain qui provoquait cette effervescence. Des Français de toutes conditions éprouvaient désormais de la frustration et de la rancœur: les militaires, dont l'avenir semblait bouché, et qui voyaient méprisé tout ce qu'ils avaient naguère vénéré; les fonctionnaires sans emploi; les ouvriers au chômage; les acquéreurs de biens nationaux; les petits agriculteurs... La colère qui montait de toute part pouvait difficilement trouver à s'exprimer dans un espace public certes beaucoup moins cadenassé que sous l'Empire ${ }^{25}$, mais que la dictature impériale avait totalement désarticulé. Il manquait des relais, des médiations, des possibilités de se regrouper, de s'organiser, pour porter un discours, exprimer des revendications, etc. La peur, le malêtre, la colère, ne pouvaient produire que des fantasmes et des rumeurs. 
À compter de la fin de l'année 1816, la situation politique se stabilisa. La dissolution de la chambre introuvable paraît avoir beaucoup contribué à apaiser les esprits. Les préfets, dans les rapports qu'ils adressaient au ministre, signalaient moins souvent les bruits « absurdes » dont ils s'étaient tant inquiétés. Toutefois, le retour au calme ne fut que progressif. En 1817, en 1818, il arrivait encore que l'on s'entretienne, dans tel ou tel village, du prochain retour de Napoléon. Cette rumeur connut une ultime flambée en 1823, au moment de l'expédition d'Espagne. De nouveau, on ne parlait que de Napoléon - que les paysans, qui n'ignoraient pas son décès, appelaient «Malmort ». Mais cette agitation ne dura guère plus longtemps que l'expédition militaire. Le culte de l'Empereur, par la suite, emprunta d'autres voies.

\section{BIBLIOGRAPHIE}

BERTAUD Jean-Paul, Napoléon et les Français. 1799-1815, Paris, Colin, 2014.

DUVERGIER de HAURANNE Prosper, Histoire du gouvernement parlementaire en France. 1814-1848, Paris, Lévy Frères, 1857.

GAIN André, La Restauration et les biens des émigrés. La législation concernant les biens nationaux de seconde origine et son application dans l'est de la France (1814-1832), Nancy, Société d'impressions typographiques, 1929.

HAZAREESINGH Sudhir, La légende de Napoléon, Paris, Tallandier, 2005.

HOBSBAWм Éric J., Les primitifs de la révolte dans l'Europe moderne, Paris, Fayard, 1966.

JOURDAN Annie, « Du sacre du philosophe au sacre du militaire : les grands hommes et la Révolution », Revue d'histoire moderne et contemporaine, 39-3, juill.-sept. 1992, p. 403-420.

LIGNEREUX Aurélien, « La Première Restauration face à l'inexplicable Vendée : la levée de boucliers des 3-5 mai 1814 », Annales de Bretagne et des Pays de l'Ouest, t. 118, n 4, 2011, p. 63-77.

MÉNAGER Bernard, Les Napoléon du peuple, Paris, Aubier, 1988.

PAIRAULT François, «Anticléricalisme et bonapartisme dans les Charentes : les troubles religieux de 1868 », Revue de la Saintonge et de l'Aunis, t. XIX, 1993, p. 83-111.

PETITEAU Natalie, Napoléon et les Français. 1799-1815, Paris, Armand Colin, 2014. 
PLOUX François, De bouche à oreille. Naissance et propagation des rumeurs dans la France du XIXe siècle, Paris Aubier, 2003.

PLoux François, « La ville des “libelles parlés”. Rumeurs et bruits publics à Paris sous la Première Restauration ", dans Bourdin Philippe, Le Bras Stéphane (dir.), Les fausses nouvelles : un millénaire de bruits et de rumeurs dans l'espace public français, Clermont-Ferrand, PUBP, 2018, p. 83-103.

TRIOMPHE Pierre, 1815. La Terreur blanche, Toulouse, Privat, 2017.

WEBER Max, La domination, Paris, La Découverte, 2013.

\section{NOTES}

1. Sauf pendant les Cent-Jours naturellement. La question a notamment été étudiée par B. Ménager, Les Napoléon du peuple, p.15-39, F. Ploux, De bouche à oreille. Naissance et propagation des rumeurs dans la France du XIXe siècle, p. 127-182, et S. Hazareesingh, La légende de Napoléon, p. 61-96.

2. La plupart se virent infliger une peine de trois mois d'emprisonnement, le minimum prévu par la loi. Mais les magistrats n'hésitaient pas à prononcer des peines plus lourdes (jusqu'à cinq ans d'emprisonnement lorsque l'auteur du délit avait, en plus de répéter des faux bruits, tenu des propos à caractère séditieux).

3. Ceci en vertu de la loi de sûreté générale.

4. F. Ploux, «La ville des "libelles parlés". Rumeurs et bruits publics à Paris sous la Première Restauration", dans Ph. Bourdin, S. Le Bras (dir.), Les fausses nouvelles: un millénaire de bruits et de rumeurs dans l'espace public français, p. 83-103.

5. On trouvera des détails sur cette paranoïa dans l'article mentionné à la note précédente.

6. Voir l'intégralité des «bulletins sur l'état des esprits» conservés aux Archives du ministères des Affaires étrangères. Mémoires et documents, vol. 336 à 345.

7. P. Triomphe, 1815. La Terreur blanche.

8. Les départements de l'Ouest, furent, dans les semaines qui suivirent la première abdication, le théâtre d'une série de paniques. C'était tantôt les acquéreurs de biens nationaux qui quittaient précipitamment leur village pour aller se réfugier à Nantes, tantôt les Vendéens qui se croyaient à la veille d'un grand massacre. A. Lignereux, « La Première Restauration face à l'inexplicable Vendée : la levée de boucliers des 3-5 mai 1814 », p. 63-77.

9. Il faudra encore plusieurs décennies pour le fantôme de la dîme cesse d'obséder les paysans. En 1868 encore, plusieurs villages de la Dordogne et des Charentes se mirent en insurrection pour s'opposer au rétablissement de cet impôt. Sur cet épisode fascinant, voir entre autres F. Pairault, "Anticléricalisme et bonapartisme dans les Charentes: les troubles religieux de $1868 »$, p. 83-111. Curieusement, dans une ville comme Paris, où une masse considérable de biens nationaux de première origine avaient été mis en vente, l'hypothèse d'une restitution ne suscita guère d'inquiétude, sans doute parce que c'est la rétrocession des biens d'émigrés qu'on redoutait.

10. On les appelait les "acquéreurs", quand bien même ils n'avaient pas fait euxmêmes l'acquisition des biens litigieux. 
11. Déclaration d'Hartwell du $1^{\mathrm{er}}$ janvier 1814 (le roi s'engageait à encourager les transactions). Déclaration du prince de Condé au nom du roi (au début de l'année 1814). Déclaration du duc d'Angoulême à Bordeaux (15 mars 1814). Constitution sénatoriale (avril 1814). Déclaration du comte d'Artois devant le Sénat (14 avril 1814). Déclaration de Saint-Ouen (2 mai). Article IX de la Charte. Déclaration de la chambre des représentants le 5 juillet 1815. Proclamation de Cambrai du 28 juin 1815.

12. P. Duvergier de Hauranne, Histoire du gouvernement parlementaire en France, p. 219 et 289.

13. C'était, d'après André Gain, l'expression d'une chouannerie dégradée. A. Gain, La Restauration et les biens des émigrés.

14. Les préfets donnaient des estimations : 3500 dans le Gard, 4200 dans la LoireInférieure, 4500 dans l'Ardèche, 5600 dans l'Aveyron, 8000 dans l'Hérault, 11000 dans Côtes-du-Nord... Correspondance des préfets reproduite dans les bulletins sur l'état des esprits, Archives du ministère des Affaires étrangères, Mémoires et documents, vol. 336 à 345.

15. Bulletin du 2 novembre 1814 , Arch. nat., $F^{7} 3836$; bull. sur l'état des esprits du 7 janvier 1815.

16. Bull. du 5 août 1814, Arch. nat., $F^{7} 3836$.

17. Bull. du 5 oct. 1814 , Arch. nat., $\mathrm{F}^{7} 3836$.

18. Voir les paragraphes que $\mathrm{S}$. Hazareesingh consacre à ces questions. La légende de Napoléon.

19. Le charisme napoléonien est aussi la conséquence de l'héroïsation du chef de guerre. A. Jourdan, « Du sacre du philosophe au sacre du militaire : les grands hommes et la Révolution », p. 403-420.

20. N. Petiteau, Les Français et l'Empire (1799-1815).

21. M. Weber, La domination, p. 301.

22. C'est ce qui ressort de l'espionnage des conversations des ouvriers réunis sur les quais ou en place de Grève.

23. J.-P. Bertaud, Napoléon et les Français. 1799-1815.

24. N. Petiteau, Les Français et l'Empire, p. 191 sq.

25. Paris fut inondé de pamphlets sous la Première Restauration.

26. M. Weber, La domination, p. 285.

27. E. J. Hobsbawm, Les primitifs de la révolte dans l'Europe moderne.

\section{RÉSUMÉS}

La transition chaotique entre le Premier Empire et la Restauration constitue un moment remarquable dans l'histoire de la propagation des rumeurs. Entre avril 1814 et mars 1816, l'espace public fut sans discontinuer parcouru par des «fausses nouvelles » politiques. Il était notamment question du retour de Napoléon en France. On s'efforcera de montrer comment, dans 
les circonstances particulières de cette période de transition politique, alors que la monarchie donnait l'impression d'être à la fois fragile et menaçante, a pu s'installer une atmosphère d'incertitude et d'angoisse, propice à la multiplication des rumeurs. Dans un espace public totalement cadenassé depuis l'Empire, en l'absence de relais, de médiations politiques, de possibilité d'expression de revendications, la peur, le mal-être, la colère, ne pouvaient guère produire que des fantasmes et des rumeurs. Tenus en respect pendant quinze ans, les Français, incapables de se mobiliser, s'en remirent à la toute-puissance d'un sauveur dont on annonçait partout le retour miraculeux.

\section{AUTEUR}

\section{FRANÇOIS PLOUX}

Professeur d'Histoire contemporaine, Université de Bretagne-Sud (Lorient), laboratoire TEMOS,

CNRS FRE 2015 


\title{
« Le vin est la plus saine et la plus hygiénique des boissons »: anatomie d'une légende ( $\mathrm{XIX}^{\mathrm{e}}$ - $\mathrm{XX}^{\mathrm{e}}$ siècles)
}

\author{
Stéphane Le Bras
}

1 À intervalles réguliers, la presse nationale se fait l'écho d'études scientifiques mettant en avant les bienfaits d'une consommation modérée et régulière de vin ${ }^{1}$. Ainsi, en août 2019, Sciences et Avenir titrait sur les effets bénéfiques du vin rouge sur nos intestins ${ }^{2}$ : l'article déroule alors un argumentaire bien connu, et régulièrement repris, sur «l'effet protecteur pour notre santé» du vin, ici en l'occurrence, l'action antioxydante et anti-inflammatoire d'un polyphénol sur le microbiote intestinal.

2 Si l'article de Sciences et Avenir garde une certaine réserve formelle par l'emploi du conditionnel, justifié par la faible ampleur de la population testée et les difficultés à prouver la causalité directe entre l'amélioration de l'état de l'intestin et la consommation de vin, le professeur Didier Raoult, spécialiste des maladies infectieuses, s'en affranchit. Dans une tribune du Point en 2011, après avoir évoqué les risques liés à une consommation excessive d'alcool, il promeut une étude scientifique liant consommation de vin et accroissement de l'espérance de vie, puis liste les apports bénéfiques du vin: protection contre les affections cardio-vasculaires, diminution des risques d'accidents vasculaires cérébraux, réduction de la mortalité 3 .

Et de conclure son intervention par un définitif :

«Mon maître, le microbiologiste Louis Pasteur, dont les premiers travaux ont porté sur la fermentation des boissons alcoolisées, prétendait que le vin était la plus saine des boissons. "

4 Le recours à Pasteur (1822-1895) pour justifier les bienfaits des vins et faire acte d'argument d'autorité n'est pas là non plus une surprise. Le scientifique français, par son statut de pionnier de la microbiologie et dont les travaux sont loués, dès son vivant, dans le monde entier ${ }^{4}$, est une figure tutélaire de la propagande en faveur des vins, et la 
phrase «la plus saine et la plus hygiénique des boissons », citée partiellement par le professeur Raoult, s'avère un support utile pour la promotion de la filière vitivinicole.

5 Sans rentrer dans les débats qui opposent les partisans du mouvement antialcoolique et ceux du secteur du vin à l'époque contemporaine à propos des bienfaits réels ou supposés de la boisson, cet article vise à interroger la manière dont cette phrase a été investie par la propagande en faveur de ce dernier, quitte à en faire une légende, c'està-dire un repère culturel propre à convaincre et rassembler, mais également un objet aux contours finalement mal connus. Pour ce faire, nous nous attacherons à démontrer les mécanismes en œuvre, depuis le contexte historique de la formulation de cette phrase, jusqu'à son instrumentalisation dans les décennies qui suivent.

\section{Le « vin hygiénique » : naissance et diffusion primitive d'un concept (années 1820-années 1860)}

Lorsque Pasteur s'intéresse plus particulièrement au vin, c'est avant tout comme spécialiste de la fermentation - dont il avait gagné les galons dans les années 1850 - et de ses conséquences sur la maturation des moûts ${ }^{5}$. Dans la première moitié des années 1860 , il s'intéresse alors à ce qu'on appelle "les maladies des vins ", qui les rendent impurs et donc impropres à la consommation dans un contexte où la demande est sans cesse croissante. Or, dans la filière, l'inquiétude est générale: en plus des maladies qui frappent depuis quelques années les vignes (l'ö̈dium est apparu en Europe au milieu des années 1840 ; le phylloxéra vient de faire ses premiers dégâts dans le sud de la France au début des années 1860), les stocks sont régulièrement gâtés ou perdus sans que l'on en comprenne les causes ni qu'on en trouve d'efficaces parades (acescence ou piqûre qui fait tourner le vin et le transforme en vinaigre ; casse ou oxydation qui troublent les vins par exemple). Dès 1863-1864, après des études sur les vins d'Arbois dans le Jura initiées à la demande de Napoléon III, qui s'inquiétait des conséquences dévastatrices des maladies des vins sur leur commerce, Pasteur est persuadé que ce sont des bactéries ("végétation» est le terme employé alors) microscopiques qui entraînent la dégradation des vins ${ }^{6}$. Il propose une mesure assez simple pour mettre un terme à l'altération des vins : les faire chauffer à $57^{\circ}$ avant de les conditionner pour les stocker ou les expédier. Le principe de pasteurisation, reprenant des idées similaires chez Nicolas Appert et probablement chez Alfred de Vergnette de Lamotte ${ }^{7}$, est alors breveté puis popularisé, offrant à son auteur un surplus de notoriété.

7 Dans la continuité, Pasteur publie en 1866 l'ensemble de ses recherches sur le sujet dans un ouvrage devenu l'un des fondements scientifiques de l'œnologie moderne, intitulé Études sur le vin, ses maladies, causes qui les provoquent, procédés nouveaux pour le conserver et pour le vieillir. Il y explique le sens de sa démarche, ses motivations, sa méthode, ses résultats. Aux pages 55-56, il tient les propos suivants :

«Plus on réfléchira aux causes des maladies des vins, plus on se convaincra que l'art de la vinification, et les soins que l'expérience des siècles a proclamés nécessaires, ont principalement leur raison d'être dans les conditions mêmes de la vie et de la manière d'agir des parasites du vin, de telle sorte que, si l'on pouvait arriver à supprimer par une opération pratique très-simple, les causes des altérations spontanées des vins, on pourrait, sans nul doute, fonder un art nouveau de faire le vin beaucoup moins dispendieux que celui qui est suivi depuis si longtemps, bien plus efficace surtout pour supprimer les pertes qu'occasionnent les maladies des vins, très-propre par conséquent à l'extension du commerce de cette denrée. 
Il est désirable que l'on atteigne ce but, car le vin peut être à bon droit considéré comme la plus saine, la plus hygiénique des boissons. Aussi, parmi celles qui sont connues aujourd'hui, c'est celle que l'homme recherche de préférence à toutes les autres, si peu que l'occasion lui ait été offerte de s'y habituer. »

Le contexte de rédaction et d'émergence de cette phrase, tout comme sa place dans l'ouvrage, sont clairs : le vin est une boisson saine lorsqu'on contrôle les parasites qui le composent, ce qui était la mission première de Pasteur. Il n'y a ici aucune ambiguïté sur le sens de cette expression: les vins sont sains lorsqu'ils ne sont pas malades ou altérés et bien faits.

Reste la question, bien plus centrale au regard de l'histoire, de l'adjectif « hygiénique ». Contrairement à ce qui peut parfois être entendu ou avancé, Pasteur n'est pas l'inventeur de l'expression «boisson hygiénique ». En effet, le terme d'« hygiénique » associé à une boisson semble apparaître dans les années 1820 . En 1826 par exemple, dans les Considérations chimiques et médicales sur l'eau de Selters ou de Seltz naturelle ${ }^{8}$, les auteurs présentent « les effets salutaires comme boisson hygiénique » de l'eau de Seltz dont on souligne "l'efficacité dans un grand nombre de maladies déclarées » et sa réputation soutenue par de grands médecins. À la même période, de nombreux ouvrages médicaux ou paramédicaux reprennent l'expression "boisson hygiénique ", dont la principale vertu est d'être favorable à la santé. En 1831, un fascicule sur le choléra propose comme méthode de prophylaxie la dissolution d'une dose modérée de nitre afin de transformer l'eau en « une boisson hygiénique très-salutaire pendant les fortes chaleurs ${ }^{9} »$. De son côté, en 1832, une publicité du Courrier-fait la liste de plusieurs eaux vendues par une maison pharmaceutique parisienne, et qui «prises en boisson hygiénique " permettent de lutter contre les maladies ${ }^{10}$. Dans les années qui suivent, le vocable sort du champ médical pour intégrer celui du commerce. Le Flâneur en octobre 1834 parle du thé comme une «boisson hygiénique agréable et exhilarante ${ }^{11} »$. En 1844, dans une étude sur le potentiel de l'exploitation du thé toujours, les Annales de l'agriculture française le présentent comme une «boisson hygiénique, d'agrément ou médicamenteuse ${ }^{12}$ ».

La chronique juridique permet de mieux cerner la définition que s'en font les contemporains de l'époque. En 1845, le tribunal de police de Paris déboute la Société de prévoyance des pharmaciens dans une action en justice contre un certain M. Fèvre et une poudre de sa préparation ${ }^{13}$, commercialisée pour « entretenir le corps entier dans un bon état de santé ». Les arguments des pharmaciens sont récusés, car la poudre de M. Fèvre n'est pas « un remède à proprement parler, mais une boisson hygiénique et d'agrément ». La même année, les vins d'un négociant parisien, saisis par les autorités car gâtés et corrompus par suite de leur dégénérescence ${ }^{14}$, sont déclarés par les experts nommés par le tribunal correctionnel de la Seine :

"Comme altérés et ne peuvent être regardés comme boisson hygiénique ; que ces vins, dans un semblable état, doivent être considérés comme gâtés et nuisibles. »

11 À la même période, le député de Dieppe Charles Levavasseur, dans une intervention à la Chambre sur l'imposition des alcools à Rouen, s'oppose à la surtaxation du vin, « une boisson hygiénique, fortifiante, utile à la santé15 ${ }^{15}$.

On le voit, dans les années 1830 puis 1840, l'emploi du terme «hygiénique » recouvre une acceptation relativement homogène, avec certaines nuances: il renvoie principalement à une perspective bienfaitrice pour la santé, même lorsqu'il est associé à une boisson alcoolisée comme le vin. Dans certains cas, il recoupe une dimension 
sanitaire, par exemple lorsque les vins sont altérés, frappés par une maladie, et que la justice considère alors qu'ils ne sont plus " hygiéniques ». Dès lors, dans les décennies qui suivent, cette association d'idées va se développer, appuyée donc sur un discours pseudo-scientifique et des références culturelles survalorisant les vins de France ${ }^{16}$, dans un contexte où l'approvisionnement en eau potable est compliqué, voire mortel ${ }^{17}$. Le registre thérapeutique lié à la consommation de vin s'ancre et s'enracine alors dans les différentes publications sur le sujet.

Par exemple, dans Le cuisinier médecin et le médecin cuisinier en 1855, on précise ${ }^{18}$ :

"Le vin est un des meilleurs toniques connus ; pris avec modération, il est de toutes les liqueurs spiritueuses la plus utile à l'homme. Le vin est nourrissant, il développe de la chaleur. Excitant puissant, il facilite la digestion, ranime, réjouit et stimule les fonctions du cerveau. [...] Il convient [...] aux vieillards, aux estomacs débiles et, en général, à toutes les personnes dont les forces ont besoin d'être entretenues ou relevées. »

Ces considérations pseudo-médicales sont dès lors associées à l'adjectif « hygiénique ", notamment dans les publications viticoles. Le professeur Jules Guyot (1807-1872), reconnu dans le milieu vitivinicole pour ses inventions et ses études des vignobles, utilise ainsi dans Culture de la vigne et vinification (1860) l'expression à plusieurs reprises. Abordant les revenus potentiels du commerce des vins, il rappelle «les effets hygiéniques et stimulants des forces physiques et intellectuelles $»$ de différents vins ${ }^{19}$. Plus loin, il détaille l'« action hygiénique » des vins blancs et des vins rouges, justifiant son avis par «l'opinion commune [...] fondée sur une expérience journalière ${ }^{20}$ » et ses propres études de médecine. La presse spécialisée n'est fort logiquement pas en reste. La même année, La Bourgogne. Revue cenologique et viticole estime que les vins rouges ordinaires de l'Hérault $\left(10-12^{\circ}\right)$, « forment une boisson hygiénique très recherchée des classes laborieuses ${ }^{21}$ ", expression et argument repris quelques années plus tard par la plus importante des revues à l'échelon national, La Revue viticole ${ }^{22}$.

Lorsque Pasteur écrit en 1866 que le vin est «la plus saine » et «la plus hygiénique » des boissons, il s'inscrit donc dans un contexte, à la fois culturel et scientifique, vieux de plusieurs décennies qui l'ont à coup sûr influencé. S'il est toutefois difficile de savoir avec certitude quel est le sens exact qu'il donne à ces mots, il est certain qu'il les écrit dans une démarche - orientée par la tutelle impériale, elle-même conditionnée par des considérations économiques - de valorisation des vertus bienfaitrices du vin ("hygiénique »), si ce dernier est exempt de toute altération («saine»). Ce qui est certain également, c'est que la phrase va devenir l'antienne des différents acteurs de la propagande en faveur du vin.

\section{Le « vin hygiénique » et Pasteur : ressorts d'une instrumentalisation (années 1870-années 1930)}

La phrase de Pasteur prend une dimension proprement apologétique très rapidement. Car, au-delà de la situation sur le marché, le vin dispose d'une place spécifique et caractéristique dans la lutte antialcoolique.

Cette spécificité est particulièrement bien explicitée en 1845 dans l'allocution du député Levavasseur devant la Chambre. Ce dernier, alors qu'il intervient à propos d'une potentielle surtaxe des vins dans le port de Rouen, met en opposition le vin, «boisson hygiénique » et « les liqueurs alcooliques [qui] sont contraires à la santé de ceux qui en 
abusent ${ }^{23} »$. Une vingtaine d'années plus tard, à l'époque même des travaux de Pasteur, La Revue viticole tient sensiblement le même discours, mettant cette fois en opposition les "petits vins ", absorbés tous les jours dans le cadre de la consommation familiale, et ceux trop forts ou trop doux, bus dans les cabarets, responsables « d'une alcoolisation excessive $^{24}$ ». Ces deux exemples, que l'on pourrait multiplier, indiquent qu'il existe dans l'opinion publique une croyance populaire - remontant à l'Antiquité et aux préceptes de certains auteurs de la période ${ }^{25}$ - faisant des vins ordinaires (qui titrent alors entre 7-9 ${ }^{\circ}$ ) un moyen de lutter contre l'alcoolisme chronique, dont les symptômes ont été récemment mis en évidence par le Suédois Magnus Huss au tournant des années $1850^{26}$. Les médecins eux-mêmes abondent dans ce sens. En 1862, le docteur Cruveilhier indique ainsi que :

« Le moyen le plus efficace et le plus sûr de nous épargner l'alcoolisme, c'est le vin à

bon marché, et la possibilité d'un usage habituel de ce précieux breuvage ${ }^{27}$. »

Abordant la question du vinage ${ }^{28}$, le docteur Bergeron présente en 1870 devant l'Académie impériale de médecine un rapport dans lequel il oppose très clairement le "vin naturel » (c'est-à-dire départi de fraudes et manipulations) et les boissons distillées dont il évoque les « ravages déjà produits " ${ }^{29}$.

Il faut dire que la période est celle d'une prise de conscience très nette des ravages de l'abus chronique de boissons fortement alcoolisées en France. Dans le sillage de Huss, dont les écrits se diffusent au début des années 1850 dans le pays, de nombreux travaux mettent en exergue les effets de l'absorption de plus en plus importante de boissons alcoolisées, telle la thèse du docteur Motet, Considérations générales sur l'alcoolisme en 1859, ainsi que nombre de rapports dans le Bulletin de l'Académie de Médecine. Tous dénoncent les ravages de ce nouveau «fléau "social, alimenté par le "poison» que constituent les spiritueux industriels et autres apéritifs à la mode alors. Ce message, initié dans les années 1820 par les médecins hygiénistes tels Villermé ou Esquirol ${ }^{30}$, prend, dans le contexte brûlant et tumultueux de l'après-guerre franco-prussienne, une nouvelle dimension. Alors qu'on recherche les raisons de l'échec militaire, un argument facile repose sur la trop grande alcoolisation des troupes françaises et du pays dans son ensemble. C'est sur ces bases que naît le mouvement antialcoolique français ${ }^{31}$, autour de plusieurs associations, parfois concurrentes, souvent complémentaires (Association patriotique de tempérance en 1871; Association française contre l'abus du tabac et des boissons alcooliques en 1872; Association française contre l'abus des boissons alcooliques en 1872, devenue Association française de tempérance en 1873), alors que l'État lui-même réagit en promulguant la première loi contre l'ivresse publique (1873). Fort de ces avancées, le mouvement antialcoolique se structure, se solidifie, se diversifie avant de s'unifier, à quelques exceptions près, dans La Ligne nationale contre l'alcoolisme en 1905.

C'est dans ce cadre que la phrase de Pasteur est réinvestie par de nombreux acteurs et scientifiques s'interrogeant sur les effets de l'intoxication alcoolique chronique. Elle commence à faire florès dans les années 1870 en raison de trois facteurs : tout d'abord, nous l'avons vu, cette décennie est celle d'une puissante et générale prise de conscience du mal endémique que représente l'alcoolisation abondante, excessive et continuelle d'une partie de la population française. Ensuite, singularité du cas français en Europe, les vins ne font pas partie - du moins ouvertement - des cibles du mouvement hygiéniste. Pour des raisons à la fois culturelles et économiques, les vins - tant qu'ils sont « loyaux et marchands ", c'est-à-dire propres à la consommation - sont épargnés 
du discours antialcoolique français. Ce dernier, en effet et à la différence de ceux produits dans les autres pays occidentaux, adopte un argumentaire de tempérance et de modération, et non pas d'abstinence rigoriste comme dans les pays anglo-saxons ou nordiques. Surtout, nous l'avons vu également, les vins apparaissent comme un «rempart » contre l'alcoolisme ${ }^{32}$. Enfin, Pasteur jouit désormais d'une notoriété déjà importante dans les années $1870^{33}$, sans pareille à compter des années 1880 , à la suite de ses découvertes pour lutter contre la rage.

Sortie de son contexte de l'époque et portée par la gloire d'une des figures proéminentes de la science contemporaine (et donc de la modernité, de l'objectivité et de la raison), la phrase devient le slogan des promoteurs de la consommation de vin. Les circonstances et contextes de cette promotion sont divers et variés, mais ils imprègnent tous l'idée que la consommation de vin est bonne pour la santé. Ainsi, en 1876, le Guide médical pratique de l'officier présente l'éventail des "boissons alcooliques " et les «dangers de l'alcool ${ }^{34}$ ». Après avoir repris les quelques idées fortes de l'époque sur la question de l'alcoolisme (alcool-poison, ivrogneries aiguë et chronique, critique de l'absinthe), fondées sur des écrits médicaux abondamment cités, les auteurs en arrivent au vin qu'ils considèrent comme «la plus hygiénique des boissons alcooliques ", valorisant notamment ses effets toniques et recommandant de «le voir adopter pour le soldat en campagne ». Le Journal des connaissances médicales pratiques va plus loin la même année ${ }^{35}$. Dans sa rubrique "Hygiène ", il présente une étude du Dr Des Barres sur «Le rôle du vin dans la nutrition ». L'article commence d'emblée par la mise en avant de la citation de Pasteur, caution incontestable de l'argumentation qui suit. Celle-ci pose les bases de ce qui devient dans les décennies qui suivent le discours commun du prosélytisme en faveur des vins. Ceux-ci dans le cadre d'une démarche médicale prophylactique sont alors présentés comme des "analeptiques [c'est-à-dire des stimulants] par excellence ». Ainsi, le «bon vin » permet "de donner à l'homme une gaîté sobre et salutaire, en raffermissant le travail musculaire, et en donnant de l'énergie aux fonctions digestives ». Et l'article de lister les maladies prévenues et autres affections soignées par la consommation d'un "vin généreux », constatations confirmées par «les déductions de la physiologie » et «l'observation clinique », ainsi que par la pratique de nombreux collègues, cités également. Dépassant le simple besoin de désaltérer voire de nourrir ${ }^{36}$, le vin, "boisson hygiénique ", est alors pleinement considéré comme une boisson utile au corps et entrant dans l'alimentation raisonnée des Français. Ce propos est d'ailleurs repris par certaines associations antialcooliques elles-mêmes, telle la Société française de tempérance. Dans son bulletin en 1875, le Dr Lunier indique ainsi en évoquant les travaux de Pasteur que le chauffage des vins permettra d'éviter l'altération des vins, favorisant leur consommation et donc éloignera les consommateurs des cabarets ${ }^{37}$. Deux ans plus tard, Lunier, membre de l'Académie de médecine, secrétaire général de la SFT, popularisera l'idée d'une opposition entre une France du Nord alcoolique et une France du Sud, viticole, sobre ${ }^{38}$. Cette acception, et cette conceptualisation, est entérinée par la présence de la phrase de Pasteur à l'entrée « Hygiène » dans le Dictionnaire encyclopédique universel de Camille Flammarion à la fin du siècle ${ }^{39}$, preuve de son enracinement dans l'opinion publique.

Fort logiquement, les acteurs de la filière vitivinicole ne ratent pas l'occasion d'exploiter la situation. Dès 1868, Le Journal de la viticulture pratique publie une série d'articles sur les vins «au point de vue de l'hygiène». Son auteur, Pierre-Constant Guillory, compile son propos dans un guide du consommateur intitulé Les vins alimentaires considérés au point de vue hygiénique l'année suivante ${ }^{40}$. Proche des milieux 
viticoles41, il articule l'ensemble de son argumentation autour de la notion d'hygiène dont le mot (ou l'adjectif) se retrouve régulièrement dans les titres de chapitres où il loue les mérites thérapeutiques des vins de telle ou telle région. Incontestablement, le terme de « vin hygiénique » prend à cette époque une nouvelle dimension.

L'expression est alors abondamment exploitée. En 1880, dans le supplément à la statistique générale de Gironde consacré à la filière viticole, Édouard Féret, auteur de Bordeaux et ses vins classés par ordre de mérite, précise que les vins du Médoc ont acquis, depuis quelques années, la réputation «tout aussi noble et tout aussi glorieuse de vin hygiénique », procurant par-là, "le plaisir et la santé »" ${ }^{41}$ Dans la décennie suivante, c'est Henri Marès, agronome réputé pour avoir vaincu l'oïdium et chez qui Pasteur réalisa certaines de ses expériences dans l'Hérault, qui évoque «la plus hygiénique des boissons alimentaires" dans sa Description des cépages principaux de la région méditerranéenne de la France ${ }^{42}$. En 1907 enfin, lors d'une discussion au Sénat sur la loi de finances, on oppose spiritueux, apéritifs et boissons hygiéniques. Jules Pams, sénateur des Pyrénées-Orientales, proche des milieux viticoles dont il défend les intérêts au Parlement, insiste sur la qualité des « vins qui contribuent au bon renom de notre pays comme des produits très hygiéniques ${ }^{43} »$.

Mais l'exploitation la plus directe et la plus visible de la phrase de Pasteur et de l'image du scientifique lui-même se retrouve dans les années 1920-1930. La consommation, dans un contexte commercial très aléatoire (années 1920) voire dégradé (années 1930), est alors encouragée par un mouvement propagandiste sans précédent organisé autour d'associations visant à faire la promotion des vins de France. La première, créée à Béziers au milieu des années 1920, est l'Association de propagande pour le vin. Elle finance à la fin de la décennie des publicités radiophoniques qui claironnent à la TSF que « le vin est la plus hygiénique des boissons ». Dans le même temps, elle crée cartes et flammes postales, très largement diffusées en France, vantant les vertus du vin ou la phrase de Pasteur (fig. 1 et fig. 2$)^{44}$. En 1932, elle édite un fascicule, Pour le vin, pour l'hygiène, dans lequel elle présente un "Comité scientifique de l'hygiène du vin " composé de « sommités de nos facultés de médecines » qui donnent « le concours moral à la lutte contre l'alcoolisme » et dont chacun signe un petit laïus vantant les mérites thérapeutiques ou antialcooliques - du vin ${ }^{45}$. Une étape supplémentaire est franchie avec le Comité national de propagande en faveur du vin, fondé en 1931 sous le patronage de l'État. Le portrait de Pasteur est alors régulièrement exploité, au même titre que sa citation. On les retrouve sur les cartes postales, les affiches, les bons points, les marque-pages que l'association diffuse à grande échelle (fig. 3 et fig. 4). Près de 40 ans après sa mort, Louis Pasteur devient alors l'instrument d'une propagande d'une intensité rare, le fondement d'un discours pseudo-scientifique visant à vanter les mérites de la consommation de vin («il faut boire du vin pour bien se porter, vivre longtemps, être gai $\left.{ }^{46} »\right)$, avec des conséquences majeures dans l'opinion publique, puisque les idées propagées par le CNPFV seront encore largement partagées jusque dans les années 1970 et $1980^{47}$. 
Fig. 1. - Carte postale deux volets.

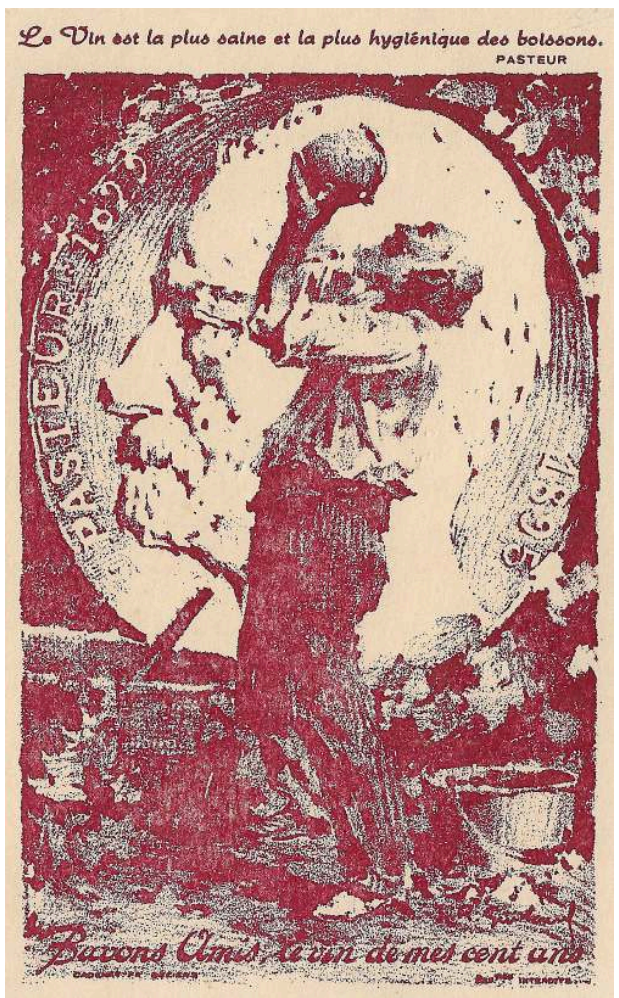

Association de propagande pour le vin, années 1920

Fig. 2. - Flamme postale.

BERTHES

Négociant en Besiaux - Chevillard

8, Rue Cavalerie

MONTPELLIER

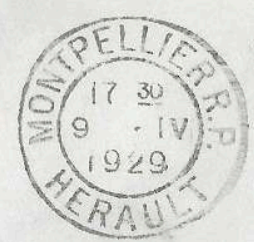

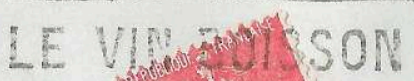
TEMRUE

ETRERANBPACE
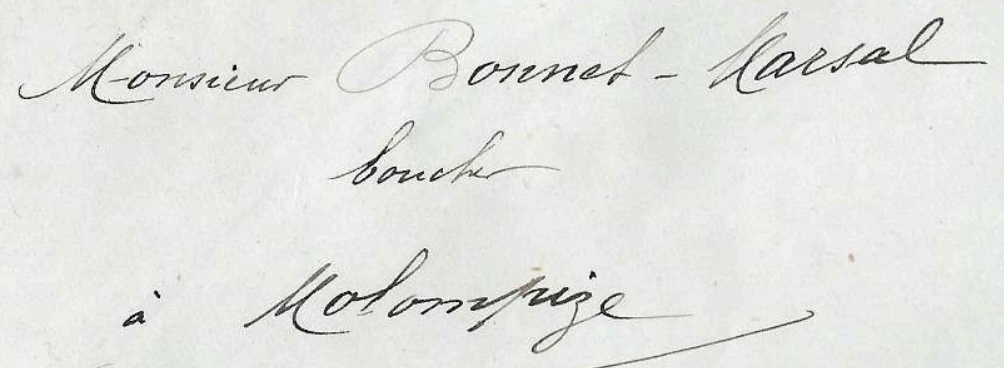

$\int$ antae 
Fig. 3. - Marque-page.

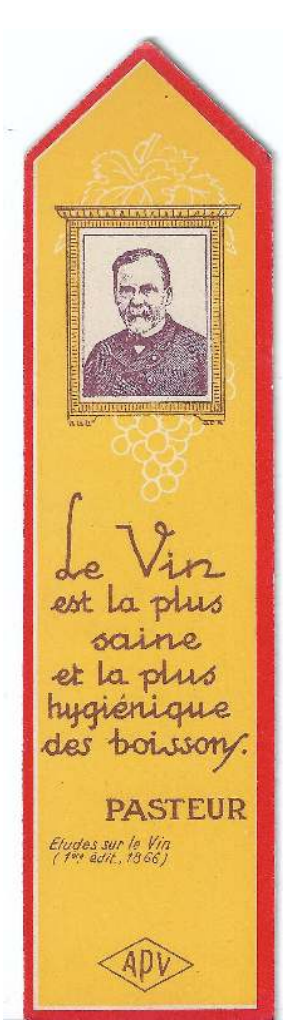

Comité national de propagande en faveur du vin (réalisé par l'Association de propagande pour le vin) années 1930. 
Fig. 4. - Couvre-livre.

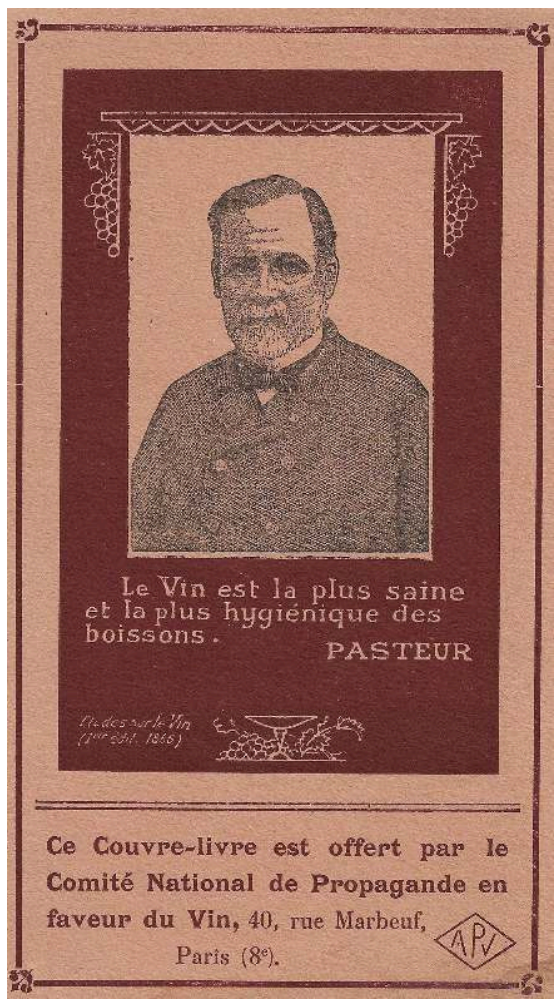

Comité national de propagande en faveur du vin (réalisé par l'Association de propagande pour le vin), années 1930.

interts pon cadre originel lorsqu'elle est investie par un ensemble dacteurs, aux intérêts parfois divergents, mais tous valorisant le vin pour en faire un tonifiant, un rempart contre l'alcoolisme ou une boisson aux vertus thérapeutiques. En quelques années, l'expression prend une dimension métonymique, visant à rassurer les consommateurs sur les bienfaits de la consommation de vin. À cet égard, elle brouille son sens originel en lui donnant une portée qu'elle n'avait pas à l'origine et une dimension légendaire à compter des années 1920-1930 quand elle devient le mantra des promoteurs officiels de la filière viticole. Elle surévalue également le legs pasteurien dont oublie l'échec du chauffage des vins, la pratique étant très vite abandonnée.

Par sa popularité, elle est en même temps vidée de son sens, reprise dans la promotion de quantité d'autres boissons : l'eau bien sûr, mais aussi le cidre mousseux, l'alcool de menthe Ricqlès, la bière ou même l'apéritif Marie-Brizard. Et, comble de l'ironie, lorsque le mouvement antialcoolique se restructure suite à l'action du président du conseil Pierre Mendès-France dans les années 1950, il exploite la figure de Louis Pasteur 
(fig. 5) dans une série de buvards consacrée à de grands personnages dont la première qualité fut... la sobriétée ${ }^{48}$.

Fig. 5. - Buvard, Les destins exemplaires, Pasteur.

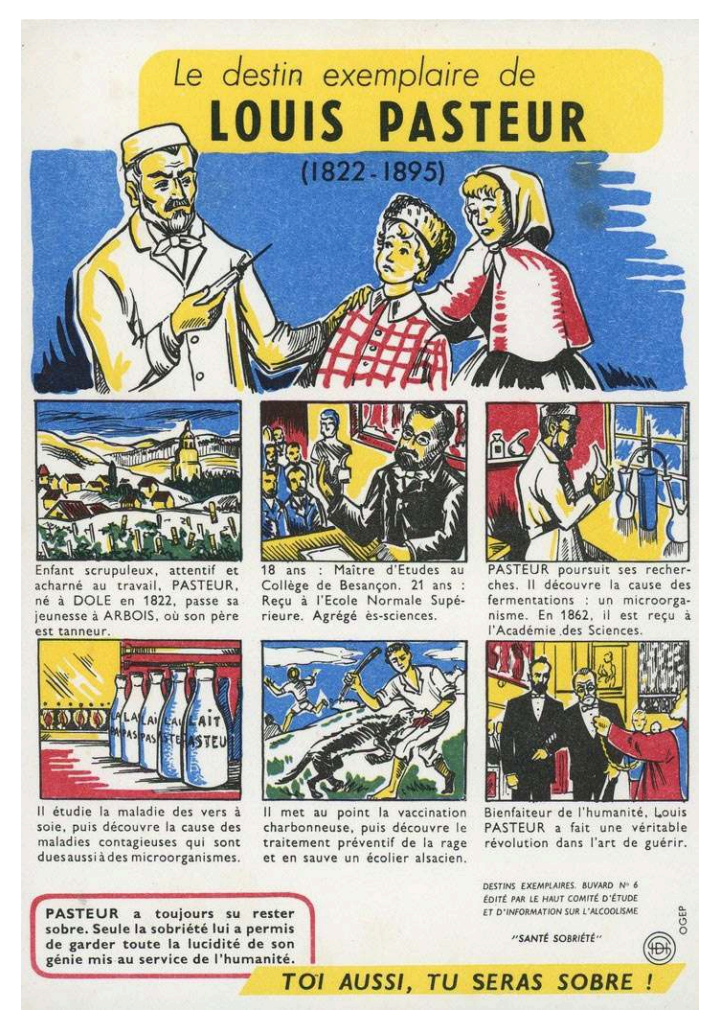

Haut comité d'études et d'informations sur l'alcoolisme, fin années 1950-début années 1960.

\section{BIBLIOGRAPHIE}

Jules BERGERON, « Rapport sur le vinage », Bulletin de l'Académie de Médecine, t. 35, 1870, p. 389-454.

Henri BERNARD, « Alcoolisme et antialcoolisme en France au XIX ${ }^{\mathrm{e}}$ siècle (autour de Magnus Huss) », Histoire, Économie et Société, vol. 3, nº 4, 1984, p. 609-628.

Joseph-Bienaimé CAVENTOU (et alii), Considérations chimiques et médicales sur l'eau de Selters, ou de seltz naturelle, comparée avec l'eau de Selters factice, Paris, Impr. De Fain, 1829.

«Chambre des députés », La Presse, 05/07/1845.

Amédée CHASSAGNE et Étienne Emery-DESBROUSSES, Guide médical pratique de l'officier, Paris, Ch. Delagrave, 1876.

«Chronique judiciaire », La Diligence : journal des voyageurs : littérature, mœurs, théâtres, modes, itinéraires, voyages, industrie, $\mathrm{n}^{\circ} 3,1845$.

Comité scientifique de l'hygiène du vin, Pour le vin, pour l'hygiène, Béziers, APV, 1932. 
«Cour de cassation », Annales de la science et du droit commercial et maritime : recueil mensuel de législation, de doctrine et de jurisprudence, 1846 (deuxième partie), p. 454.

Louis CRUVEILHIER (Dr), Éléments d'hygiène générale, Paris, Impr. de Dubuisson, 1862.

Pierre DARMON, Pasteur, 1995, Paris, Fayard.

Bertrand DARGELOS, La lutte antialcoolique en France depuis le XIXe siècle, Paris, Dalloz, 2008.

« Du rôle du vin dans la nutrition », Journal des connaissances médicales pratiques, 1876, p. 348.

« Du thé », Le Flâneur, un journal parisien, 30/10/1834.

Journal officiel de la République française. Débats parlementaires. Sénat, Séance du 24/01/1907.

Jacques JOUANNA, « Le vin et la médecine dans la Grèce ancienne », Revue des Études Grecques, t. 109, juillet-décembre 1996, p. 410-434.

Alexis-François JOUBERT, Les vins : manière de les soigner et de les servir, Paris, Paul Renouard, 1842.

Édouard FÉRET, Supplément à la statistique générale du département de la Gironde, Bordeaux, Féret et Fils, 1880.

Thierry FILLAUT, « De l'allié d'hier à l'ennemi d'aujourd'hui : les luttes antialcooliques et le vin en France de la Belle Époque à nos jours », dans Frédérique Pitou et Jacqueline Sainclivier (dir.) Les affrontements : usages, discours et rituels, Rennes, PUR, 2008, p. 159-170.

Camille FlAmMARION, « Hygiène », Dictionnaire encyclopédique universel, t. 5, Paris, E. Flammarion, 1894-1898.

Stéphane FRIOUX, Les batailles de l'hygiène. Villes et environnement de Pasteur aux Trente Glorieuses, Paris, PUF, 2013

Pierre-Constant GUILLORY (aîné), Les Vins alimentaires considérés au point de vue hygiénique. Guide du consommateur, Paris, Librairie agricole, 1869.

Nicolas GUTIEREZ, « Le vin rouge aurait un effet bénéfique sur le microbiote, selon une étude ", Sciences et Avenir, 31/08/2019.

Jules GUYOT, Culture de la vigne et vinification, Paris, Librairie de la maison rustique, 1860.

Paul LANGEVIN, «Pasteur, le savant et l'homme », La Pensée, nº 7, 1946, p. 3-10.

Léandre-Moïse LOMBARD (dir.), Le cuisinier et le médecin et le médecin et le cuisinier ou le cuisinier médecin et le médecin cuisinier, Paris, L. Curmer, 1855.

Ludger LUNIER (Dr), « De la production et de la consommation des boissons alcooliques en France. Partie deux », La Tempérance. Bulletin de la Société française de tempérance, 1875, p. 5-60.

Ludger LUNIER (Dr), De la production et de la consommation des boissons alcooliques en France et de leur influence sur la santé physique et intellectuelle des populations, Paris, F. Savy, 1877.

Henri MARÈs, Description des cépages principaux de la région méditerranéenne de la France, Montpellier, C. Coulet, 1890.

Emmerich MAURY, Soignez-vous par le vin, Paris, Éditions du Jour, 1974.

MÉRAT (Docteur), « Mémoire sur la possibilité de cultiver le thé en pleine terre et en grand en France ", Annales de l'agriculture française, 1844.

Victor de MOLÉON, Du choléra-morbus : notice générale sur cette maladie, Paris, [s.n.], 1831. 
« Note sur la richesse alcoolique des vins du département de l'Hérault », La Bourgogne : revue œnologique et viticole, deuxième année, 1860, 405-408.

Didier NOURRISSON, « Aux origines de l'antialcoolisme », Histoire, économie et société, 1988, 7 e année, $\mathrm{n}^{\circ} 4$, p. 491-506.

Didier NOURISSON, Le buveur du XIXe siècle, Paris, Albin Michel, 1990.

Patricia E. PRESTWICH, Drink and the Politics of Social Reform: Alcoholism in France since 1870, Palo Alto, The Society for the Promotion of Science and Scholarship, 1988.

Publicité « Eaux minérales naturelles », Le Courrier, 07/07/1832.

Didier RAOULT, « Pasteur, le vin et la santé », Le Point, 21/12/2011.

La Revue viticole. Annales de la viticulture et de l'œnologie françaises et étrangères, $6^{\mathrm{e}}$ année, 1864.

Élisée THOREL, Hygiène populaire des villes et des campagnes ou Conseils spécialement destinés aux ouvriers des deux sexes sur les moyens de conserver leur santé, Paris, J. B. Baillière, 1853.

René VALLERY-RADOT, La vie de Pasteur, Paris, Hachette, 1900.

\section{NOTES}

1. Cette étude s'inscrit dans le cadre d'un programme de recherche portant sur les achats alimentaires. Financé par la Fondation Nestlé et soutenu par le Centre d'histoire « Espaces et cultures » de l'UCA, il interroge les mécanismes et logiques concourant aux pratiques d'achats des produits alimentaires en France à l'époque contemporaine.

2. N. Gutierez, «Le vin rouge aurait un effet bénéfique sur le microbiote, selon une étude ».

3. D. Raoult, « Pasteur, le vin et la santé ».

4. Il existe de nombreuses publications sur les travaux et la vie de Louis Pasteur ; citons par exemple à trois époques différentes: R. Vallery-Radot, La vie de Pasteur (1900), P. Langevin, « Pasteur, le savant et l'homme » (1946) ou P. Darmon, Pasteur (1995).

5. Le moût est le jus de raisin qui n'a pas encore subi la fermentation alcoolique.

6. R. Vallery-Radot, La vie de Pasteur, p. 137.

7. Ce dernier publie un mémoire sur le même thème en 1850. Bien qu'il connaisse son auteur et ses travaux, Pasteur a toujours affirmé n'avoir eu connaissance de ce mémoire qu'en 1865.

8. J.-B. Caventou (et alii), Considérations chimiques et médicales sur l'eau de Selters, p. 12.

9. V. de Moléon, Du choléra-morbus : notice générale sur cette maladie, p. 89.

10. Publicité « Eaux minérales naturelles », Le Courrier, 07/07/1832.

11. « Du thé », Le Flâneur, un journal parisien, 30/10/1834.

12. Dr Mérat, « Mémoire sur la possibilité de cultiver le thé en pleine terre et en grand en France », p. 42.

13. «Chronique judiciaire ", La Diligence : journal des voyageurs, p. 18.

14. «Cour de cassation », Annales de la science et du droit commercial et maritime, p. 454.

15. La Presse, 05/07/1845. 
16. Voir par exemple l'introduction d'A.-F. Joubert, Les vins : manière de les soigner et de les servir.

17. Voir S. Frioux, Les batailles de l'hygiène. Villes et environnement de Pasteur aux Trente Glorieuses.

18. L.-M. Lombard, Le cuisinier et le médecin et le médecin et le cuisinier..., p. 361.

19. J. Guyot, Culture de la vigne et vinification, p. 78.

20. Ibid., p. 291.

21. « Note sur la richesse alcoolique des vins du département de l'Hérault », p. 406.

22. L'expression revient à plusieurs reprises. Voir par exemple La Revue viticole, 1864, p. 295, 315 ou 400.

23. La Presse, 05/07/1845.

24. La Revue viticole, 1864, p. 295.

25. Voir J. Jouanna, « Le vin et la médecine dans la Grèce ancienne ».

26. Voir H. Bernard, «Alcoolisme et antialcoolisme en France au XIX ${ }^{e}$ siècle (autour de Magnus Huss) ».

27. Dr L. Cruveilhier, Éléments d'hygiène générale, p. 142.

28. Il s'agit d'une opération consistant à rajouter de l'alcool dans les moûts de vin, afin d'en relever son degré.

29. J. Bergeron, « Rapport sur le vinage », p. 449-451.

30. Voir D. Nourrisson, « Aux origines de l'antialcoolisme ».

31. Sur le sujet, voir les ouvrages de B. Dargelos, La lutte antialcoolique en France depuis le XIX ${ }^{e}$ siècle; D. Nourisson, Le buveur du XIXe siècle; P. E. Prestwich, Drink and the Politics of Social Reform: Alcoholism in France since 1870.

32. Sur le sujet, voir T. Fillaut, «De l'allié d'hier à l'ennemi d'aujourd'hui : les luttes antialcooliques et le vin en France de la Belle Époque à nos jours ».

33. En 1875, l'Assemblée nationale accorde au scientifique une pension à titre de récompense nationale pour le remercier des services rendus au pays. En 1878, il est fait Grand officier de la Légion d'honneur, puis il reçoit la grand-croix en 1881.

34. A. Chassagne et É. Emery-Desbrousses, Guide médical pratique de l'officier, p. 95-96.

35. « Du rôle du vin dans la nutrition », p. 348.

36. Cf. le concept de «vin aliment» qui se développe également à compter des années 1860 .

37. Dr L. Lunier, « De la production et de la consommation des boissons alcooliques en France », p. 39.

38. Dr L. Lunier, De la production et de la consommation des boissons alcooliques en France et de leur influence sur la santé physique et intellectuelle des populations.

39. C. Flammarion, Dictionnaire encyclopédique universel, t. 5, p. 489.

40. P.-C. Guillory, Les vins alimentaires considérés au point de vue hygiénique.

41. É. Féret, Supplément à la statistique générale du département de la Gironde, p. 6.

42. H. Marès, Description des cépages principaux de la région méditerranéenne de la France, p. 22. 
43. Journal officiel de la République française. Débats parlementaires. Sénat, 24/01/1907, p. 297.

44. Arch. nat., F 10/5385, Comité nationale de propagande en faveur du vin, correspondance et comptes rendus de séance, « Rapport Nougaret », s.d. (1932).

45. Comité scientifique de l'hygiène du vin, Pour le vin, pour l'hygiène.

46. Arch. nat., F 10/5385, Comité nationale de propagande en faveur du vin, Correspondance et comptes rendus de séance, « Rapport Nougaret », s.d. (1932).

47. E. Maury, Soignez-vous par le vin (1974). L'ouvrage est réédité à plusieurs reprises dans les années 1980.

48. Ce qui est peu probable pour Pasteur dont la passion pour le vin est largement documentée.

\section{RÉSUMÉS}

Longtemps présenté comme une boisson parée de vertus thérapeutiques et bénéfiques pour la santé, le vin jouit d'un statut à part dans la culture française. Celui-ci est en partie fondé à l'époque contemporaine sur la phrase de Pasteur, « le vin est la plus saine et le plus hygiénique des boissons" (1866), qui lui octroie une légitimité sans pareille dans la filière des boissons alcoolisées et, par extension, dans l'opinion publique. Cet article vise à déconstruire la dimension légendaire de cette phrase, en la replaçant dans son contexte historique, puis en montrant les mécanismes qui ont participé à son exploitation et son instrumentalisation jusqu'à une époque toute récente.

\section{AUTEUR}

\section{STÉPHANE LE BRAS}

Maître de conférences en Histoire contemporaine à l'université Clermont-Auvergne, membre du Centre d'histoire « Espaces \& Cultures» 